UNIVERSIDADE DE SÃO PAULO

INSTITUTO DE GEOCIÊNCIAS

\title{
Geocronologia e proveniência dos sedimentos holocênicos da confluência dos rios Negro e Solimões, AM
}

\author{
Manuela Pinheiro Ferreira \\ Orientador: Prof. Dr. André Oliveira Sawakuchi \\ DISSERTAÇÃO DE MESTRADO \\ Programa de Pós-Graduação em Geoquímica e Geotectônica \\ SÃO PAULO \\ 2013
}


UNIVERSIDADE DE SÃO PAULO

INSTITUTO DE GEOCIÊNCIAS

\title{
Geocronologia e proveniência dos sedimentos holocênicos da confluência dos rios Negro e Solimões, AM
}

\author{
Manuela Pinheiro Ferreira
}

Orientador: Prof. Dr. André Oliveira Sawakuchi

\section{DISSERTAÇÃO DE MESTRADO}

Programa de Pós-Graduação em Geoquímica e Geotectônica

\author{
SÃO PAULO
}


Ficha catalográfica preparada pelo Serviço de Biblioteca e Documentação do Instituto de Geociências da Universidade de São Paulo

Ferreira, Manuela Pinheiro

Geocronologia e proveniência dos sedimentos holocênicos da confluência dos rios Negro e Solimões, AM / Manuela Pinheiro Ferreira. - São Paulo, 2013

95 p.: il

Dissertação (Mestrado) : IGc/USP

Orient.: Sawakuchi, André Oliveira

1. Geocronologia 2. Luminescência 3 . Sedimentologia fluvial I. Título 
A lei da mente é implacável.

O que você pensa você cria.

O que você sente você atrai.

O que você acredita, torna-se realidade.

(Buda) 


\section{AGRADECIMENTOS}

Primeiramente, agradeço minha família, pai Chico, mãe Eni e irmão Matheus pelo apoio e amor incondicional em todas as fases deste trabalho, apesar da distância e dos poucos retornos.

Agradeço ao meu orientador Fruta, pelas experiências em campos e congressos, pela paciência, dedicação, empolgação e amor à ciência. Além das

alfinetadas que proporcionaram, de certa forma, meu crescimento profissional e pessoal.

Agradeço a todas as pessoas que me ajudaram na realização do campo em Manaus: Paula, pela comida maravilhosa e pelos momentos de descontração; Manuel, por guiar o Carlos Cesar; Cláudio, Abraão, Neguinho, Pará, Lázaro, Henrique, Guano, Lalas, Cris, Emílio, Pink, Lina, Fruta e llana pela indispensável ajuda na coleta de amostras e na logística de todo o campo.

Ao Sfincter, por toda a paciência e didática nas inúmeras explicações e esclarecimentos sobre luminescência e sedimentologia.

Às meninas dos laboratórios: Jordana pelo auxílio com o Malvern e pela transmissão de uma energia sempre boa, limpa e tranquila; Elaine pelo suporte no manuseio dos itens do Laboratório de Sedimentologia; Patrícia e Luciana por todo o apoio e ajuda no manuseio das amostras no escuro Laboratório de Luminescência Opticamente Estimulada e de Espectrometria Gama.

Agradeço a todos que me ajudaram de alguma forma na realização e finalização dessa dissertação, seja nos laboratórios, nas discussões ou confecção de mapas: Déborah, Pegmatito, Ana Góes, Zular, Fabíola e Rebita.

Agradeço às minhas amigas queridas: Pará, Vesga, Gemida, Espanha, Caça, Farol, Wally, Atoladinha, Mocotó, Tonhão, Gringa, Iná, Ariela, Naiana e Yasmin pelos momentos de alegria e reflexões nos bares, nos intervalinhos necessários para o café e nos almoços.

À Lua e à Kenga, por serem minhas guerreiras da pós e transmitirem toda essa energia positiva de determinação, coragem e amor à geologia que eu sinto delas.

Aos Seixos pra Um, Oncinha, Sheila, Fiona, Mimozo e Dé por proporcionar um som maravilhoso, elevar o astral de todos nos momentos mais propícios e causar a reflexão sobre as letras de Raul Seixas. 


\section{RESUMO}

O sistema fluvial amazônico representa a maior bacia de captação de sedimentos do mundo. Neste contexto, o objetivo deste estudo foi caracterizar as areias transportadas pelos rios Negro e Solimões e discriminar a contribuição do aporte sedimentar arenoso derivado destes dois rios para a formação do rio Amazonas. Além disso, buscou-se identificar variações temporais da geomorfologia fluvial da zona de confluência dos rios Negro e Solimões. Para tanto, foram utilizados métodos de análise geomorfológica e de fácies, granulometria, sensibilidade por luminescência opticamente estimulada (LOE) da fração areia e datações LOE e ${ }^{14} \mathrm{C}$. Os sedimentos das barras do rio Negro apresentam maior porcentagem de areia, com diâmetro médio em $375,76 \mu \mathrm{m}$, os quais são dominados por grãos de quartzo de sensibilidade LOE moderada $(3,06)$. Já os sedimentos das barras dos rios Solimões e Amazonas são mais finos, com diâmetro médio em 154,58 $\mu \mathrm{m}$ e 134,36 $\mu \mathrm{m}$, respectivamente, alta porcentagem de feldspato e grãos de quartzo com baixa sensibilidade $\operatorname{LOE}(2,49$ e 2,53, respectivamente). O aporte arenoso do rio Solimões (88,08\% para sedimentos de calha e $98,23 \%$ para barras) sobre o rio Amazonas é dominante em relação ao aporte do rio Negro $(11,91 \%$ para sedimentos de calha e $1,76 \%$ para barras). Os dados de sensibilidade LOE sugerem que os sedimentos do rio Negro são acomodados principalmente na calha do rio Amazonas. Os arenitos da Formação Alter do Chão adjacentes ao canal do baixo rio Negro representam a principal área fonte dos sedimentos deste rio. A baixa maturidade composicional e sensibilidade LOE reduzida dos sedimentos do rio Solimões sugerem rápido transporte sedimentar a partir de áreas fontes andinas. O tempo de estocagem mínimo para as areias de barras expostas durante a seca do rio Negro varia entre 0,34 $\pm 0,04$ ka e $1,7 \pm 0,26$ ka. Já o período mínimo de estocagem das areias em barras dos rios

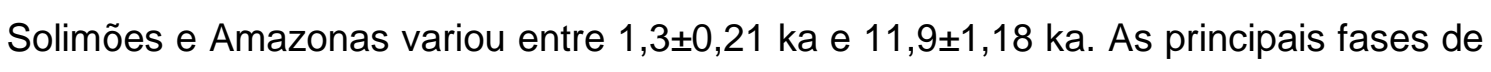
construção das barras dos rios Solimões e Amazonas estariam relacionadas principalmente com eventos de precipitação extrema do Holoceno.

Palavras-chave: Geocronologia; Luminescência; Sedimentologia fluvial 


\begin{abstract}
The Amazon river system is the largest sediment catchment basin in the world. In this context, this study aims to differentiate the sands carried by the Negro and Solimões rivers and estimate the sandy sedimentary supply derived from these two rivers to the Amazon river. Furthermore, this research also deals with temporal variations of fluvial geomorphology in the confluence area of the Negro and Solimões rivers. For this purpose, we used methods of geomorphological, facies and grain size analysis coupled with optically stimulated luminescence (OSL) sensitivity of sand fraction and OSL and ${ }^{14} \mathrm{C}$ dating. The sediments of the Negro river bars showed a higher percentage of sand, with mean diameter of $375,76 \mu \mathrm{m}$, which are dominated by quartz grains with moderate OSL sensitivity $(3,06)$. On the other hand, sediment from bars of Solimões and Amazonas rivers are thinner, with mean diameter of $154,58 \mu \mathrm{m}$ and $134,36 \mu \mathrm{m}$, respectively, high percentage of feldspar and quartz grains with low OSL sensitivity (2,49 and 2,53, respectively). The contribution of Solimões river sands $(98.23 \%)$ to the Amazon river is dominant in relation to the contribution of the Negro river (1.76\%). OSL sensitivity data suggest that the Negro river sediments are accommodated mainly in the Amazon River channel. The Alter of Chão Formation sandstones outcropping adjacent to the lower Negro river channel area represent the main source of sediments for this sector of the Negro river. The low compositional maturity and reduced OSL sensitivity of Solimões river sediments suggest rapid sediment transport from Andean source areas. The minimum storage time for the Negro river sand bars exposed during the dry season varies between 0,34 $\pm 0,04 \mathrm{ky}$ and 1,7 $\pm 0,26 \mathrm{ky}$. The minimum storage time of sands in bars from the Solimões and Amazonas rivers ranged between 1,3 $\pm 0,21 \mathrm{ky}$ and 11,9 $\pm 1,18 \mathrm{ky}$. The main construction phases of the Solimões and Amazonas rivers bars would be related to extreme precipitation events during the Holocene.
\end{abstract}

Keywords: Geochronology; Luminescence; Fluvial sedimentology 


\section{SUMÁRIO}

1. INTRODUÇÃO 1

2. OBJETIVOS 3

3. SÍNTESE BIBLIOGRÁFICA 3

3.1. Contexto geológico regional 3

3.2. Geomorfologia 5

3.3. Clima 8

$\begin{array}{ll}\text { 3.4. Hidrologia } & 10\end{array}$

3.5. Sensibilidade da luminescência opticamente estimulada (LOE) do quartzo e sua relação com o transporte sedimentar

3.6. Datação de sedimentos por luminescência opticamente estimulada (LOE)

4. MATERIAIS E MÉTODOS

4.1. Análise geomorfológica por sensoriamento remoto 19

4.2. Análise de fácies e coleta de amostras 19

$\begin{array}{lr}\text { 4.3. Análise granulométrica } & 19\end{array}$

4.4. Análise de sensibilidade LOE $\quad 20$

4.5. Datações LOE 21

4.6. Datações ${ }^{14} \mathrm{C} \quad 23$

5. RESULTADOS 24

5.1. Geomorfologia 24

5.2. Análise de fácies 39

5.3. Análise granulométrica 45

5.4. Análise de Sensibilidade LOE $\quad 50$

5.5. Geocronologia 53

6. DISCUSSÃO

6.1. Dinâmica sedimentar e proveniência das areias dos rios Negro, Solimões e Amazonas $\quad 62$

6.2. Idades e tempo de estocagem de sedimentos nos rios Negro, Solimões e Amazonas 
6.3. Fatores que controlam a acumulação e erosão de sedimentos fluviais e sua relação com as idades de deposição obtidas

7. CONCLUSÕES

REFERÊNCIAS BIBLIOGRÁFICAS 


\section{LISTA DE FIGURAS}

Figura 1. Localização da área de estudo nas proximidades da cidade de Manaus, AM. Imagem em Landsat 4-5 TM. A área de estudo está destacada pelo retângulo no mapa de drenagem (modificado de Archer et al., 2005).

Figura 2. Contexto geológico da confluência dos rios Negro e Solimões. Adaptado de Faria et al. (2004).

Figura 3. Ilhas rochosas do alto rio Negro (unidade I de Latrubesse \& Franzinelli, 2005). Imagem Landsat 4-5 TM.

Figura 4. Arquipélago de Mariuá e confluência dos rios Branco e Negro (unidade III de Latrubesse \& Franzinelli, 2005). Imagem Landsat 4-5 TM.

Figura 5. Arquipélago Anavilhanas (unidade V de Latrubesse \& Franzinelli, 2005). Imagem Landsat 4-5 TM.

Figura 6. Confluência dos rios Negro e Solimões (unidade VI de Latrubesse \& Franzinelli, 2005). Imagem Landsat 4-5 TM.

Figura 7. Flutuações anuais dos níveis dos rios Negro (Manaus), Solimões (Manacapuru), Amazonas (Óbidos), Tapajós (Santarém) e Xingu (Altamira e Porto de Moz). Elaborado a partir de dados da Agência Nacional de Águas (ANA) para o período entre os anos de 2006 e 2012.

Figura 8. Exemplo ilustrativo do processo de datação por luminescência. Adaptado de Duller (2008a).

Figura 9. Comparação entre o sinal natural (vermelho) e o sinal natural com transferência térmica (azul), que subestima a dose equivalente.

Figura 10. Exemplo de curva de dose-resposta. Lx/Tx corresponde ao sinal de luminescência corrigido pela dose teste. $\mathrm{D}_{\mathrm{N}}$ corresponde à dose natural estimada.

Figura 11. Mapa altimétrico baseado em modelo de relevo SRTM da confluência dos rios Negro e Solimões. A reta A-B indica o traçado do perfil altimétrico da Figura 12.

Figura 12. Perfil altimétrico transversal (NW-SE) à calha do rio Solimões (linha A-B no mapa da Figura 11). Notar as diferenças de altitude entre as unidades A e B.

Figura 13. Imagem do Google Eatrh (Image 2013 Geoeye) com a delimitação das unidades B1 e B2 nos rios Solimões e Amazonas.

Figura 14. Imagem do Google Earth (Image 2013 Geoeye) com a delimitação das unidades B1 e B2 na região de confluência dos rios Negro e Solimões com as barras (1 a 5) do rio Solimões.

Figura 15. Geometria interna da barra $1 \mathrm{com}$ o sentido de crescimento (setas brancas) dos cordões (em vermelho).

Figura 16. Geometria interna das barras 2, 3 e 4 com o sentido de crescimento (setas brancas) dos cordões (em vermelho).

Figura 17. Geometria interna da barra 5 com o sentido de crescimento (setas brancas) dos cordões (em vermelho).

Figura 18. Geometria interna das barras do rio Amazonas com o sentido de crescimento (setas brancas) dos cordões (em vermelho). 
Figura 19. Mapa de localização dos perfis batimétricos.

Figura 20. Perfil batimétrico A-A' do rio Negro (vide localização na Figura 19).

Figura 21. Perfil batimétrico B-B' do rio Negro (vide localização na Figura 19).

Figura 22. Perfil batimétrico C-C' do rio Negro (vide localização na Figura 19).

Figura 23. Perfil batimétrico D'-D do rio Solimões (vide localização na Figura 19).

Figura 24. Perfil batimétrico E'-E do rio Solimões (vide localização na Figura 19).

Figura 25. Perfil batimétrico F'-F do rio Solimões (vide localização na Figura 19).

Figura 26. Perfil batimétrico G'-G do rio Amazonas (vide localização na Figura 19).

Figura 27. Perfil batimétrico H'-H do rio Amazonas (vide localização na Figura 19).

Figura 28. Perfil batimétrico l'-I do rio Amazonas (vide localização na Figura 19).

Figura 29. Mapa com a localização dos pontos onde foram descritas as seções colunares.

Figura 30. Praia do Japonês no rio Negro (ponto NSM-07).

Figura 31. Seção colunar da trincheira na praia do Japonês (ponto NSM-07 do rio Negro).

Figura 32. Afloramento NSM-16 (Ilha da Marcheteria, rio Solimões) com intercalações de fácies arenosas e lamosas. Local onde foi descrita a seção colunar da Figura 34.

Figura 33. Afloramento NSM-32 (Paraná da Eva, rio Amazonas) onde foi descrita a seção colunar da Figura 35. Notar a ocorrência de intercalações de fácies arenosas e lamosas.

Figura 34. Seção colunar do afloramento NSM-16, na llha da Marchetaria no rio Solimões. A foto inferior indica local de coleta de amostra para datação LOE.

Figura 35. Seção colunar do afloramento NSM-32, no Paraná da Eva no rio Amazonas.

Figura 36. Localização das amostras da calha (pontos amarelos) e das barras (pontos vermelhos) dos rios Negro, Solimões e Amazonas utilizadas para a realização das análises de granulometria e de sensibilidade.

Figura 37. Curvas granulométricas dos sedimentos superficiais da calha do rio Negro.

Figura 38. Curvas granulométricas dos sedimentos das barras do rio Negro.

Figura 39. Curvas granulométricas dos sedimentos superficiais da calha do rio Solimões.

Figura 40. Curvas granulométricas dos sedimentos das barras do rio Solimões.

Figura 41. Curvas granulométricas dos sedimentos superficiais de calha do rio Amazonas.

Figura 42. Curvas granulométricas dos sedimentos das barras do rio Amazonas. 
Figura 43. Sensibilidade LOE para alíquotas individuais dos sedimentos de calha dos rios Negro, Solimões e Amazonas. IRr: componente rápido com estímulo por IR; LOEr: componente rápido com estímulo por azul; e LOEt: sinal total com estímulo por azul. Alíquotas na fração 180-250 $\mu \mathrm{m}$.

Figura 44. Sensibilidade para alíquotas individuais dos sedimentos das barras dos rios Negro, Solimões e Amazonas. IRr: componente rápido com estímulo por IR; LOEr: componente LOE rápido com estímulo por azul; e LOEt: sinal LOE total. Alíquotas na fração 180-250 $\mu \mathrm{m}$.

Figura 45. Sensibilidade para a média das alíquotas dos sedimentos de calha dos rios Negro, Solimões e Amazonas. M-IRr/LOEt: média da razão entre o componente rápido com estímulo por $I R$ e componente LOE total com estímulo por azul; e MLOEr/LOEt: média da razão entre o componente LOE rápido e componente LOE total com estímulo por azul. Alíquotas na fração 180-250 $\mu \mathrm{m}$.

Figura 46. Sensibilidade média das alíquotas dos sedimentos das barras dos rios Negro, Solimões e Amazonas. M-IRr/LOEt: média da razão entre o componente rápido com estímulo por IR e componente LOE total com estímulo por azul; e MLOEr/LOEt: média da razão entre o componente LOE rápido e componente LOE total com estímulo por azul. Alíquotas na fração 180-250 $\mu \mathrm{m}$.

Figura 47. Mapa de localização das amostras datadas por luminescência opticamente estimulada $e^{14} \mathrm{C}$. Pontos amarelos indicam as amostras com idades LOE e pontos em vermelho indicam amostras com idades LOE e ${ }^{14} \mathrm{C}$.

Figura 48. Sinal IR para dose de 0,18 Gy em alíquota de areia do rio Negro (NSM08). Sinal ao nível do background indica ausência de resposta proveniente de feldspato.

Figura 49. Sinal IR natural obtido em sedimentos arenosos do rio Solimões (NSM24e). Sinal acima do background indica presença significativa de feldspato.

Figura 50. Sinal IR natural obtido em sedimentos do rio Amazonas (NSM-38a). Sinal acima do background indica presença significativa de feldspato.

Figura 51. Teste de recuperação de dose para sedimentos dos rios Solimões (NSM16b) e Amazonas (NSM-32g). Foram utilizadas 12 alíquotas por amostra $(n=24)$.

Figura 52. Curva de dose-resposta LOE de alíquota de areia do rio Negro. Lx/Tx representa o sinal LOE corrigido.

Figura 53. Curva de dose-resposta LOE de alíquota de areia do rio Solimões. Lx/Tx representa o sinal LOE corrigido.

Figura 54. Curva de dose-resposta LOE de alíquota de areia do rio Amazonas. Lx/Tx representa o sinal LOE corrigido.

Figura 55. Histograma ponderado da amostra NSM-08 (rio Negro) com dispersão das doses relativamente baixa.

Figura 56. Valores das doses equivalentes das alíquotas da amostra NSM-08 (rio Negro). Apesar de ocorrer certa variação, a dispersão é relativamente baixa. A reta horizontal indica a dose estimada pelo Central Age Model.

Figura 57. Distribuição de frequências das doses equivalentes da amostra NSM-24e (rio Solimões). Notar a alta dispersão. 
Figura 58. Valores das doses equivalentes das alíquotas da amostra NSM-24e (rio Solimões). Notar a alta dispersão. A reta horizontal indica a dose estimada pelo Central Age Model.

Figura 59. Distribuição de frequências das doses da amostra NSM-32g (rio Amazonas) com alta dispersão.

Figura 60. Valores das doses equivalentes por alíquota da amostra NSM-32g (rio Amazonas) com alta dispersão. A reta horizontal indica a dose estimada pelo Central Age Model.

Figura 61. Mapa com a delimitação das unidades morfológicas B1 e B2 e as idades obtidas para os rios Negro, Solimões e Amazonas.

Figura 62. Cordões de crescimento (em vermelho) da barra $1 \mathrm{com}$ as idades LOE obtidas dos pontos NSM-23e $(1,3 \pm 0,21 \mathrm{ka})$ e NSM-24e $(3,0 \pm 0,26 \mathrm{ka})$.

Figura 63. Cordões de crescimento das barras 2, 3 e 4 (em vermelho) e as idades LOE obtidas nos pontos NSM-16b (10,9 $\pm 1,06 \mathrm{ka}), \mathrm{NSM}-16 \mathrm{LAj}(7,1 \pm 0,67 \mathrm{ka})$, NSM$17 \mathrm{LAb}(1,5 \pm 0,20 \mathrm{ka})$ e NSM-21b $(6,5 \pm 0,55 \mathrm{ka})$.

Figura 64. Cordões de crescimento da barra 5 (em vermelho) e as idades obtidas dos pontos NSM-29K (1,8 $\pm 0,19 \mathrm{ka})$ e NSM-31j $(3,4 \pm 0,32 \mathrm{ka})$.

Figura 65. Cordões de crescimento das barras do rio Amazonas (em vermelho) e as idades obtidas dos pontos NSM-32g $(4,7 \pm 0,43 \mathrm{ka}), \mathrm{NSM}-36 \mathrm{~g}(1,8 \pm 0,18 \mathrm{ka}), \mathrm{NSM}-38 \mathrm{a}$ $(1,6 \pm 0,20 \mathrm{ka})$ e NSM-50k $(11,9 \pm 1,18 \mathrm{ka})$

Figura 66. Comparação das idades de crescimento das barras dos rios Solimões e Amazonas (quadrados pretos) com os registros de $\delta^{18} \mathrm{O}$ em espelotemas dos Andes peruanos (curva preta que representa a média de 11 pontos dos dados de $\delta^{18} \mathrm{O}$ ). Modificado de Van Breukelen et al. (2008). 


\section{LISTA DE TABELAS}

Tabela 1. Estatísticas da granulometria dos sedimentos superficiais da calha dos rios Negro, Solimões e Amazonas.

Tabela 2. Estatísticas da granulometria dos sedimentos de barras dos rios Negro, Solimões e Amazonas. As amostras foram coletadas em zonas expostas durante 0 período de seca.

Tabela 3. Médias dos valores de M-IRr/LOEt e MLOEr/LOEt e porcentagens dos sedimentos de calha dos rios Negro e Solimões fornecidos para o rio Amazonas.

Tabela 4. Médias dos valores de M-IRr/LOEt e MLOEr/LOEt e porcentagens dos sedimentos das barras dos rios Negro e Solimões fornecidos para o rio Amazonas.

Tabela 5. Profundidade (P), número de alíquotas aceitas ( $n^{\circ}$ al.), doses equivalentes do Central Age Model (DEC), doses equivalentes do Mininum Age Model (DEM), taxas de doses (TD) e idades centrais e mínimas obtidas (ka) dos rios Negro, Solimões e Amazonas.

Tabela 6. Resultados das idades ${ }^{14} \mathrm{C}$ obtidas em fragmentos vegetais dos sedimentos dos rios Solimões e Amazonas. 


\section{INTRODUÇÃO}

Sistemas fluviais são sensíveis às mudanças na atmosfera e na superfície terrestre e fornecem informações importantes sobre variações do clima, do nível do mar e da tectônica. O rio Amazonas e seus tributários formam a maior bacia de captação de sedimentos do mundo (Hoorn et al., 2010). Esta bacia transfere grande volume de sedimentos oriundos da denudação das porções oeste, norte e central da plataforma sul-americana para o oceano Atlântico. Estudos sobre a proveniência e dinâmica de transporte de sedimentos nos rios amazônicos, principalmente no que se refere à carga arenosa, são ainda escassos. O rio Amazonas, formado pela confluência dos rios Negro e Solimões, percorre mais de $1000 \mathrm{~km}$ até sua foz no oceano Atlântico. O rio Negro, de águas escuras devido ao elevado teor de ácidos orgânicos e com baixa concentração de sedimentos terrígenos em suspensão, e o rio Solimões, de águas "brancas" devido à elevada carga de sedimentos em suspensão, possuem dinâmica sedimentar distinta (Franzinelli \& Igreja, 2002). Estudos recentes sobre a zona de confluência dos rios Negro e Solimões têm enfatizado aspectos geomorfológicos, estratigráficos ou tectônicos (Latrubesse \& Franzinelli, 2005; Soares, 2007; Soares et al., 2010).

Neste contexto, a presente pesquisa tem como objetivo a busca de critérios de diferenciação entre as areias transportadas pelos rios Negro e Solimões. Isto possibilitou caracterizar a contribuição do aporte sedimentar arenoso derivado destes dois rios à jusante da zona de confluência, onde se forma o rio Amazonas. Assim, a proveniência e o grau de retrabalhamento sedimentar das areias dos rios Negro e Solimões foram avaliadas pela sensibilidade da luminescência opticamente estimulada (LOE) do quartzo (Pietsch et al., 2008; Sawakuchi et al., 2011) e por curvas de distribuição granulométrica.

Datações por luminescência opticamente estimulada de amostras coletadas em barras arenosas estabilizadas situadas à montante e jusante da confluência dos rios Negro e Solimões (Figura 1) possibilitaram avaliar variações temporais da morfologia e do aporte sedimentar destes dois rios. A obtenção de idades de depósitos fluviais tem sido dificultada pelo número limitado de amostras de material orgânico para datação por ${ }^{14} \mathrm{C}$ e problemas de retrabalhamento de materiais orgânicos antigos nos sedimentos fluviais (Stanley \& Hait, 2000). Outras técnicas, tais como a datação de superfícies de terraços por nuclídeos cosmogênicos e datações das séries U/Th de carbonato pedogenético, fornecem idades mínimas da deposição de sedimentos (Gosse \& Phillips, 2001). A Luminescência Opticamente Estimulada (LOE) tem a vantagem de datar diretamente o tempo de deposição dos sedimentos, tendo sido 
cada vez mais utilizada em sedimentos fluviais durante a última década (Rittenour, 2008).
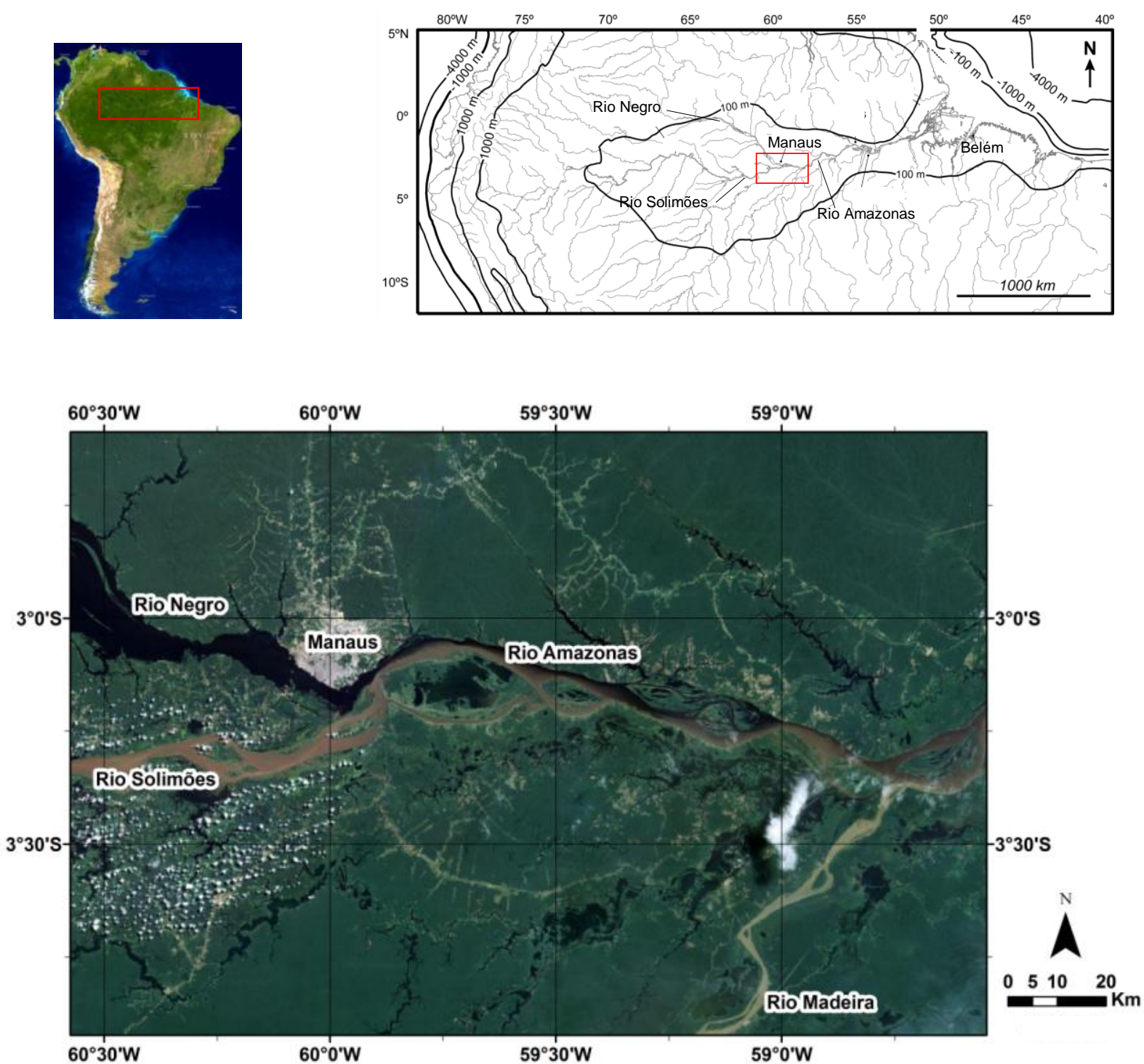

Figura 1. Localização da área de estudo nas proximidades da cidade de Manaus, AM. Imagem em Landsat 4-5 TM. A área de estudo está destacada pelo retângulo no mapa de drenagem (modificado de Archer et al., 2005). 


\section{OBJETIVOS}

Os objetivos desta pesquisa envolveram a busca de critérios de diferenciação do aporte sedimentar arenoso derivado dos rios Negro e Solimões e a avaliação das variações temporais deste aporte na zona de confluência destes rios, onde se forma 0 rio Amazonas. Para atingir estes objetivos, foram realizadas as seguintes tarefas:

1. Caracterização geomorfológica da zona de confluência dos rios Negro e Solimões e seleção de pontos de amostragem para caracterização dos sedimentos dos rios Negro, Solimões e Amazonas.

2. Coleta de amostras de sedimentos arenosos na calha e em barras ativas ou estabilizadas, com descrição de fácies sedimentares para avaliação das diferenças entre os modos de deposição dos sedimentos dos três rios estudados.

3. Análise granulométrica das amostras de sedimentos arenosos e sensibilidade LOE de grãos de quartzo na fração areia com o propósito de avaliar a proveniência.

5. Datação LOE de amostras de barras estabilizadas para verificação de variações temporais da geomorfologia fluvial e da sensibilidade LOE das areias.

\section{SÍNTESE BIBLIOGRÁFICA}

\subsection{Contexto geológico regional}

O Estado do Amazonas é recoberto em sua maior parte por unidades sedimentares quaternárias, mas apresenta também unidades paleoproterozóicas do vulcanismo-plutonismo cálcio-alcalino Jatapu e unidades neoproterozóicas dos domínios alto rio Negro e Imeri; Jamari e Roosevelt-Juruena; Uatumã-Anauã e Guiana Central (Faria et al., 2004).

O alto rio Negro drena uma pequena área sedimentar da Colômbia coberta por cerrado e tratos de rochas graníticas e granulíticas Pré-cambrianas (Faria et al., 2004). O médio rio Negro drena área com rochas paleoproterozóicas do Complexo Cauaburi, o qual é representado por hornblenda-biotita tonalitos, granodioritos e biotita monzogranitos. Nessa região, encontram-se também arenitos ferruginosos, siltitos e argilitos da Formação Iça (Pleistoceno), além de depósitos aluvionares (Holoceno) formados por areia, cascalho e argila (Faria et al., 2004). O médio rio Negro recebe alguns afluentes no seu lado esquerdo, sendo o maior deles o rio Branco, que drena áreas montanhosas de rochas cristalinas do Estado de Roraima e da fronteira entre Brasil e Guiana. No curso médio, o rio Branco atravessa o Pantanal Norte, que 
apresenta extensa planície com baixo gradiente de relevo (Latrubesse \& Franzinelli, 2005).

O neotectonismo no baixo rio Negro seria responsável pela sua maior profundidade e pela ocorrência de falésias ao longo de algumas partes do seu curso (Franzinelli \& Igreja, 2002). Contudo, a interpretação de movimentos tectônicos por evidências puramente geomorfológicas, sem controle geocronológico preciso, impossibilita avaliação segura do papel da neotectônica na modelagem do sistema fluvial amazônico atual. As escarpas lineares do baixo rio Negro também podem ser produto da erosão por ondas, cuja ação é regular neste setor do rio.

O embasamento da região de confluência dos rios Negro e Solimões é composto por unidades cretáceas (Formação Alter do Chão) e miocênicas, sobrepostas por depósitos pleistocênicos (Formação Iça) (Soares, 2007). Caputo (2011) propôs idade cenozóica para a Formação Alter do Chão, constituída por intercalações de arenitos, argilitos, siltitos e conglomerados sugestivas da deposição em leques aluviais e em deltas fluviais relacionados a ambientes lacustres. Ainda segundo este autor, nas proximidades de Manaus, em subsuperfície, as camadas cretáceas (Formação Jazida da Fazendinha) foram truncadas pela Formação Alter do Chão (Cenozóico) e os afloramentos desta região são compostos apenas por sedimentos terciários e quaternários. Este conjunto recobre parcialmente as unidades paleozóicas da Bacia do Amazonas, desde a Formação Nova Olinda até o Grupo Trombetas, em discordância erosiva (Caputo, 2011).

Soares et al. (2001) individualizaram cinco unidades pleistocênicas no baixo rio Negro. As unidades mais antigas estariam associadas aos rios Negro e Paraná do Ariaú e são representadas por depósitos de planície de inundação. A unidade mais jovem, relacionada ao rio Solimões, é constituída por depósitos de barra em pontal. $\mathrm{Na}$ região de Manaus, Latrubesse \& Franzinelli (2002) reconheceram três unidades sedimentares distintas. A unidade mais antiga corresponde a depósitos de terraços fluviais com relevo plano, os quais são compostos por silte e argila. A unidade intermediária é constituída por depósitos de planície fluvial com lagos, sendo também constituída por areias e argilas. A unidade mais jovem representa complexo mosaico de formas fluviais, com canais, barras de areia, diques marginais, planícies, ilhas e sistemas de canais abandonados.

Soares (2007) caracterizou três fácies sedimentares distintas nas unidades morfoestratigráficas da área de confluência dos rios Negro e Solimões: areia/lama com estratificação heterolítica inclinada; lama laminada a maciça e areias com laminação cruzada cavalgante. 
A Figura 2 apresenta o mapa geológico da região de confluência dos rios Negro e Solimões, com destaque para as formações Alter do Chão e Iça e os depósitos aluvionares.

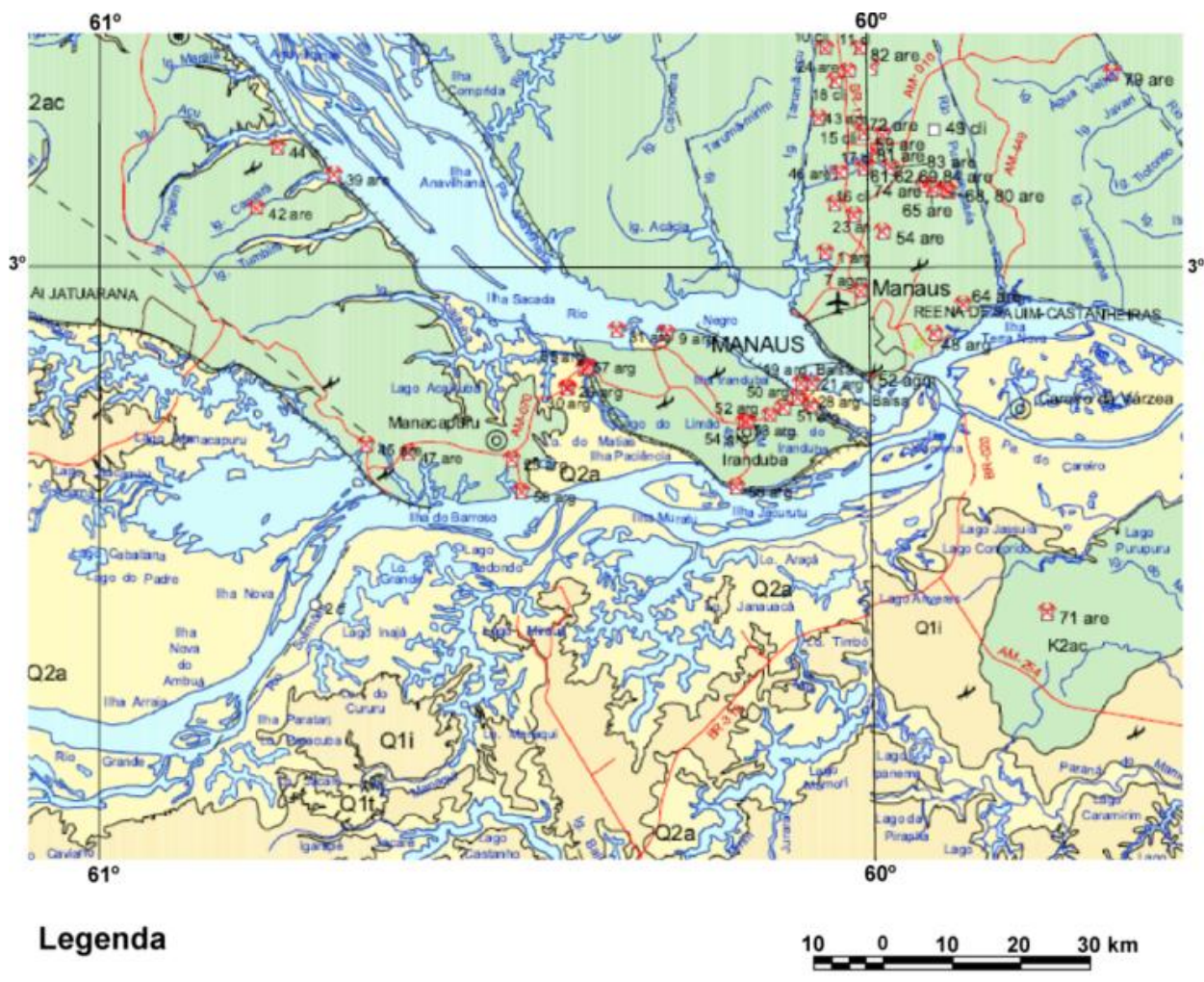

$$
\begin{aligned}
& \text { Q2a Depósitos Aluvionares: cascalho, areia e argila } \\
& \text { Q1i Formação Içá: arenito ferruginoso, siltito e argilito } \\
& \text { K2ac Formação Alter do Chão: arenito argiloso, arcóseo, argilito }
\end{aligned}
$$

Figura 2. Contexto geológico da confluência dos rios Negro e Solimões. Adaptado de Faria et al. (2004).

\subsection{Geomorfologia}

A reativação de falhas no substrato cretáceo por esforços de distensão durante - Pleistoceno permitiu a implantação e desenvolvimento da bacia do rio Negro (Soares, 2007) e influenciou na configuração morfológica da região do baixo rio Negro. Segundo este autor, o rio Negro apresentou estilo fluvial retilíneo, encaixado em rochas do embasamento cretáceo, com desenvolvimento de planície aluvial restrita durante o Pleistoceno Tardio.

Latrubesse \& Franzinelli (2005) dividiram o rio Negro em seis unidades, de acordo com critérios geomorfológicos e estruturais. A unidade I corresponde ao alto rio Negro e nela são formadas corredeiras e grandes ilhas rochosas (Figura 3). Bancos de 
areia branca são irregularmente distribuídos ao longo do curso superior do rio Negro, sendo mais frequentes em zonas de afloramentos rochosos. A unidade II é marcada pela formação de ampla planície de inundação durante o Holoceno.

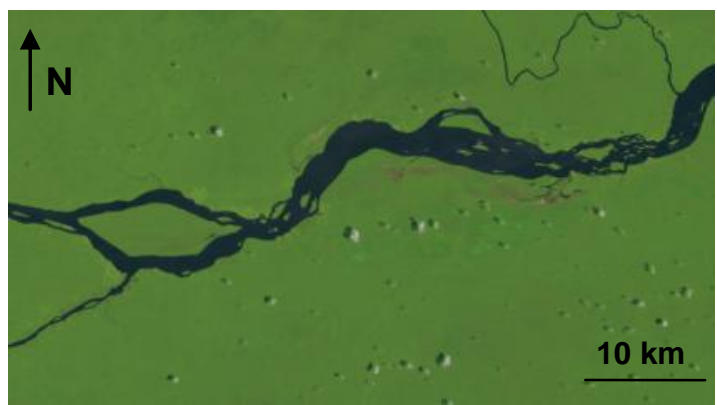

Figura 3. Ilhas rochosas do alto rio Negro (unidade I de Latrubesse \& Franzinelli, 2005). Imagem Landsat 4-5 TM.

A unidade III inicia-se em trecho onde o rio adquire orientação NW-SE até aproximadamente a confluência dos rios Branco e Negro (Latrubesse \& Franzinelli, 2005) e seu elemento geomorfológico mais marcante é o arquipélago de Mariuá (Figura 4).

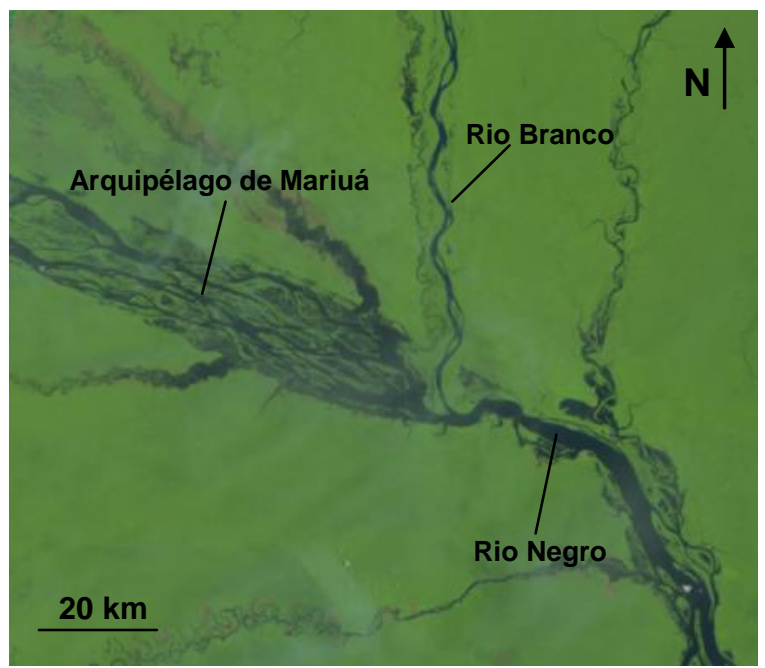

Figura 4. Arquipélago de Mariuá e confluência dos rios Branco e Negro (unidade III de Latrubesse \& Franzinelli, 2005). Imagem Landsat 4-5 TM.

A unidade IV de Latrubesse \& Franzinelli (2005) é caracterizada pela ocorrência de afloramentos rochosos em zona restrita do canal. $A$ unidade $V$ coincide com um largo canal onde ocorre o arquipélago Anavilhanas (Figura 5), que atravessa as rochas cretáceas da Formação Alter do Chão. 


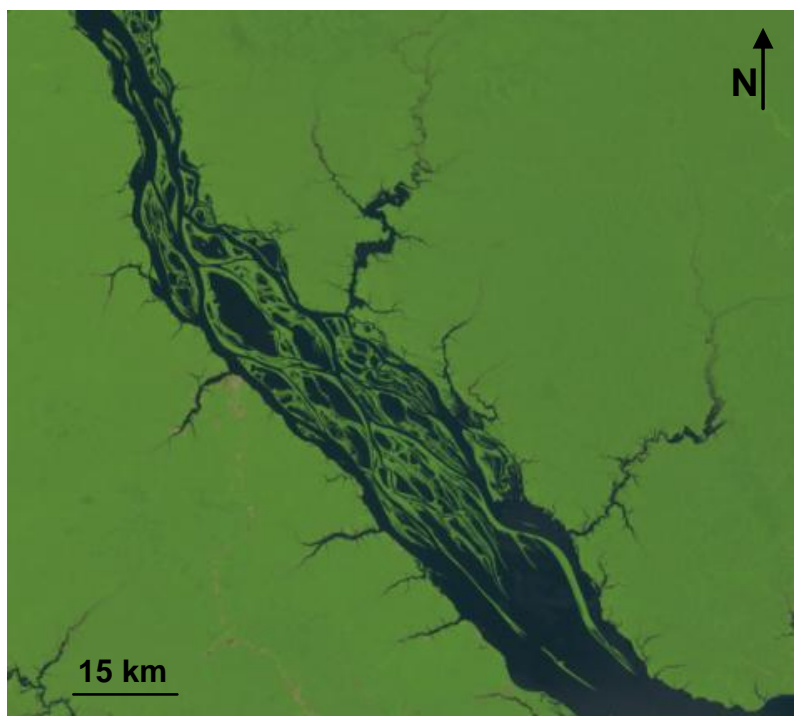

Figura 5. Arquipélago Anavilhanas (unidade V de Latrubesse \& Franzinelli, 2005). Imagem Landsat 4-5 TM.

A unidade VI abrange o setor entre Anavilhanas e a confluência dos rios Negro e Solimões (Figura 6). Apesar da baixa carga sedimentar em suspensão no baixo rio Negro, barras longitudinais depositadas na desembocadura de tributários desenvolvidos sobre os depósitos cretáceos formaram lagos de vales bloqueados, como, por exemplo, o igarapé Tarumã-Mirim (Latrubesse \& Franzinelli, 2005).

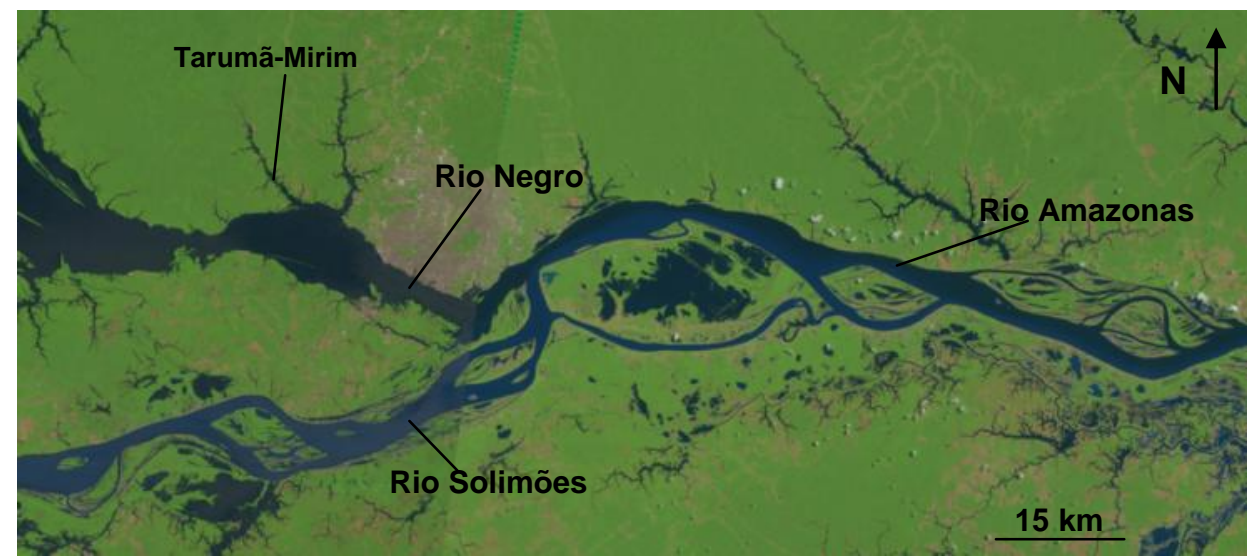

Figura 6. Confluência dos rios Negro e Solimões (unidade VI de Latrubesse \& Franzinelli, 2005). Imagem Landsat 4-5 TM.

Soares (2007) dividiu as unidades pleistocênicas na região da confluência dos rios Negro e Solimões em três unidades morfológicas: terra firme, áreas inundáveis e barras de canal.

O desenvolvimento do padrão de barras de acréscimo lateral do rio Solimões é iniciado quando tais barras são formadas com curvatura equivalente ao meandro principal. Em seguida canais secundários se desenvolvem e migram na planície de inundação, o que retrabalha as barras deixadas pelo canal principal e deposita barras 
menores relacionadas aos canais secundários. Concomitantemente, nas áreas mais rebaixadas da planície, lagos se instalam principalmente nas depressões entre barras (Mertes, 1996).

Segundo Soares et al. (2010), o rio Negro exibe canal com padrão retilíneo, confinado no embasamento de rochas cretáceas e miocênicas e com planície aluvial restrita. Já os terraços do rio Solimões apresentam morfologia de cordões abandonados com estratificação heterolítica inclinada, que seria indicativa de padrão de canal meandrante. Porém, atualmente, o sistema Solimões-Amazonas apresenta estilo anastomosado-ramificado (Soares et al., 2010).

A região de Manaus apresenta baixos valores de declividade, com gradiente máximo de $18^{\circ}$ (Sarges et al., 2011). As maiores declividades, entre $12^{\circ}$ e $18^{\circ}$, ocorrem nas bordas dos terraços fluviais e nas vertentes dos interflúvios alongados de topos planos. Declives entre $6^{\circ}$ e $11^{\circ}$ ocorrem nas vertentes dos interflúvios intensamente dissecados. Já as menores declividades ( $0^{\circ}$ a $\left.5^{\circ}\right)$ correspondem aos fundos de vales, às planícies e aos topos dos interflúvios tabulares (Sarges et al., 2011).

\subsection{Clima}

O clima da região de confluência dos rios Negro e Solimões é tropical úmido com precipitação média de 1700 a 2000 mm/ano, a qual aumenta para noroeste onde pode chegar a $3000 \mathrm{~mm} / \mathrm{ano}$ e diminui no sentido leste até $1400 \mathrm{~mm} / \mathrm{ano}$ (Silva et al., 2011). Segundo dados da Agência Nacional de Águas (ANA), nessa região, há maior precipitação entre os meses de janeiro e julho.

O ciclo sazonal de precipitação da região amazônica é controlado pela dinâmica anual da Zona de Convergência Inter-Tropical (ZCIT), que migra para o sul da linha do equador durante o verão (dezembro, janeiro e fevereiro), promovendo o aumento de precipitação na região durante este período (Vera et al., 2006). A migração da ZCIT ocorre devido às variações na temperatura da superfície do oceano Atlântico, que provocam contrastes com a temperatura do continente sul-americano, propiciando o ciclo sazonal de precipitação característico da Amazônia (NoguesPaegle et al., 2002).

As anomalias interanuais de precipitação na América do Sul são provocadas pelos ciclos do El Niño-Oscilação Sul (ENOS) (Bookhagen \& Strecker, 2010; Cheng et al., 2013). As anomalias El Ninõ são caracterizadas por aquecimento anormal da superfície marinha do oceano Pacífico tropical que promovem períodos de seca na região amazônica e no nordeste do Brasil e períodos chuvosos na costa oeste da 
América do Sul. Por outro lado, as anomalias La Ninã são caracterizadas pelo esfriamento anormal das águas superficiais no oceano Pacífico tropical e geram aumento na precipitação da bacia amazônica e da região sul do Brasil (Cheng et al., 2013).

Estudos sobre as mudanças da ZCIT na região amazônica durante o Quaternário são baseados em testemunhos de sedimentos da bacia Cariaco na Venezuela (Haug et al., 2001) e em espeleotemas dos Andes peruanos (Van Breukelen et al., 2008; Kanner et al., 2012). Essas duas regiões correspondem às zonas de captação das bacias hidrográficas dos rios Negro e Solimões.

Segundo Haug et al. (2001), modelos sugerem que o aumento do gradiente de temperatura da superfície do mar (norte e sul) nos oceanos Pacífico e Atlântico provocam a migração de chuvas convectivas em direção ao sul, levando a condições secas nos trópicos do norte (Haug et al., 2001) e a condições úmidas nos trópicos do sul (Baker et al., 2001). Van Breukelen et al. (2008) afirmam que o padrão alternado entre os registros de pluviosidades tropicais do norte e do sul é evidente quando se comparam os valores de $\delta^{18} \mathrm{O}$ em espeleotemas de Tigre Perdido (Peru, localizado nos trópicos do sul) com os valores de Ti e Fe (Haug et al., 2001) dos sedimentos da bacia de Cariaco (Venezuela, localizada nos trópicos do norte). Ambos indicadores registram valores de precipitação na América do Sul ao longo dos últimos 13,5 ka. Os espeleotemas de Tigre Perdido demonstraram aumento significativo na precipitação a partir de 9,0 ka atrás (Van Breukelen et al., 2008). Apesar das regiões de Cariaco e Tigre Perdido estarem separadas por milhares de quilômetros de distância, as variações de precipitação observadas nestas regiões são semelhantes e caracterizadas pela correlação entre fases secas na Venezuela e fases úmidas no Peru (Van Breukelen et al., 2008). Estes registros apontam a migração da ZCIT para o sul da linha do equador durante o verão e para o norte durante o inverno austral, como principal controle nos padrões milenares de precipitação da América do Sul tropical (Van Breukelen et al., 2008).

No município de Humaitá, sul da Amazônia, dados de isótopos de carbono em matéria orgânica do solo demonstraram uma cronologia da dinâmica da vegetação indicativa de mudanças climáticas (Freitas et al., 2001). Foram identificadas duas fases mais úmidas com o predomínio de floresta entre 17,0 e 9,0 ka AP e 3,0 ka AP até o recente, intercaladas por fases mais secas com expansão de savana (Freitas et al., 2001).

Dados palinológicos obtidos em sedimentos do Lago do Calado (Amazônia Ocidental) indicam clima mais seco no início do Holoceno, com baixas taxas anuais de 
precipitação até 4,0 ka AP, e clima mais úmido no final do Holoceno (Behling et al., 2001).

Os resultados das análises biogeoquímicas apresentadas por Cordeiro et al. (2011) revelaram três regimes hidrológicos e climáticos para a região amazônica. A primeira fase, entre 50,0 e 26,3 ka cal AP, foi caracterizada por clima úmido, como sugerido pelo carbono orgânico total (COT) alto e as concentrações de clorofila derivadas, indicativos de alta produtividade orgânica. Porém a produtividade pode ser favorecida também pelo clima seco que diminui a turbidez da água e favorece a fotossíntese e proliferação de algas. A segunda fase, entre 26,3 e 15,3 ka cal AP, foi caracterizada pela diminuição na produtividade orgânica, tal como indicado pelo minímo das clorofilas e das taxas de acumulação de COT. Isto sugere fase seca durante este período (Cordeiro et al., 2011). A terceira fase, entre 15,3 e 10,0 ka cal AP, foi caracterizada pelo aumento na produtividade orgânica lacustre, que provavelmente corresponde à elevação do nível do lago durante período mais úmido (Cordeiro et al., 2011).

\subsection{Hidrologia}

A vazão média anual do rio Negro é de $29.600 \mathrm{~m}^{3} / \mathrm{s}$ (Dunne et al., 1998) e a temperatura média anual da sua água é de $26^{\circ} \mathrm{C}$ (Leon, 2006). A profundidade da calha do rio Negro varia aproximadamente de 30 a $100 \mathrm{~m}$ e sua carga sedimentar é relativamente baixa se comparada à carga total anual do rio Amazonas (Dunne et al., 1998).

Os rios Solimões (Manacapuru) e Amazonas (Óbidos) apresentam vazão média de $102.340 \mathrm{~m}^{3} / \mathrm{s}$ e $171.810 \mathrm{~m}^{3} / \mathrm{s}$, respectivamente, medidas no período de 1995 a 2008 (Mangiarotti et al., 2013). A concentração de sedimentos em suspensão do rio Solimões equivale a $209 \mathrm{~g} / \mathrm{m}^{3}$ e a do rio Amazonas a $149 \mathrm{~g} / \mathrm{m}^{3}$, medidas entre $2000 \mathrm{e}$ 2007 (Mangiarotti et al., 2013). A taxa de acumulação de sedimentos do rio Solimões corresponde a 12,3 mm/ano e a do rio Amazonas a 27,1 mm/ano (Mangiarotti et al., 2013).

As flutuações anuais dos níveis dos rios Negro, Solimões, Amazonas, Tapajós e Xingu são controladas pelo aumento de precipitação entre os meses de janeiro e julho e declínio de agosto a novembro (Figura 7). 


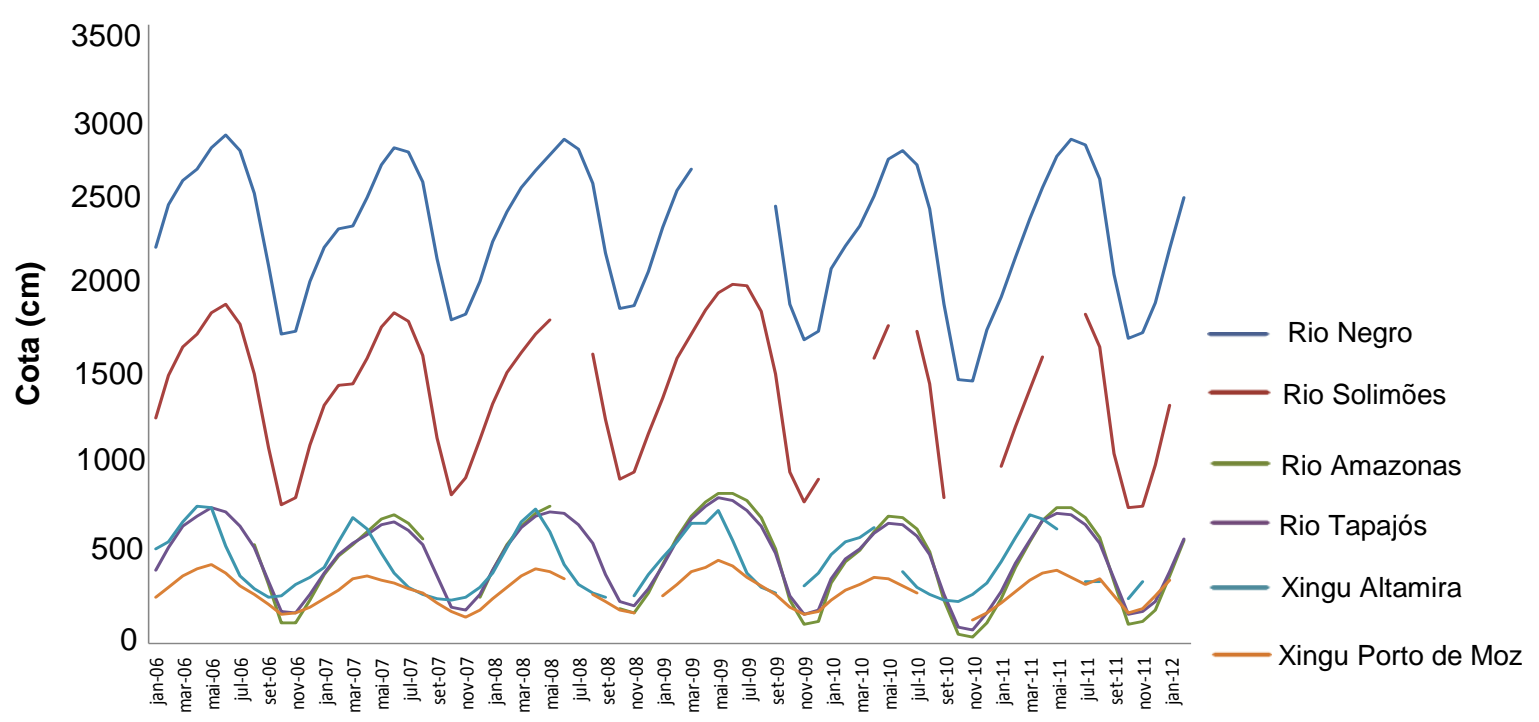

Figura 7. Flutuações anuais dos níveis dos rios Negro (Manaus), Solimões (Manacapuru), Amazonas (Óbidos), Tapajós (Santarém) e Xingu (Altamira e Porto de Moz). Elaborado a partir de dados da Agência Nacional de Águas (ANA) para o período entre os anos de 2006 e 2012.

\subsection{Sensibilidade da luminescência opticamente estimulada (LOE) do quartzo e sua relação com o transporte sedimentar}

A luminescência opticamente estimulada (LOE) ocorre quando certos materiais que foram previamente expostos à radiação ionizante são estimulados por luz. A intensidade da emissão de luz é proporcional à quantidade ou dose absorvida de radiação ionizante que o material foi previamente exposto. A luz emitida relaciona-se a defeitos no retículo cristalino do mineral e pode ser detectada e amplificada através de uma fotomultiplicadora. Os defeitos no retículo cristalino responsáveis pela LOE são formados pela incorporação de íons estranhos (impurezas) de um determinado cristal ou pela ausência dos íons principais (vacâncias). A sensibilidade LOE equivale à intensidade de luz emitida em termos de determinada dose de radiação, indicando a capacidade do material em transformar a energia recebida em luz (Pietsch et al., 2008).

Experimentos laboratoriais planejados para simular as condições de irradiação durante o soterramento e exposição à luz solar no transporte sedimentar e medidas realizadas em sedimentos fluviais recentes têm demonstrado que a sensibilidade LOE é incrementada durante o período de residência dos grãos de quartzo em ambientes de sedimentação (Moska \& Murray, 2006; Pietsch et al., 2008). Pietsch et al. (2008) observaram que o incremento da sensibilidade LOE das areias do rio Castlereagh (Austrália) no sentido jusante ocorre tanto devido ao aumento da sensibilidade de grãos inicialmente luminescentes quanto à ativação do mecanismo de luminescência 
em grãos inicialmente não luminescentes. Dados obtidos por Sawakuchi et al. (2011) em areias do rio Jacupiranguinha (Cajati, SP) confirmaram as observações de Pietsch et al. (2008). Contudo, o aumento da sensibilidade LOE observado nas areias do rio Jacupiranguinha é menor que o registrado no rio Castlereagh, se considerada a mesma distância de transporte. Esta variação no incremento da sensibilidade LOE observada nos rios Castlereagh e Jacupiranguinha resultaria de diferenças da dinâmica destes dois rios (Sawakuchi et al., 2011). O rio Castlereagh drena região semi-árida e possui fluxo efêmero. Já o rio Jacupiranguinha atravessa área úmida e apresenta fluxo permanente. A dinâmica sedimentar de rios efêmeros pode favorecer o incremento da sensibilidade LOE dos grãos de quartzo devido à sua maior capacidade de repetir ciclos de deposição, exposição à luz solar e remobilização dos seus sedimentos. Os rios de áreas úmidas, os quais possuem fluxo permanente e águas turvas, dificultam a exposição solar dos grãos de quartzo. Além disso, o fluxo permanente dos rios de área úmida acarretaria menor número de ciclos de soterramento e erosão dos sedimentos, considerando-se uma mesma distância de transporte. Assim, a sensibilidade LOE do quartzo estaria relacionada à dinâmica sedimentar de sistemas fluviais.

\subsection{Datação de sedimentos por luminescência opticamente estimulada (LOE)}

As datações absolutas por luminescência de minerais constituem os únicos métodos geocronológicos para eventos de deposição de sedimentos detríticos (Duller, 2004). Apesar de diversos minerais apresentarem luminescência opticamente estimulada, tais como calcita, fluorita, anfibólios, piroxênios e zircão, quartzo e feldspato são considerados mais adequados para datação devido à abundância nos sedimentos e propriedades de dosimetria de radiação por luminescência relativamente bem conhecidas.

Os métodos de datação por luminescência opticamente estimulada permitem obter idades desde alguns anos até cerca de centenas de milhares de anos, dependendo das características das amostras, as quais incluem a sensibilidade e nível de saturação do sinal de luminescência e taxa de dose de radiação no ambiente de deposição (Murray \& Wintle, 2000 e Wintle \& Murray, 2006). Feldspatos usualmente apresentam nível de saturação mais elevado que o do quartzo (Buylaert et al., 2009), o que permite maior alcance temporal para a datação de sedimentos. 


\section{Princípios de datação LOE}

A datação por luminescência explora a presença de radionuclódeos naturais das séries do urânio $\left({ }^{238} \mathrm{U}\right)$, do tório $\left({ }^{232} \mathrm{Th}\right)$ e do potássio $\left({ }^{40} \mathrm{~K}\right)$. Minerais, tais como quartzo e feldspato, agem como dosímetros nesse processo, armazenando em sua estrutura cristalina pequena proporção de energia proveniente das emissões liberadas pelo decaimento radioativo destes radionuclídeos naturais, além de raios cósmicos (Duller, 2008a). A energia ou dose de radiação acumulada nos grãos de quartzo e feldspato após a deposição pode ser liberada sob a forma de luz, mediante a exposição dos cristais a um estímulo. Se este estímulo é a luz, o fenômeno é denominado luminescência opticamente estimulada. A exposição dos minerais à luz do sol durante o transporte sedimentar impede a acumulação da energia derivada da radiação ionizante (Duller, 2008a; Buylaert et al., 2009). Deste modo, tal energia acumula-se nos cristais somente após a deposição. $O$ sinal de luminescência aumenta com o tempo de soterramento após o último evento de deposição do sedimento. Assim, é possível determinar a idade de deposição por meio da dose de radiação acumulada desde o último evento de exposição solar e pela taxa de dose de radiação do sítio de deposição.

Desta forma, a datação de sedimentos por luminescência permite obter idades para o último evento de exposição dos sedimentos à luz solar (Duller, 2008a). As medidas do sinal de luminescência são utilizadas para estimar a dose de radiação acumulada na amostra durante o soterramento.

A unidade de medida de absorção de radiação no Sistema Internacional é o Gray (Gy), a qual significa a quantidade de energia absorvida por uma amostra ou a sua dose equivalente $(\mathrm{De})\left(1 \mathrm{~Gy}=1 \mathrm{~J}^{\mathrm{kg}}{ }^{-1}\right)$. A taxa de dose corresponde à quantidade de energia absorvida por intervalo de tempo, a partir da radiação ionizante no ambiente que envolve a amostra. Em trabalhos de datação de sedimentos, a taxa de dose é usualmente representada em Gy/ka. Assim, a equação da idade por luminescência é expressa por:

$$
\text { Idade }(k a)=\frac{\text { Dose equivalente }\left(D_{\underline{e}}\right)(G y)}{\text { Taxa de Dose }(G y / k a)}
$$

Um exemplo didático para entender o funcionamento da datação por luminescência é exposto a seguir, onde uma bateria recarregável representa os grãos de minerais. Se estes grãos forem expostos à luz na superfície durante o transporte, irão liberar a energia da bateria, de modo que o grão é soterrado desprovido de 
energia acumulada. Após o soterramento, a bateria começa a ser recarregada pela radiação ionizante oriunda do ambiente. Com o passar do tempo essa energia armazenada aumenta na proporção da quantidade de radiação ambiental ou taxa de dose de radiação. A amostra é coletada e medida em laboratório para obtenção do sinal natural da luminescência. O sinal de luminescência observado está relacionado diretamente com a quantidade de energia acumulada por essa bateria desde o seu último esvaziamento. Se for possível saber a velocidade com que esta bateria estava sendo recarregada, é possível calcular o período de tempo desde que a bateria foi esvaziada, ou seja, a idade de deposição do sedimento (Duller, 2008a) (Figura 8).

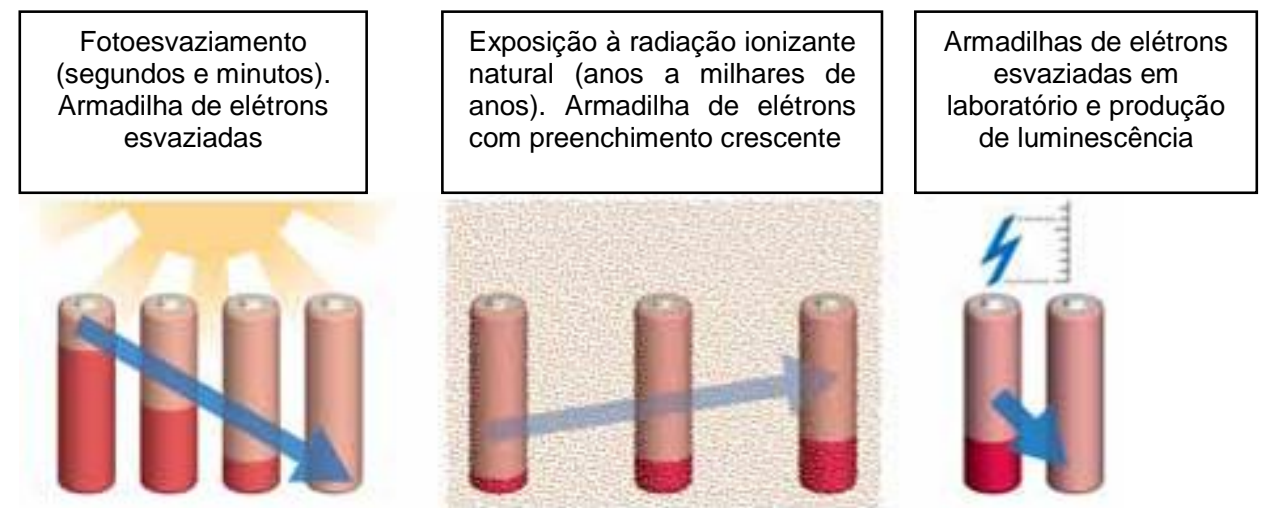

Figura 8. Exemplo ilustrativo do processo de datação por luminescência. Adaptado de Duller (2008a).

\section{Cálculo de dose equivalente (De)}

O intervalo de doses equivalentes que podem ser estimadas para quartzo geralmente varia de 0,5 a 150 Gy. Doses mínimas dependem da sensibilidade da amostra, já que a medida de doses muita baixas pode ser limitada pelo sinal de luminescência próximo ao background enquanto que a estimativa de doses elevadas é limitada pela saturação do sinal. Taxas de dose comumente obtidas para sedimentos arenosos com quartzo estão entre 1 e 3 Gy/ka. Logo, a idade máxima obtida para grãos de quartzo é usualmente inferior a $150 \mathrm{ka}$.

Para a estimativa de doses baixas (<0,5 Gy), é necessário ressaltar dois problemas principais. O primeiro estaria relacionado à baixa sensibilidade da amostra (sinal de luminescência) em relação à sensibilidade do sistema de medidas (background). O segundo é relacionado à transferência térmica provocada pelo préaquecimento, que pode gerar sinal residual e subestimar a dose equivalente (Figura 9). Esses problemas podem ser minimizados a partir do aumento da sensibilidade do 
instrumento de detecção, do uso do feldspato (se o quartzo apresentar baixa sensibilidade) e da avaliação da transferência térmica.

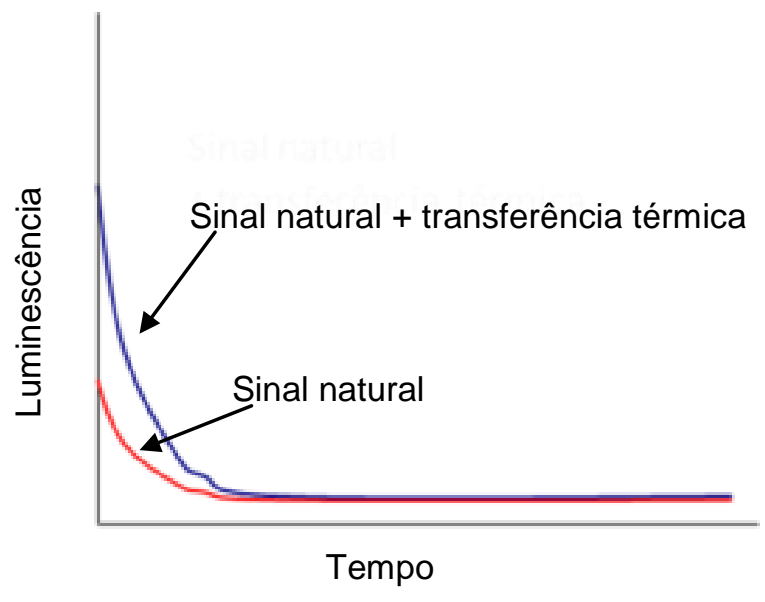

Figura 9. Comparação entre o sinal natural (vermelho) e o sinal natural com transferência térmica (azul), que subestima a dose equivalente.

Para a estimativa de doses altas, é preciso ressaltar que a dose máxima da amostra depende do nível de saturação do sinal de luminescência, sendo que o feldspato apresenta saturação em doses mais altas que o quartzo, como já referido. Porém, feldspatos apresentam sinal de luminescência instável, suscetível a esvaziamento espontâneo (fading).

O protocolo de rotina utilizado para estimar doses equivalentes é o Single Aliquot Regenerative Dose (SAR) (Murray \& Wintle, 2000 e Wintle \& Murray, 2006).

O protocolo SAR para estimativa de dose equivalente inclui as seguintes etapas:

1. Dose $D_{i}$;

2. Pré-aquecimento $\left(160^{\circ} \mathrm{C}-300^{\circ} \mathrm{C}\right.$ por $\left.10 \mathrm{~s}\right)$;

3. Estimulação por 40 s a $125^{\circ} \mathrm{C}$;

4. Dose teste $D_{t}$;

5. Aquecimento a $160^{\circ} \mathrm{C}$;

6. Estimulação por 40 s a $125^{\circ} \mathrm{C}$;

7. Retorno à etapa 1 .

A sequência é repetida para doses crescentes, sendo $\mathrm{i}=0$ (natural), D0, D1, D2, D3, D4, D5=0 Gy, D6=D1=D7 (Murray \& Wintle, 2000; Wintle \& Murray, 2006).

A finalidade do protocolo SAR é a correção das mudanças de sensibilidade que ocorrem com as amostras durante os procedimentos de medida. As mudanças de sensibilidade são monitoradas e corrigidas por meio do sinal LOE de uma dose-teste 
constante. Essas mudanças são provocadas por irradiação, iluminação e aquecimento realizados durante as medidas para estimativa de dose equivalente (Duller, 2008a).

A segunda etapa do protocolo, que consiste no pré-aquecimento entre $160^{\circ} \mathrm{e}$ $300^{\circ} \mathrm{C}$ por $10 \mathrm{~s}$ tem como vantagens eliminar os componentes LOE instáveis e homogeneizar a sensibilidade. O teste do plateau é realizado para definir essa temperatura de pré-aquecimento. Neste teste, aplica-se dose conhecida e avalia-se a dose recuperada em termos de diferentes temperaturas de pré-aquecimento. Esperase a obtenção de um plateau no nível do valor da dose aplicada.

A estimulação da amostra a $125^{\circ} \mathrm{C}$ (etapa 3 ) tem como objetivo prevenir o reaprisionamento de cargas nas armadilhas correspondentes ao pico da termoluminescência $\left(\mathrm{TL}\right.$ ) em $110^{\circ} \mathrm{C}$ (instável e que pode transferir cargas para armadilhas LOE).

A dose-teste constante $D_{t}$ geralmente corresponde a cerca de $20 \%$ da dose natural. A etapa 5 , que é o pré-aquecimento a $160^{\circ} \mathrm{C}$ para leitura do sinal da doseteste é realizado para esvaziar as armadilhas instáveis correspondentes ao pico TL em $110^{\circ} \mathrm{C}$ (Duller, 2008a). Esta temperatura é menor para minimizar mudanças de sensibilidade.

A primeira sequência de medidas é utilizada para medir o sinal LOE da dose natural. Posteriormente, são aplicadas doses crescentes com o objetivo de construir a curva de dose-resposta (Figura 10) para estimativa da dose natural por meio do sinal LOE natural. A curva de dose-resposta é composta pelo sinal LOE da dose $D_{i}(L x)$ corrigido pelo sinal da dose teste $(\mathrm{Tx})$ e pelas respectivas doses crescentes de radiação.

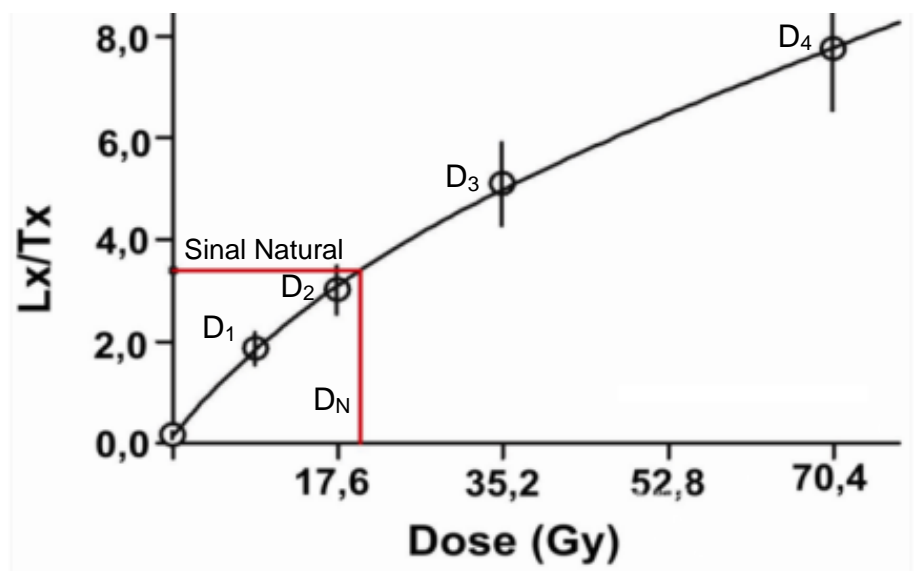

Figura 10. Exemplo de curva de dose-resposta. Lx/Tx corresponde ao sinal de luminescência corrigido pela dose teste. $D_{N}$ corresponde à dose natural estimada. 
$\underline{\text { Testes de confiabilidade (reciclagem, recuperação e teste de feldspato) }}$

Os testes utilizados para validar as curvas de dose-resposta das alíquotas medidas com o protocolo SAR consistem em: reciclagem (recycling), recuperação (recuperation) e teste do feldspato (feldspar test). O protocolo SAR ajustado para determinado conjunto de amostras também deve ser avaliado por teste de recuperação de dose (dose recovery test) antes de ser aplicado para estimativa de doses naturais.

O teste de reciclagem consiste na comparação dos sinais de doses iguais administradas no início e no final da sequência SAR (D1=D6), sendo que a razão entre os sinais das doses D1 e D6 (LOE $\left.{ }_{D 1} / L_{D}\right)$ deve estar situado entre 0,9 e 1,1. Este teste é utilizado para avaliar a precisão de medidas repetidas e validar a correção do sinal LOE durante o ciclo SAR (Murray \& Roberts, 1998).

O teste de recuperação é feito aplicando-se dose de 0 Gy após a última dose utilizada para a elaboração da curva de dose-resposta (D5=0 Gy). Isto permite avaliar a intensidade do sinal residual devido à transferência térmica causada pelo efeito do tratamento térmico sobre a transferência de cargas para armadilhas fotossensíveis (Duller, 2008a).

O teste do feldspato é feito a partir da introdução de uma estimulação por infravermelho (IR) por $40 \mathrm{~s}$ a $60^{\circ} \mathrm{C}$ antes da medida do sinal de luminescência (estímulo com luz azul) referente à última dose da sequência SAR (D7). O IR provoca emissão de luz somente no felsdspato. Deste modo, é possível avaliar a presença de feldspatos. Este teste tem por objetivo avaliar a eficácia da preparação de amostras e a contaminação por feldspatos.

No teste de recuperação de dose, é feito o fotoesvaziamento de alíquotas das amostras sob a luz do sol para simular condições naturais. A seguir, aplica-se dose de radiação conhecida, a qual será estimada por meio do protocolo SAR e comparada com o valor correto. Isto permite testar se a amostra se comporta como dosímetro natural e se o protocolo SAR ajustado está adequado.

\section{Cálculo de taxa de dose}

A taxa de dose é composta pela soma da dose de radiação a (partículas pesadas com penetração de $0,04 \mathrm{~mm}$ ), $\beta$ (elétrons, com penetração de $\sim 2 \mathrm{~mm}$ ) e $\gamma$ (fótons, com penetração de $\sim 30 \mathrm{~cm}$ ) proveniente de radionuclídeos naturais disseminados nos sedimentos e da radiação cósmica (mistura de partículas leves, pesadas e fótons - componentes hard e soft). No caso da datação de grãos de 
quartzo na fração areia $(0,180-0,250 \mathrm{~mm})$, o efeito da radiação a é eliminado por meio da dissolução com HF da camada externa dos grãos. Deste modo, a taxa de dose é reduzida para o efeito da radiação $\beta$, y e cósmica (Duller, 2008a).

Os radionuclídeos disseminados nos sedimentos, principalmente em minerais pesados, argilominerais e feldspatos, são responsáveis pela maior parte da radiação ionizante depositada nos grãos de quartzo. Já os raios cósmicos apresentam usualmente baixa porcentagem da taxa de dose total $(<10 \%)$, sendo mais importantes somente para sedimentos muito ricos em quartzo e acomodados em baixas profundidades de soterramento.

A taxa de dose pode ser medida por meio do uso de dosímetros in situ ou pela determinação da concentração dos radionuclídeos naturais. A medida da taxa de dose in situ através de dosímetros elimina o efeito de heterogeneidades composicionais, porém informa somente a taxa de dose atual e não permite avaliar desequilíbrios causados pela lixiviação ou precipitação de radionuclídeos. Já a medida da concentração de radionuclídeos $\left({ }^{238} \mathrm{U}+\right.$ filhos, ${ }^{232} \mathrm{Th}+$ filhos, $\left.{ }^{40} \mathrm{~K}\right)$ através da espectrometria y possui as vantagens de avaliar os desequilíbrios (perda e ganho de radionuclídeos). No entanto, deve-se considerar o efeito de heterogeneidades na composição dos sedimentos, já que o efeito da radiação $\gamma$ e $\beta$ nos sedimentos é respectivamente cerca de $30 \mathrm{~cm}$ e $2 \mathrm{~cm}$. A taxa de dose da radiação cósmica é estimada por meio de modelos teóricos, os quais consideram a densidade do sedimento e a altitude, latitude e profundidade do ponto de coleta de amostra.

Para a coleta de amostras destinadas ao cáculo de taxa de dose, é recomendável evitar horizontes influenciados por variação do nível freático, os quais podem apresentar maior mobilidade de radionuclídeos, horizontes com alteração pósdeposicional intensa e níveis com concentração de minerais pesados. 


\section{MATERIAIS E MÉTODOS}

\subsection{Análise geomorfológica por sensoriamento remoto}

Mapas geomorfológicos e perfis topográficos da zona de confluência dos rios Negro e Solimões foram elaborados a partir de modelos de relevo SRTM e imagens de satélite (Landsat), acessíveis nos sítios eletrônicos da NASA (North America Spatial Agency) e do Google Earth. Os mapas e perfis foram elaborados com auxílio de software de sistema de informação geográfica (ArcGis 9.3). Também foram obtidos perfis batimétricos transversais ao canal dos rios Negro, Solimões e Amazonas com o auxílio do Sonar Garmin GPSmap 521S.

\subsection{Análise de fácies e coleta de amostras}

Unidades geomorfológicas definidas por sensoriamento remoto foram visitadas durante os trabalhos de campo para descrição de fácies sedimentares e coleta de amostras. A análise de fácies foi executada, segundo os critérios propostos por Walker \& James (1992), em afloramentos naturais ou trincheiras abertas manualmente.

Amostras para datação LOE foram coletadas em barras arenosas estabilizadas por meio de tubos de alumínio, para impedir a exposição à luz solar e manter o sinal LOE natural.

Os trabalhos de campo foram executados durante o período de seca para facilitar a abertura de trincheiras e a coleta de amostras superficiais em barras arenosas ativas. As amostras de sedimentos de canal foram coletadas com amostrador do tipo Van-veen (grab), que permitiu a coleta de amostras de sedimentos superficiais submersos.

\subsection{Análise granulométrica}

A granulometria foi realizada em granulômetro a laser Malvern Instruments, modelo Mastersizer 2000 com acessório Hydro 2000MU do Laboratório de Sedimentologia do Instituto de Geociências da USP. O intervalo granulométrico utilizado nessa análise foi para grãos menores que $1 \mathrm{~mm}$ dispersos em água deionizada. Os resultados de granulometria foram expressos por distribuições de frequência e estatísticas descritivas. 


\subsection{Análise de sensibilidade LOE}

As amostras para análise de sensibilidade LOE foram peneiradas a úmido para aquisição do intervalo granulométrico entre 180 e $250 \mu \mathrm{m}$. Posteriormente, as amostras foram submetidas aos seguintes processos para separação de grãos de quartzo e feldspatos:

- Ataque com $\mathrm{H}_{2} \mathrm{O}_{2}$ para eliminação de matéria orgânica.

- Separação de minerais pesados em solução de metatungstato de lítio (densidade de $2,85 \mathrm{~g} / \mathrm{cm}^{3}$ ).

Foram realizadas medidas de sensibilidade LOE em doze alíquotas de concentrados de grãos de quartzo e feldspato com igual volume por amostra. A sensibilidade LOE foi representada pelas alíquotas individuais e pela média aritmética das doze alíquotas. Alíquotas dispersas em placas de aço foram submetidas à seguinte sequência de medidas:

1. Iluminação com LED azul por $100 \mathrm{~s}$;

2. Dose $D$ (10 Gy) de radiação beta;

3. Pré-aquecimento a $190^{\circ} \mathrm{C}$ por 10 s para eliminação de componentes instáveis;

4. Estimulação com IR (infravermelho) por $300 \mathrm{~s}$ a $60^{\circ} \mathrm{C}$;

5. Estimulação com LED azul (intensidade constante) por $100 \mathrm{~s} \mathrm{a} 125^{\circ} \mathrm{C}$;

6. Estimulação com LED azul (intensidade constante) por $100 \mathrm{~s}$ a $125^{\circ} \mathrm{C}$.

A iluminação da etapa 1 teve como objetivo esvaziar o sinal LOE natural. O objetivo da estimulação por IR foi obter um índice do teor de feldspatos e esvaziá-los para que a LOE azul subsequente fornecesse o sinal de luminescência do quartzo ou dominado pelo quartzo. A estimulação com luz azul da etapa 6 visou a avaliação do background.

As medidas LOE foram efetuadas em equipamento Risoe DA-20 TL/OSL systems do Laboratório de Espectrometria Gama e Luminescência do Instituto de Geociências da USP. Este equipamento possibilita a irradiação, tratamento térmico e medidas de luminescência de modo automatizado em conjuntos de até 48 alíquotas de minerais em grãos. 


\subsection{Datações LOE}

As amostras analisadas foram coletadas em tubos de alumínio $(5 \mathrm{~cm}$ de diâmetro por $30 \mathrm{~cm}$ de comprimento) em profundidades de soterramento entre $35 \mathrm{~cm}$ e $9,5 \mathrm{~m}$. Também foram coletadas amostras para espectrometria gama, a um raio de até $30 \mathrm{~cm}$ da posição de retirada do tubo de alumínio.

A separação e preparação das alíquotas de grãos para medidas de dose natural de radiação foram executadas sob luz vermelha para preservação do sinal LOE natural. Primeiramente, foi realizado o procedimento padrão para preparação de amostras que consiste nas seguintes etapas:

1) Peneiramento a úmido para aquisição da fração 180-250 $\mu \mathrm{m}$;

2) Ataque com $\mathrm{H}_{2} \mathrm{O}_{2} 29 \%$ para eliminação de matéria orgânica;

3) Ataque com HCL 3,75\% para eliminação de carbonatos;

4) Ataque com HF $40 \%$ por 40 min para eliminação de feldspatos e dissolução da camada externa dos grãos de quartzo;

5) Separação de minerais pesados em solução de metatungstato de lítio (densidade=2,85 $\mathrm{g} / \mathrm{cm}^{3}$ );

6) Separação de feldspatos remanescentes em solução de metatungstato de lítio (densidade $=2,62 \mathrm{~g} / \mathrm{cm}^{3}$ ).

As medidas de luminescência das amostras do rio Negro apresentaram sinal IR (infravermelho) baixo, indicando quantidade desprezível de feldspato nas alíquotas analisadas. Porém, as areias dos rios Solimões e Amazonas apresentaram alto sinal $I R$, o que indica alto conteúdo de feldspato e inadequação para a separação de quartzo por meio do procedimento padrão.

A observação das areias dos rios Solimões e Amazonas em microscópio estereoscópico indicou cerca de $30 \%$ de fragmentos líticos compostos por cristais finos de feldspato, mica e quartzo. Com o propósito de eliminar os grãos com feldspatos, a preparação destas amostras foi modificada pela inserção de ataque adicional com HF $40 \%$ por 1h20min, após a separação de minerais pesados e feldspatos. Este ataque adicional foi seguido por novo peneiramento para aquisição da fração 180-250 $\mu \mathrm{m}$ e descarte de grãos com diâmetro abaixo de $125 \mu \mathrm{m}$ reduzidos pelo tratamento com HF.

Depois destas etapas de preparação, as amostras foram submetidas à leitura de luminescência para estimativa de dose natural no leitor automático Risoe DA-20 
TL/OSL systems com fonte ${ }^{90} \mathrm{Sr} /{ }^{90} \mathrm{Y}$ para irradiação beta do Laboratório de Espectrometria Gama e Luminescência do Instituto de Geociências da USP.

As estimativas de dose natural de radiação para as datações LOE foram realizadas, segundo o protocolo SAR (Single-Aliquot Regenerative) (Murray \& Wintle, 2000), em grãos de quartzo provenientes de amostras de barras fluviais estabilizadas. Para as amostras do rio Negro, a estimativa de dose envolveu as seguintes etapas:
1. Dose $\mathrm{Di}$;
2. Pré-aquecimento a $190^{\circ} \mathrm{C}$ por $10 \mathrm{~s}$;
3. Estimulação com LEDs azuis a $125^{\circ} \mathrm{C}$ por $40 \mathrm{~s}$;
4. Dose teste Dt;
5. Aquecimento a $190^{\circ} \mathrm{C}$;
6. Estimulação com LEDs azuis a $125^{\circ} \mathrm{C}$ por $40 \mathrm{~s}$;
7. Iluminação com LEDs azuis $(90 \%)$ a $0^{\circ} \mathrm{C}$ por $40 \mathrm{~s}$;
8. Repetição dos passos 1-7 para uma série crescente de Di.

As amostras dos rios Solimões e Amazonas apresentaram alta quantidade de feldspato ressaltada pelo alto sinal IR das alíquotas, não sendo possível sua total eliminação nas etapas de preparação. Portanto, para essas amostras foi usado o protocolo SAR modificado para medir o sinal LOE em presença de feldspato (Wallinga et al., 2002). Isto envolveu a adição de estimulação por IR antes de cada medida LOE com estímulo por luz azul. Deste modo, foi possível eliminar o sinal do feldspato e obter sinal LOE dominado pelo quartzo. O protocolo modificado utilizado para essas amostras foi:

\section{Dose Di;}

2. Pré-aquecimento a $200^{\circ} \mathrm{C}$ por $10 \mathrm{~s}$;

3. Estimulação com IR a $60^{\circ} \mathrm{C}$ por $300 \mathrm{~s}$;

4. Estimulação com LEDs azuis a $125^{\circ} \mathrm{C}$ por $40 \mathrm{~s}$;

5. Dose Dt;

6. Aquecimento a $200^{\circ} \mathrm{C}$;

7. Estimulação com IR a $60^{\circ} \mathrm{C}$ por $300 \mathrm{~s}$;

8. Estimulação com LEDs azuis a $125^{\circ} \mathrm{C}$ por $40 \mathrm{~s}$;

9. Iluminação com LEDs azuis (90\%) a $0^{\circ} \mathrm{C}$ por 40 s;

10. Repetição dos passos 1-9 para uma série de Di (D1<D2<D3<D4; D5=0; $\mathrm{D} 6=\mathrm{D} 1=\mathrm{D} 7)$. 
Os critérios para aceitação ou rejeição de alíquotas envolveram a consideração do teste de recycling em até $10 \%$ e do valor do sinal residual menor que $20 \%$ do sinal natural.

A estimativa de dose equivalente foi realizada a partir dos modelos de idade Central Age Model (CAM) (Galbraith \& Laslett, 1993, Galbraith et al., 1999, Galbraith et al., 2005) e Minimum Age Model (MAM) (Galbraith et al., 1999 e Thomsen et al., 2003).

As medidas de taxa de dose de radiação foram realizadas por espectrometria gama em sistema com detector de germânio de alta pureza (HPGe, eficiência relativa de 55\%) em blindagem ultralow background do Laboratório de Espectrometria Gama e Luminescência do Instituto de Geociências da USP. Estas medidas envolveram os seguintes procedimentos:

1- Secagem e pesagem da amostra para estimativa do teor de umidade;

2- Embalagem em recipiente plástico vedado e armazenamento por 28 dias, com a finalidade de eliminar o desequilíbrio causado pelo escape de radônio;

3- Medição da radiação gama natural por 12h;

4- Determinação da radiação de fundo (background) em recipientes plásticos vazios;

A contribuição da radiação cósmica para a taxa de dose de radiação foi calculada de acordo com Prescott \& Stephan (1982), usando-se informações sobre latitude, longitude, altitude, profundidade de coleta e densidade de cada amostra. Foi calculado o erro total da dose anual de acordo com a lei gaussiana de propagação de erro.

Os radionuclídeos naturais analisados foram ${ }^{40} \mathrm{~K},{ }^{208} \mathrm{TI},{ }^{212} \mathrm{~Pb},{ }^{228} \mathrm{Ac}$ (série do ${ }^{232} \mathrm{Th}$ ) e ${ }^{214} \mathrm{Bi},{ }^{214} \mathrm{~Pb},{ }^{226} \mathrm{Ra}$ (série do ${ }^{238} \mathrm{U}$ ). A partir da atividade e de suas respectivas incertezas, calculou-se as taxas de dose das radiações beta e gama, que somadas à taxa de dose da radiação cósmica formam a taxa de dose total.

\subsection{Datações ${ }^{14} \mathrm{C}$}

Foram coletadas 6 amostras de fragmentos de madeira para datação AMS ${ }^{14} \mathrm{C}$ no Laboratório Poznań Radiocarbon (Polônia). As amostras datadas foram calibradas no programa CALIB 6.0 (Stuiver \& Reimer, 1993) com intervalos de confiança de 95\% 
(2б). Foi utilizado o protocolo SHCal (McComarc et al., 2004) para correção da variação isotópica atmosférica do hemisfério sul.

\section{RESULTADOS}

\subsection{Geomorfologia}

\section{$\underline{\text { Altimetria das áreas emersas }}$}

A Figura 11 apresenta o Modelo Digital de Elevação (MDE), elaborado a partir de imagem SRTM (Shuttle Radar Topography Mission), para a região da confluência dos rios Negro e Solimões. Este MDE possibilitou diferenciar duas unidades com relevos contrastantes. A unidade A (Figura 12) que apresenta altitudes maiores, variando de 50 a $100 \mathrm{~m}$ (regiões em vermelho do mapa), é caracterizada por dissecações marcantes que formam grandes igarapés. Esta unidade corresponde ao substrato da drenagem atual da região.

A unidade B (Figura 12) apresenta altitudes máximas entre 10 e $30 \mathrm{~m}$ (regiões em verde no mapa da Figura 11). Esta unidade é caracterizada por áreas inundáveis e barras fluviais. A ausência de dissecações indica que esta unidade é dominada por zonas deposicionais. 


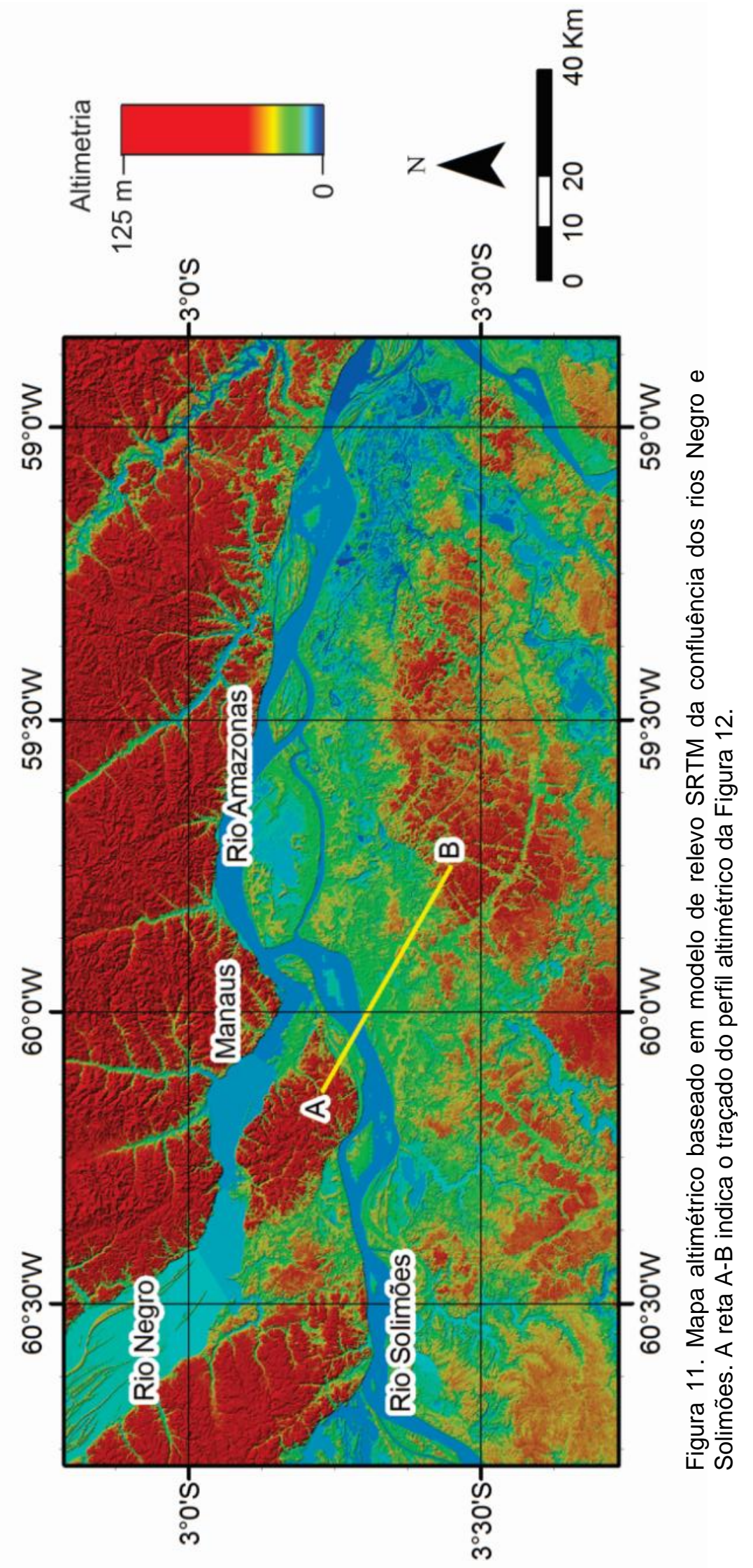




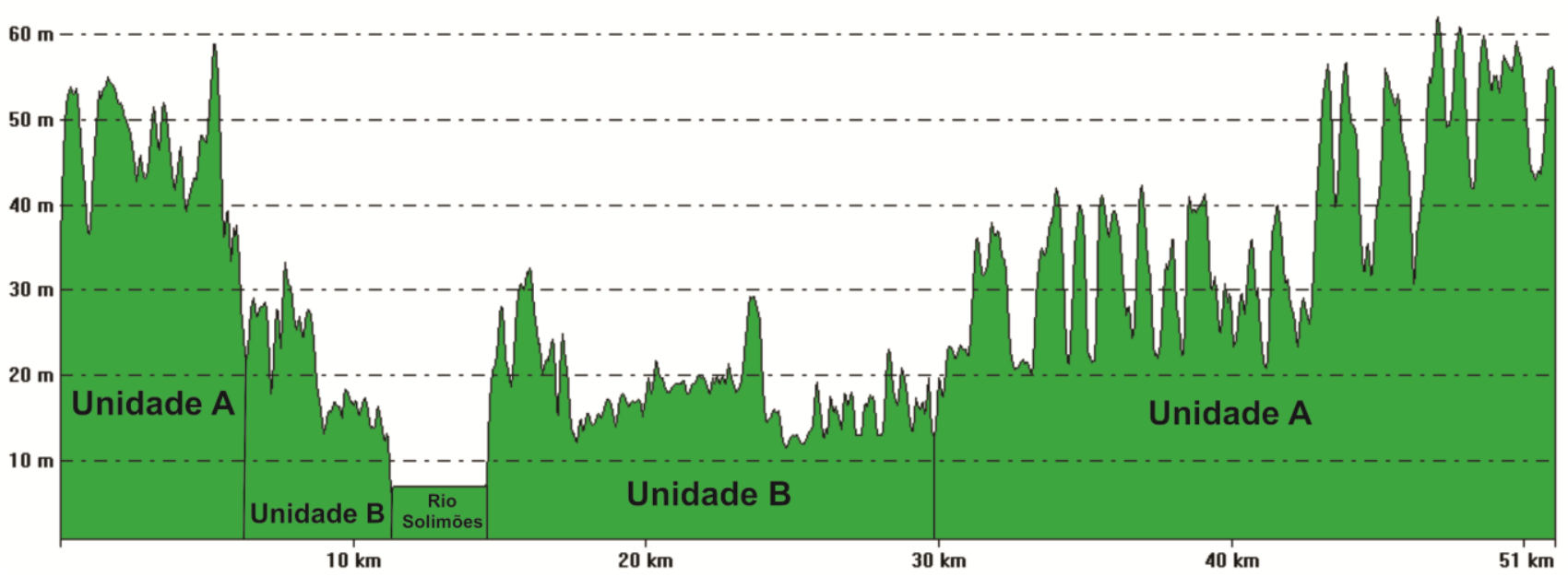

Figura 12. Perfil altimétrico transversal (NW-SE) à calha do rio Solimões (linha $A-B$ no mapa da Figura 11). Notar as diferenças de altitude entre as unidades A e B.

A comparação dos mapas SRTM (Figura 11) e geológico (Figura 2) permite correlacionar a unidade $A$ com zonas dominadas pela Formação Alter do Chão. E a unidade $B$ corresponderia aos depósitos aluvionares. Essa unidade está presente principalmente nos rios Solimões e Amazonas.

\section{Morfologia das zonas deposicionais (unidade B)}

Na região da confluência dos rios Negro e Solimões, é possível diferenciar duas unidades dentro das zonas deposicionais: unidade B1 que corresponde às áreas inundáveis e a unidade B2, representada pelas barras fluviais (Figura 13).

A unidade B1 é caracterizada por relevo plano e lagos. Esta unidade está localizada na margem direita do rio Solimões, que corresponde à área de deposição de sedimentos desse rio na área de estudo.

A unidade B2 é representada pelas barras fluviais formadas pela sedimentação do canal. Foram destacadas 5 barras principais no rio Solimões na área estudada (Figura 14), as quais apresentam cordões que indicam a sua direção de crescimento. 


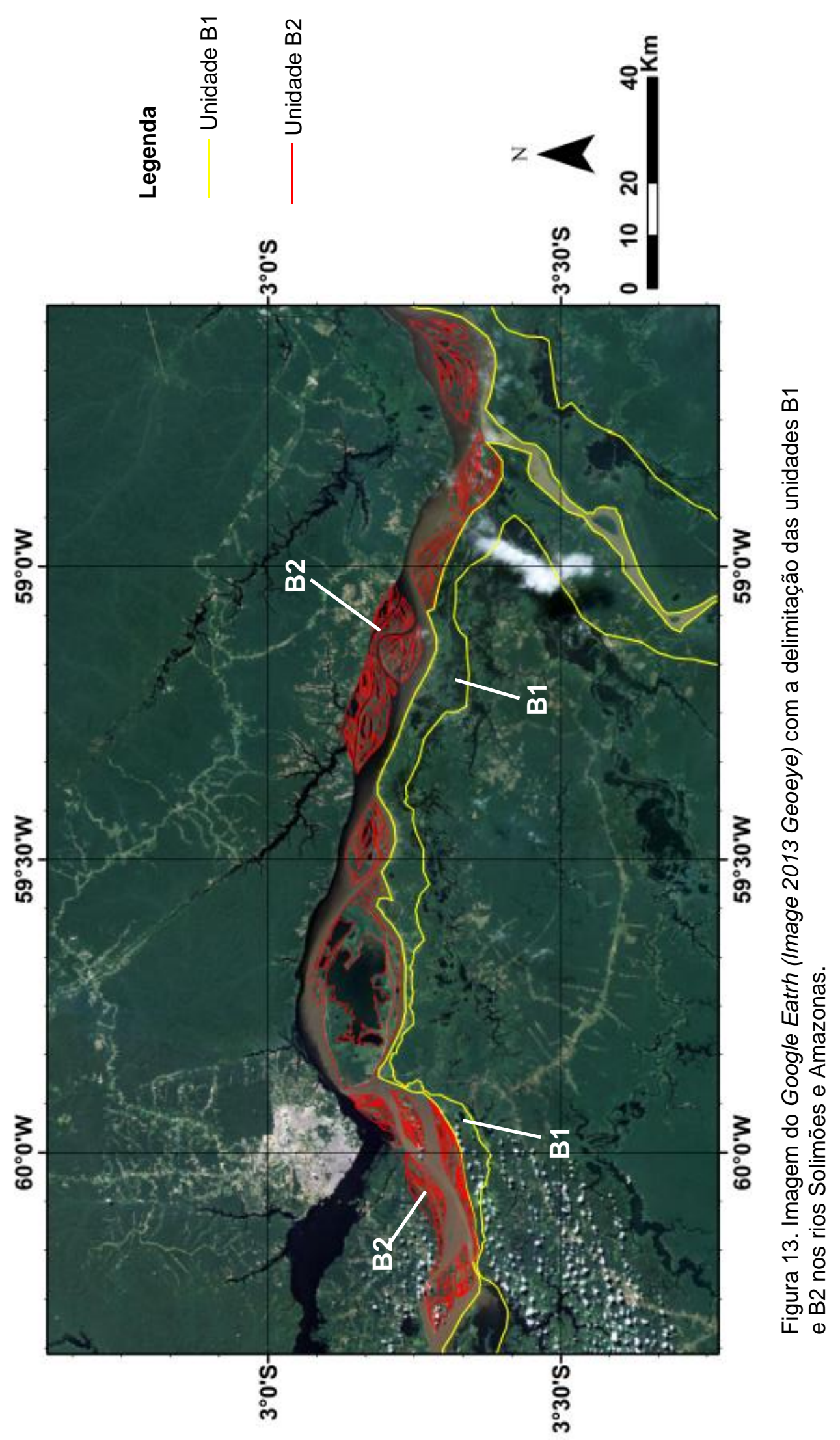




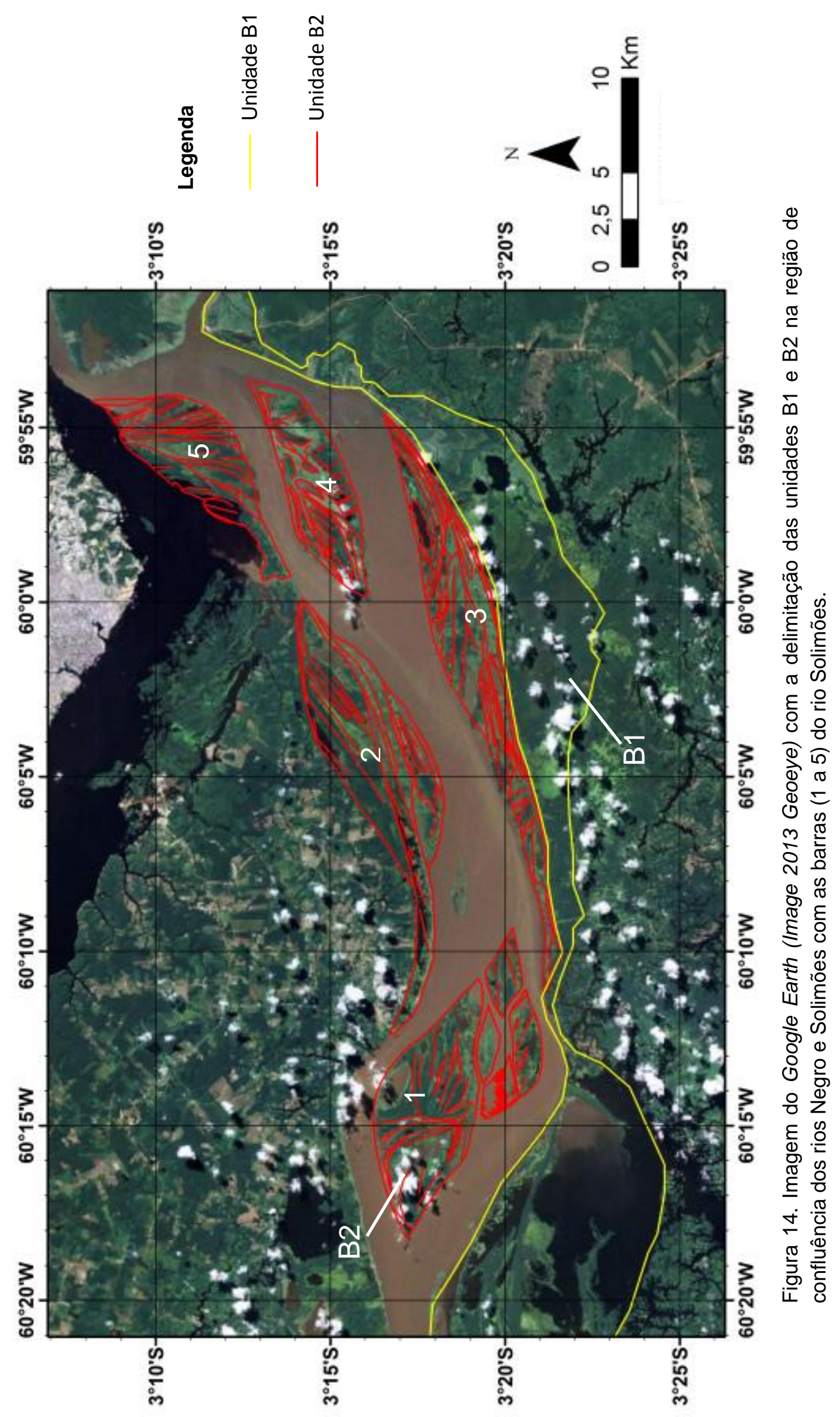


A barra 1 (Figura 15) apresenta dois padrões de cordões de crescimento. Um antecessor, na sua porção oeste, com direção de crescimento de W para E, e outro, posterior, na parte leste da barra, com direção de crescimento de $\mathrm{N}$ para $\mathrm{S}$. Na região mais a sul da barra, é possível observar deposição mais recente com formação de dunas subaquosas. Essa geometria interna curvilínea remete a um padrão meandrante do rio Solimões, predecessor do padrão anastomosado atual.

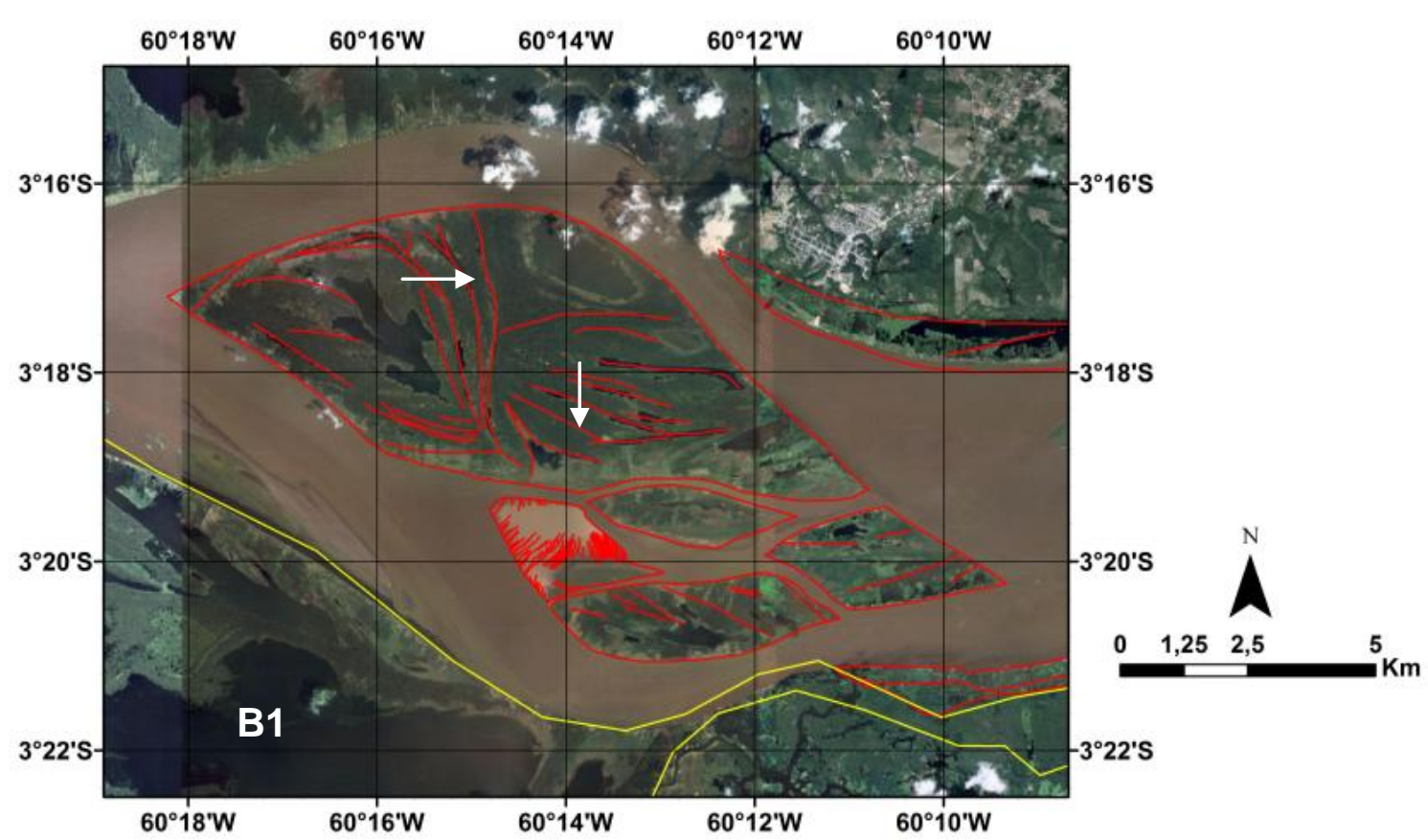

Figura 15. Geometria interna da barra 1 com o sentido de crescimento (setas brancas) dos cordões (em vermelho).

A barra 2 está localizada na margem esquerda do rio Solimões e apresenta duas gerações de cordões (Figura 16). A geração mais antiga está em contato com o substrato e possui crescimento de NW para SE. A geração mais jovem acompanha a margem do rio e cresce para SSE.

A barra 3 está localizada na margem direita do rio Solimões e apresenta em sua porção nordeste crescimento dos cordões para SSE. Na parte central da barra, os cordões crescem para SSW (Figura 16). Na região mais a oeste da barra, o crescimento dos cordões se altera para SW, tendo sido formado posteriormente à porção nordeste dessa barra. A direção de crescimento desses cordões indica que o canal principal do rio Solimões corria na área inundável adjacente, delimitada pela linha amarela na Figura 16.

A barra 4 apresenta em sua parte sudoeste crescimento de cordões em direção a SSE e NNW, sendo que a borda sul desta porção, formada posteriormente, tem crescimento para NE (Figura 16). Adjacente à borda sul dessa barra, ocorre deposição 
recente de sedimentos, com formação de bancos de areia que ficam expostos nos períodos de seca.

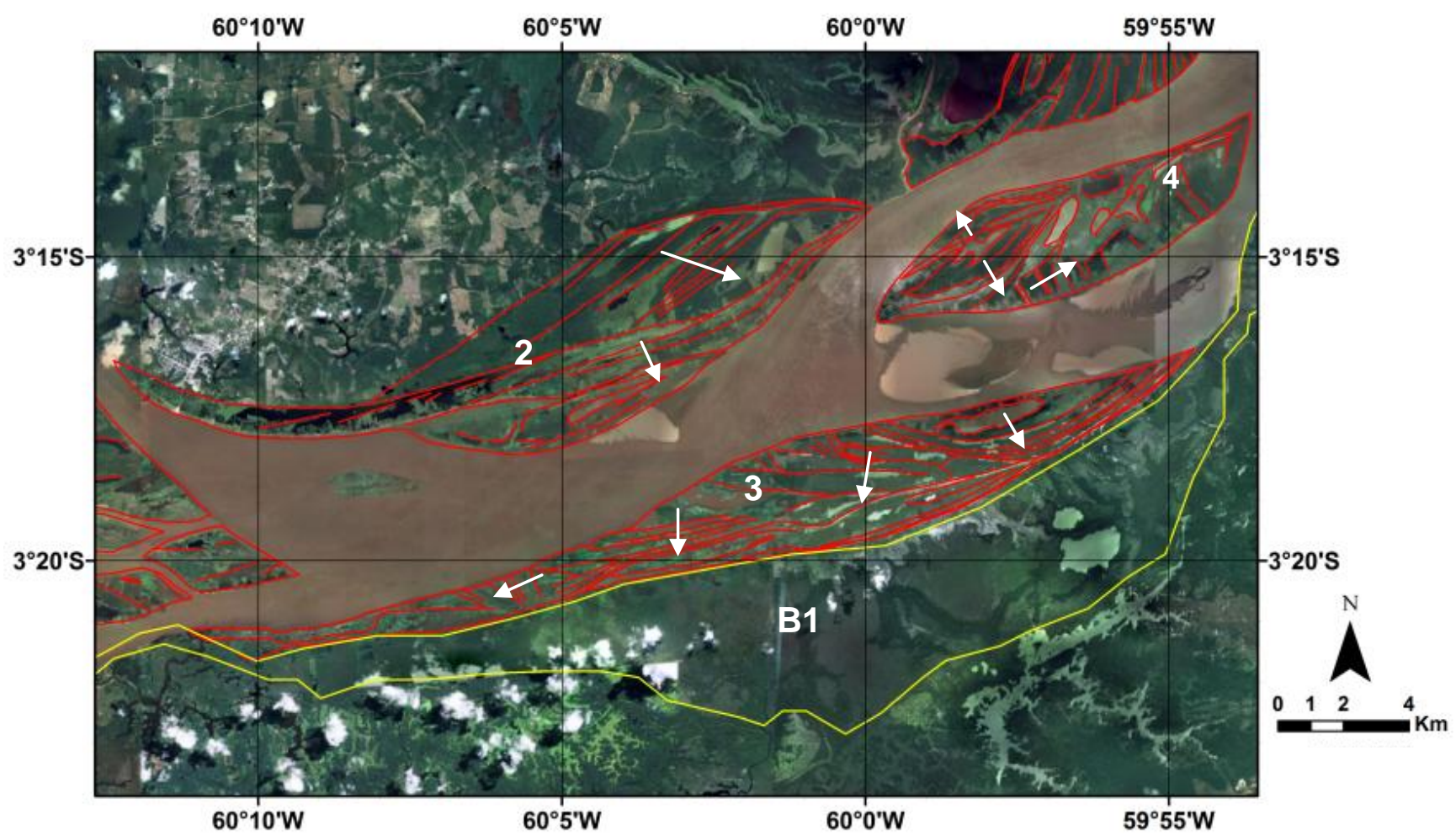

Figura 16. Geometria interna das barras 2, 3 e 4 com o sentido de crescimento (setas brancas) dos cordões (em vermelho).

A barra 5 bloqueia o rio Negro na sua junção com o rio Solimões (Figura 17). A parte nordeste desta barra apresenta cordões com direção de crescimento para NE e SW conforme indicado pelas setas da Figura 17. Já região central da barra apresenta cordões com crescimento para E e para W. Essa barra exerce papel importante nos fluxos de sedimentos dos rios Negro e Solimões, pois dificulta a entrada de sedimentos do rio Negro no rio Amazonas. 


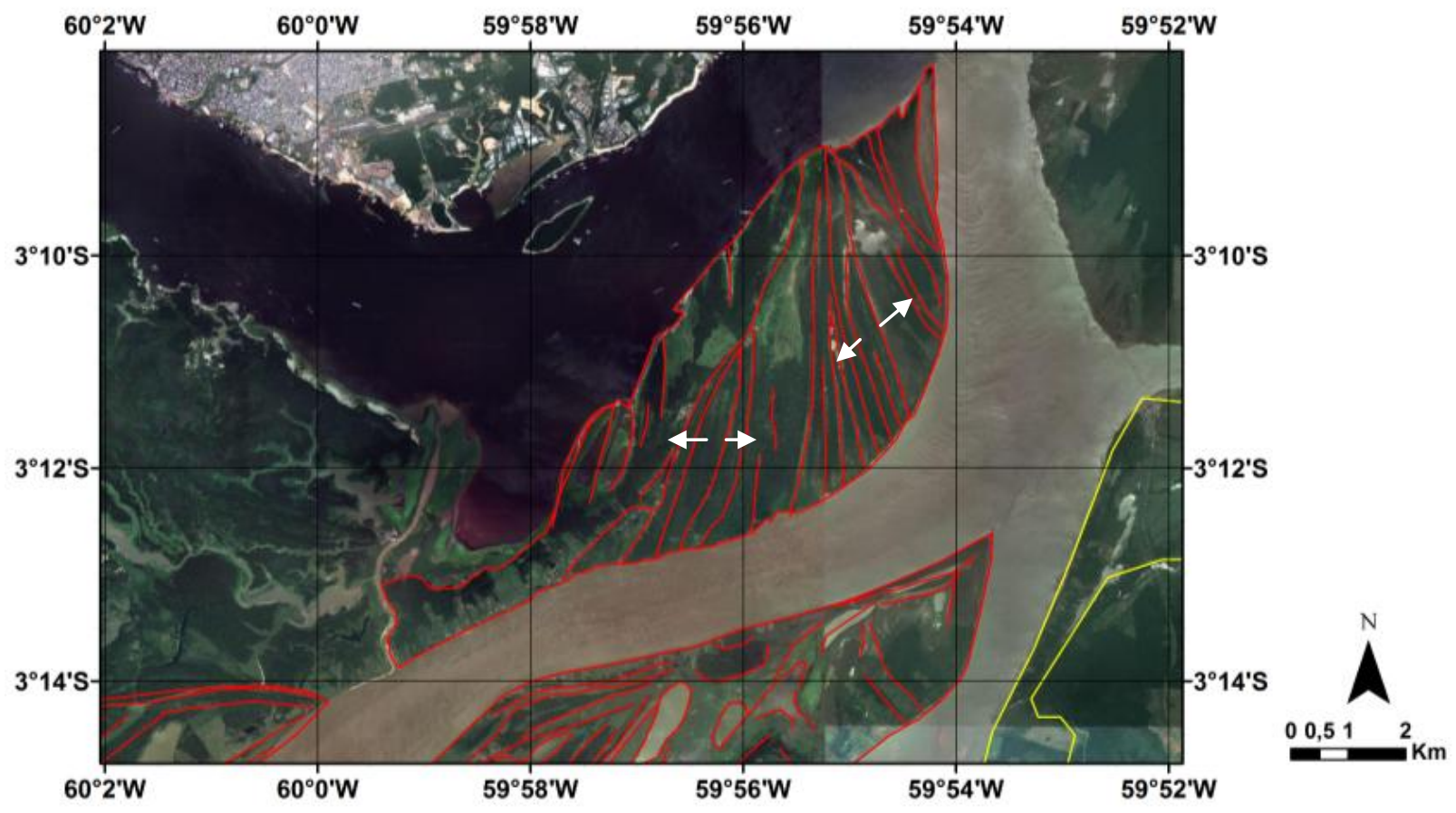

Figura 17. Geometria interna da barra 5 com o sentido de crescimento (setas brancas) dos cordões (em vermelho).

O rio Amazonas apresenta barras em ambas as margens e na parte central do canal. O setor ao longo do Paraná da Eva (6 na Figura 18) demonstra um complexo de barras com crescimento para SE e NE. As duas barras situadas na parte central do mapa apresentam cordões com direção de crescimento para NE (barra 7) e SSW (barra 8). A barra 9, localizada a jusante do encontro dos rios Madeira e Amazonas, exibe cordões de crescimento para SSE (Figura 18). 


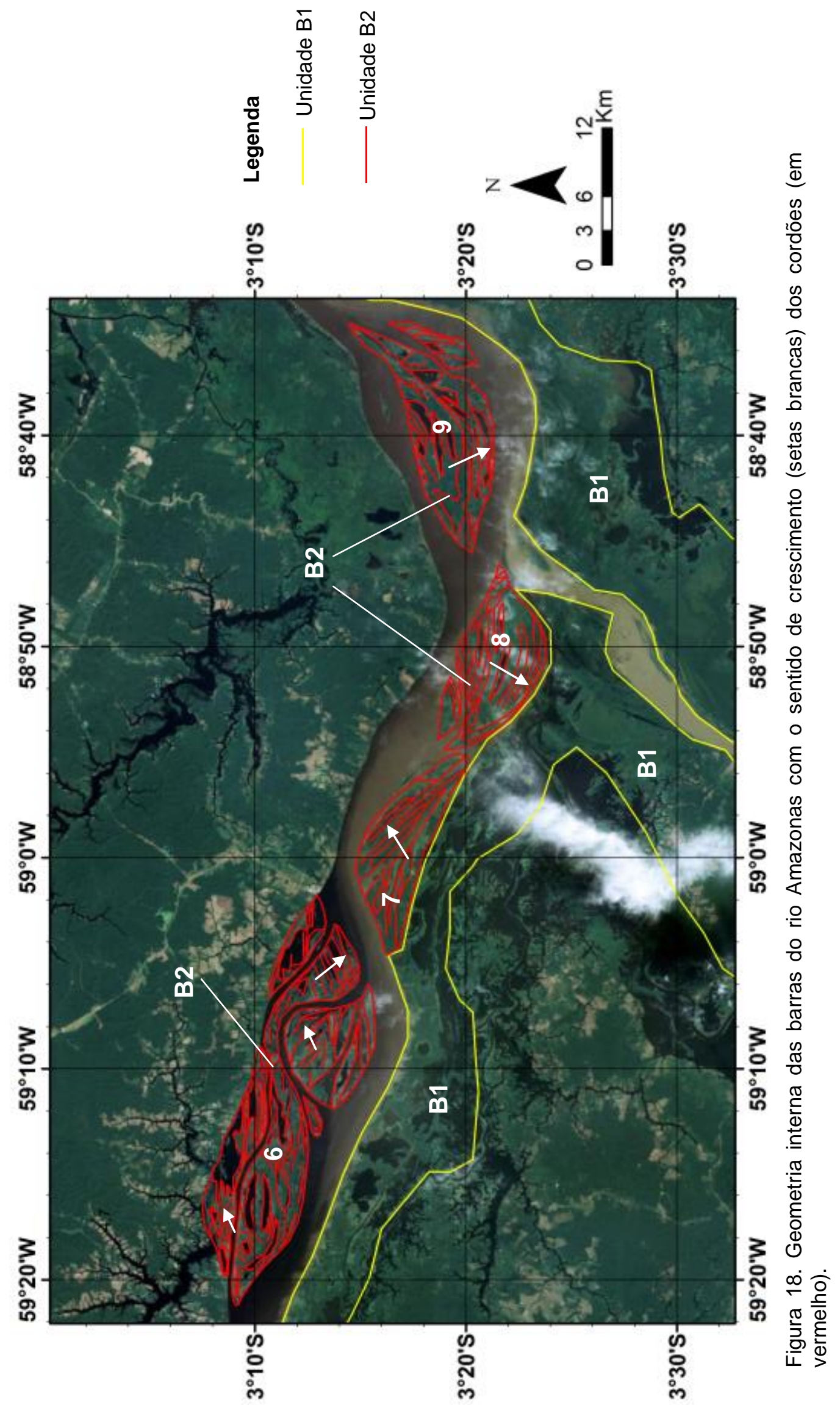




\section{Perfis de batimetria}

A elaboração dos perfis batimétricos transversais ao canal permitiu identificar a morfologia das zonas submersas dos rios estudados. Foram realizados 9 perfis durante o período de seca (novembro de 2011), sendo os perfis A-A', B-B' e C-C' do rio Negro, D-D', E-E', F-F' do rio Solimões e G-G', H-H' e I-I' do rio Amazonas, cuja localização é apresentada na Figura 19.

O perfil A-A' do rio Negro (Figura 20) demonstra que a profundidade aumenta da margem direita para a margem esquerda, com três depressões, cujas profundidades alcançam $15 \mathrm{~m}, 18 \mathrm{~m}$ e $35 \mathrm{~m}$ em trecho de $7 \mathrm{~km}$ de largura.

No perfil B-B', o canal do rio Negro (Figura 21) possui cerca de 1,8 km de largura, sendo possível observar o talvegue de $85 \mathrm{~m}$ de profundidade mais próximo à margem esquerda do canal. Este talvegue ocorre em trecho de estreitamento do canal do rio Negro, onde sua largura passa de 6,7 km para 2,0 km. Neste trecho, o canal apresenta mais que o dobro da profundidade no setor correspondente do perfil A-A'.

O perfil C-C' do rio Negro (Figura 22), a jusante dos perfis anteriores, também apresenta assimetria. Porém, a zona mais profunda $(24 \mathrm{~m})$ ocorre próximo à margem direita. O perfil é caracterizado por duas depressões, com profundidades de $24 \mathrm{~m}$ e 16 $\mathrm{m}$ em um trecho de 5,6 km de largura.

O perfil D'-D do rio Solimões (Figura 23) é caracterizado por depressão única próxima à margem esquerda, com profundidade de aproximadamente $44 \mathrm{~m}$.

No perfil E'-E do rio Solimões (Figura 24), a profundidade aumenta gradualmente da margem esquerda em direção à margem direita até atingir aproximadamente $25 \mathrm{~m}$.

O perfil F'-F da foz do rio Solimões (Figura 25) apresenta aumento gradual da profundidade da margem esquerda para a direita, chegando à profundidade máxima de $27 \mathrm{~m}$.

O perfil G-G' do rio Amazonas (Figura 26), localizado no encontro das águas dos rios Solimões e Negro, indica canal profundo de até $55 \mathrm{~m}$ de profundidade na sua parte central.

O perfil H-H' do rio Amazonas (Figura 27), localizado na entrada (montante) do Paraná da Eva, apresenta depressão principal com cerca de $50 \mathrm{~m}$ de profundidade a $500 \mathrm{~m}$ de distância da margem direita. Nota-se elevação para $10 \mathrm{~m}$ de profundidade, seguida de suave depressão com $18 \mathrm{~m}$ de profundidade próxima à margem esquerda.

No perfil I-I' do rio Amazonas (Figura 28), a jusante do Paraná da Eva, a calha principal apresenta cerca de $50 \mathrm{~m}$ de profundidade e ocorre próximo à margem direita. A diminuição da profundidade é gradual até a margem esquerda do rio. 


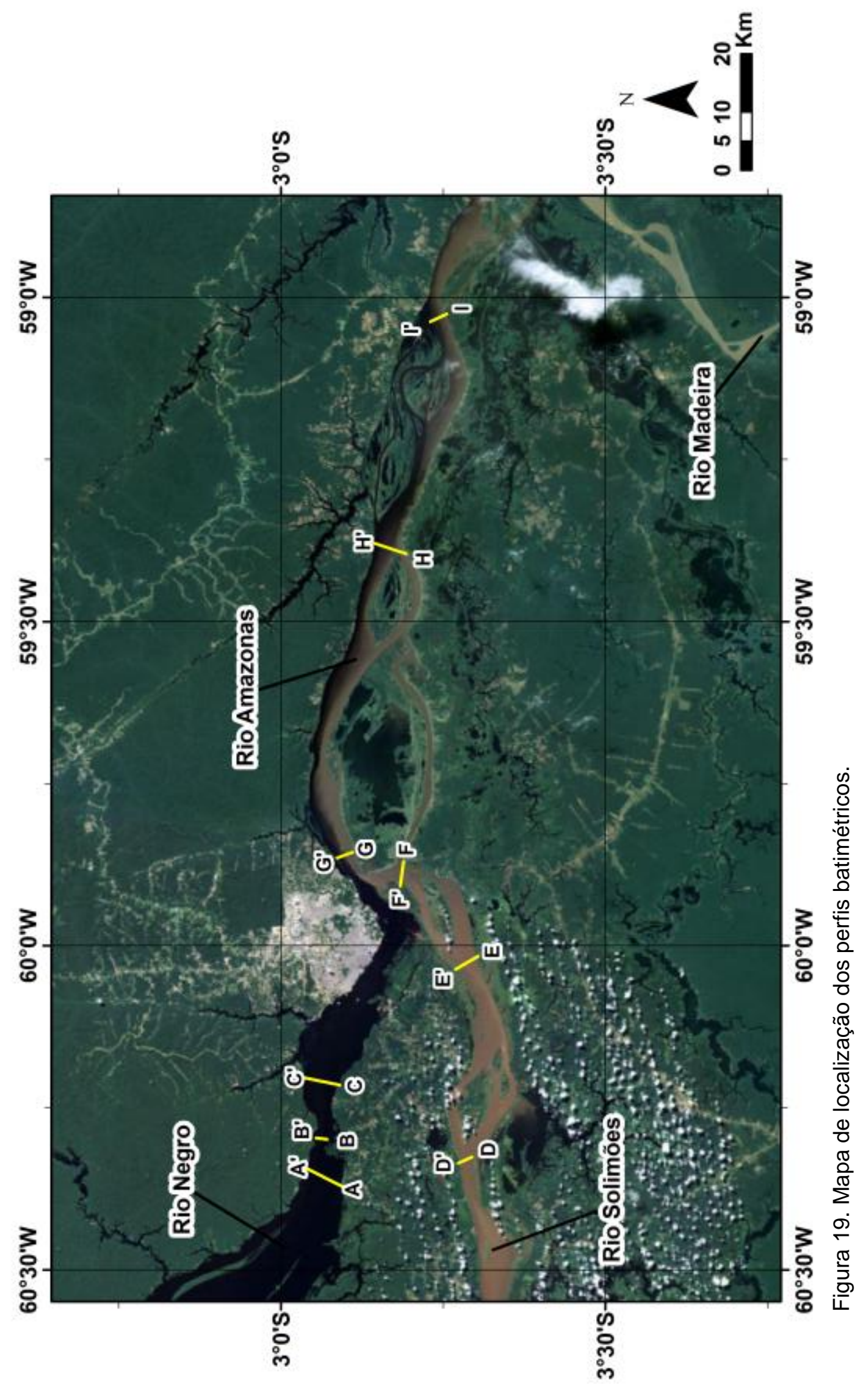




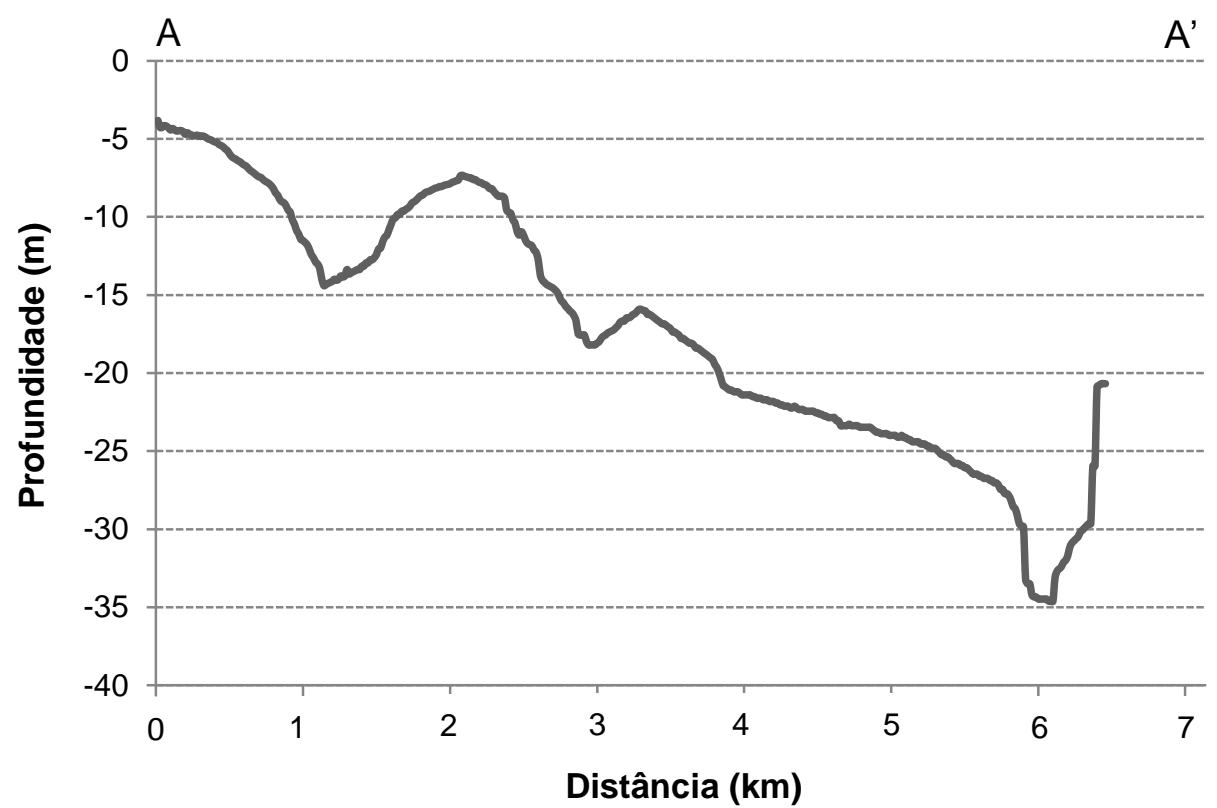

Figura 20. Perfil batimétrico A-A' do rio Negro (vide localização na Figura 19).

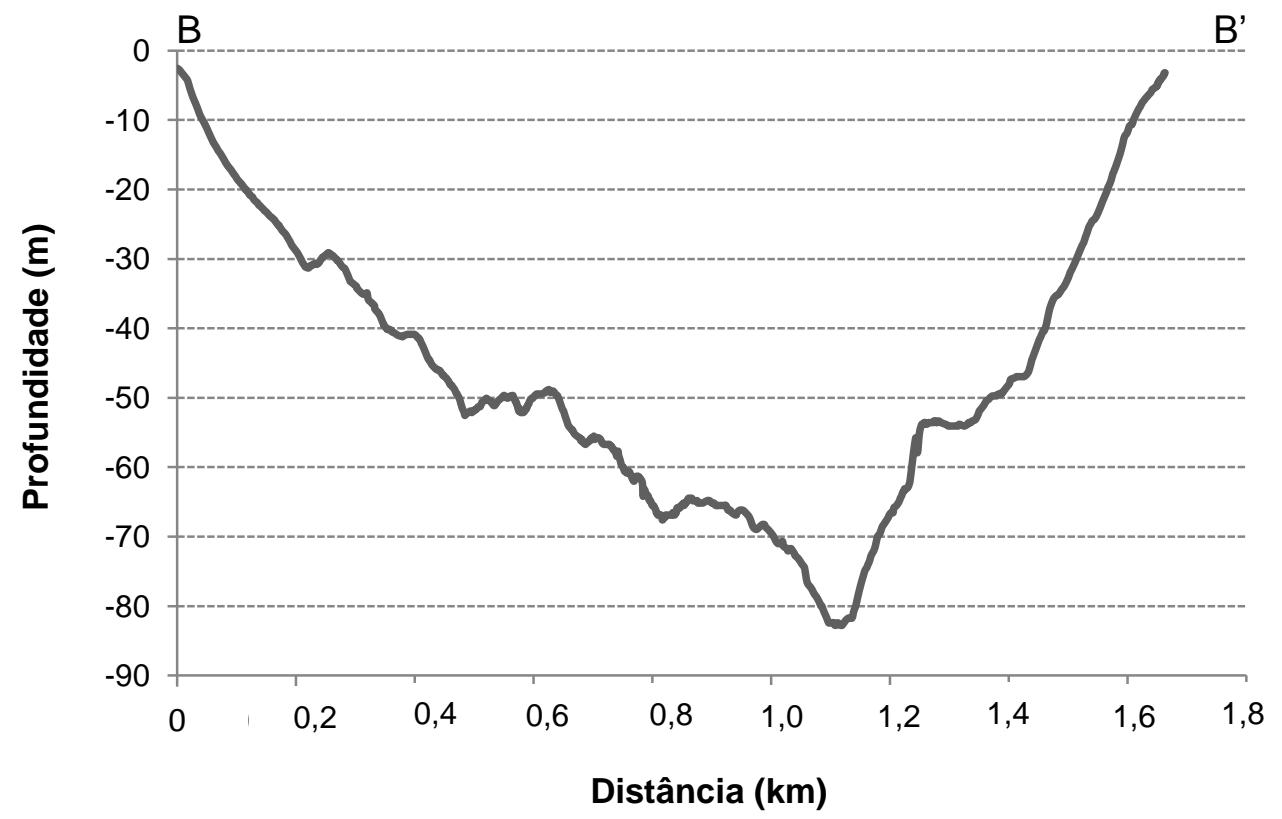

Figura 21. Perfil batimétrico B-B' do rio Negro (vide localização na Figura 19). 


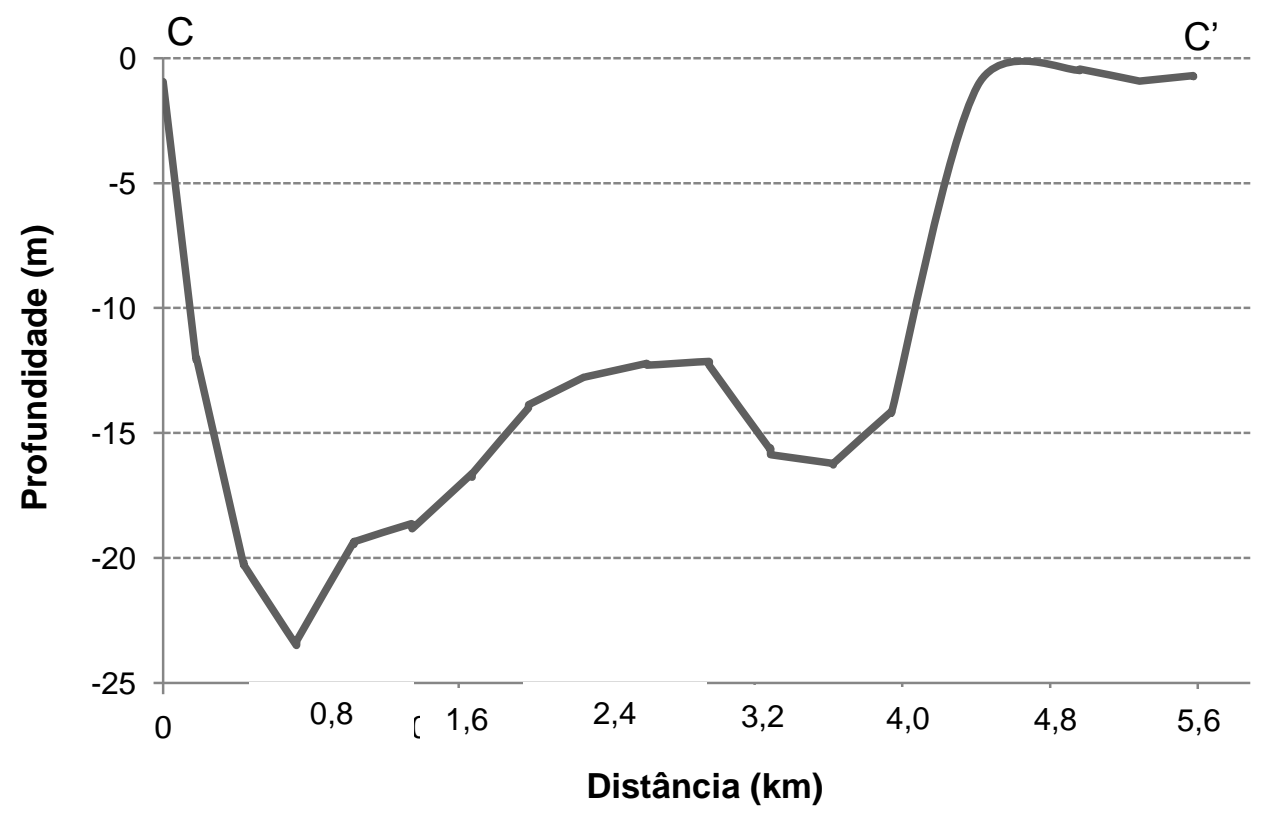

Figura 22. Perfil batimétrico C-C' do rio Negro (vide localização na Figura 19).

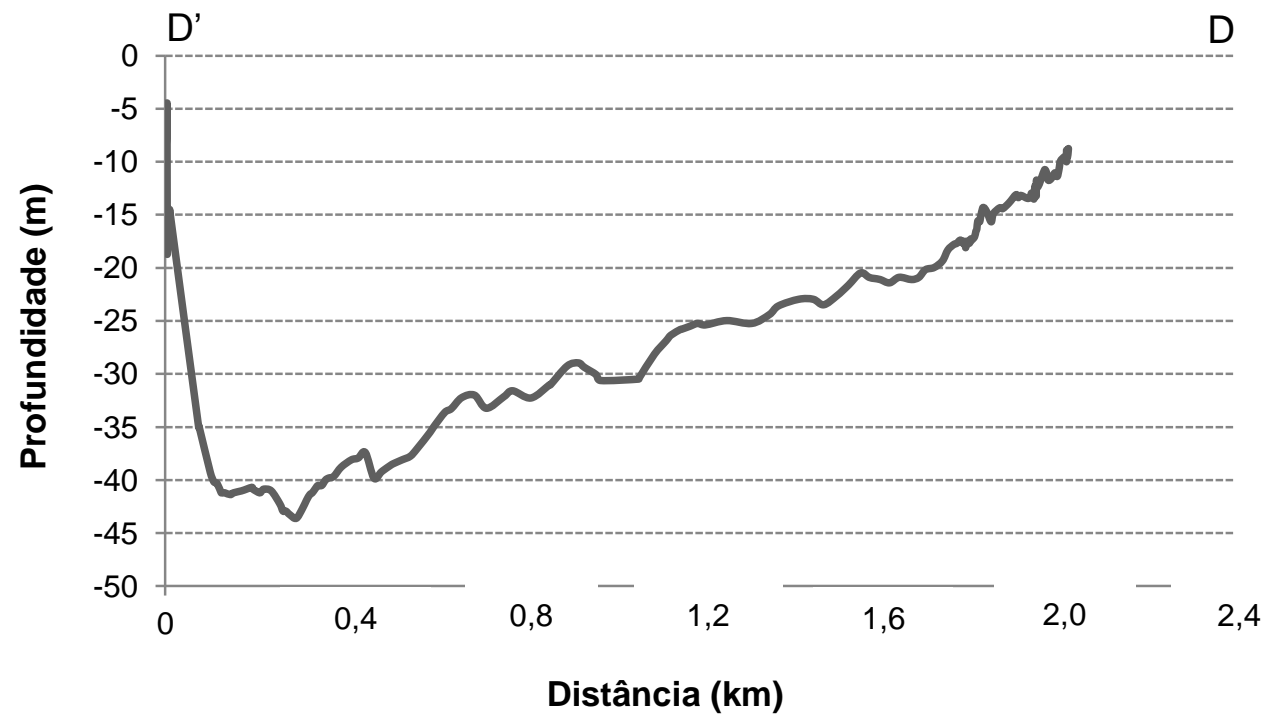

Figura 23. Perfil batimétrico D'-D do rio Solimões (vide localização na Figura 19). 


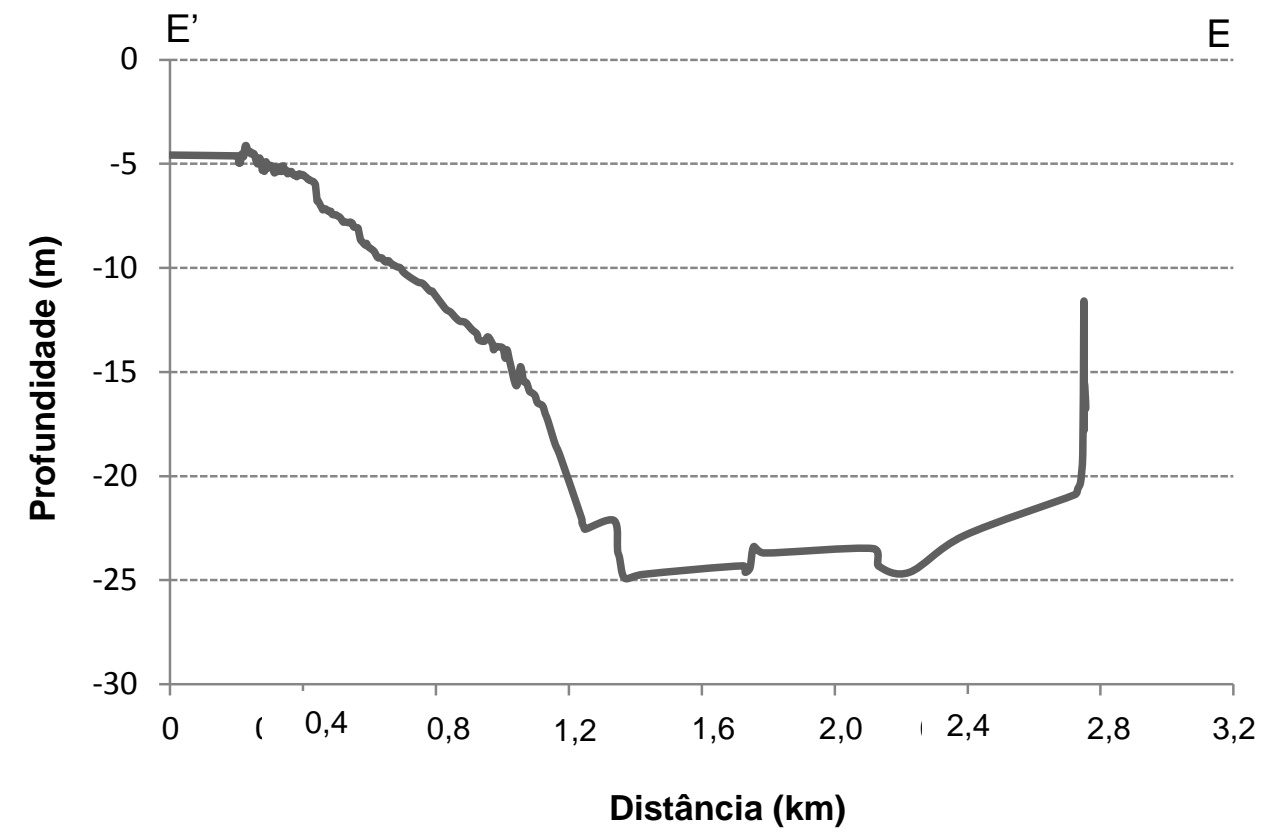

Figura 24. Perfil batimétrico E'-E do rio Solimões (vide localização na Figura 19).

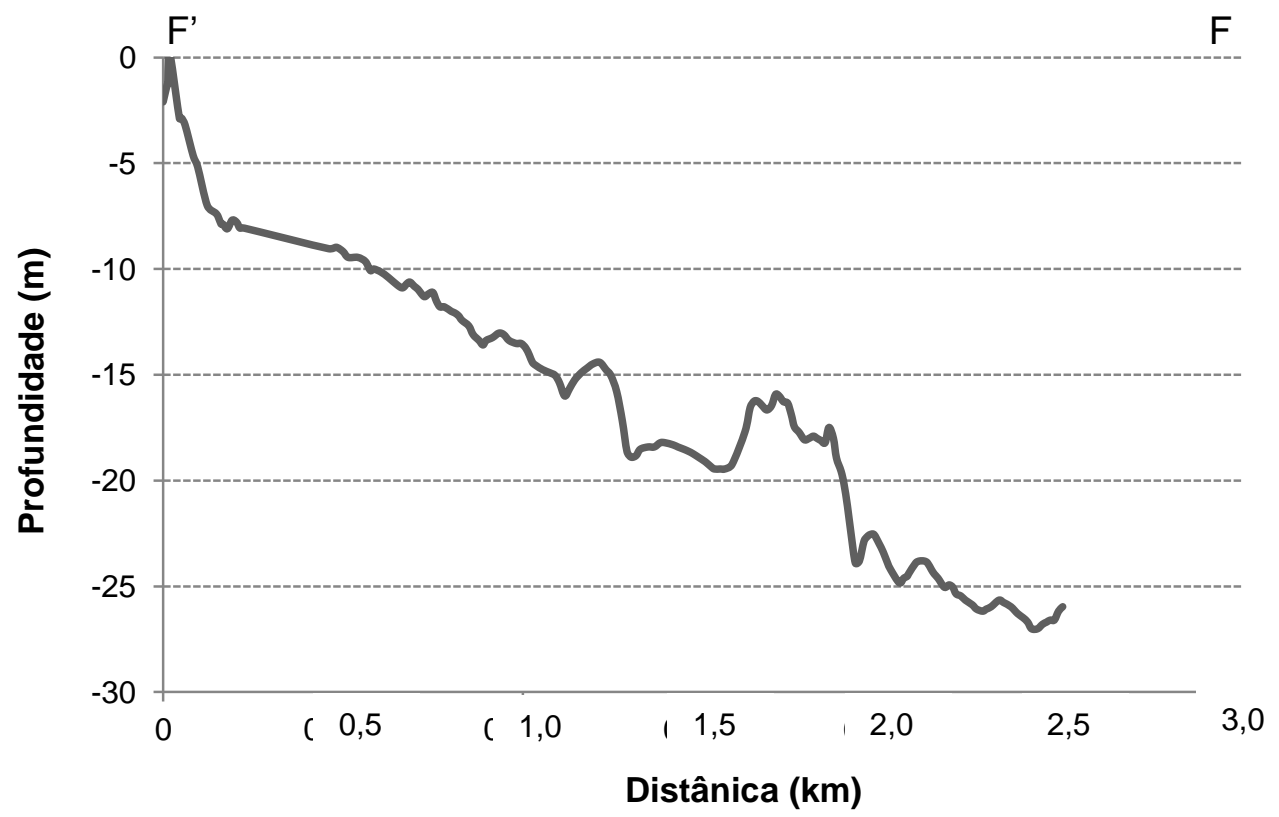

Figura 25. Perfil batimétrico F'-F do rio Solimões (vide localização na Figura 19). 


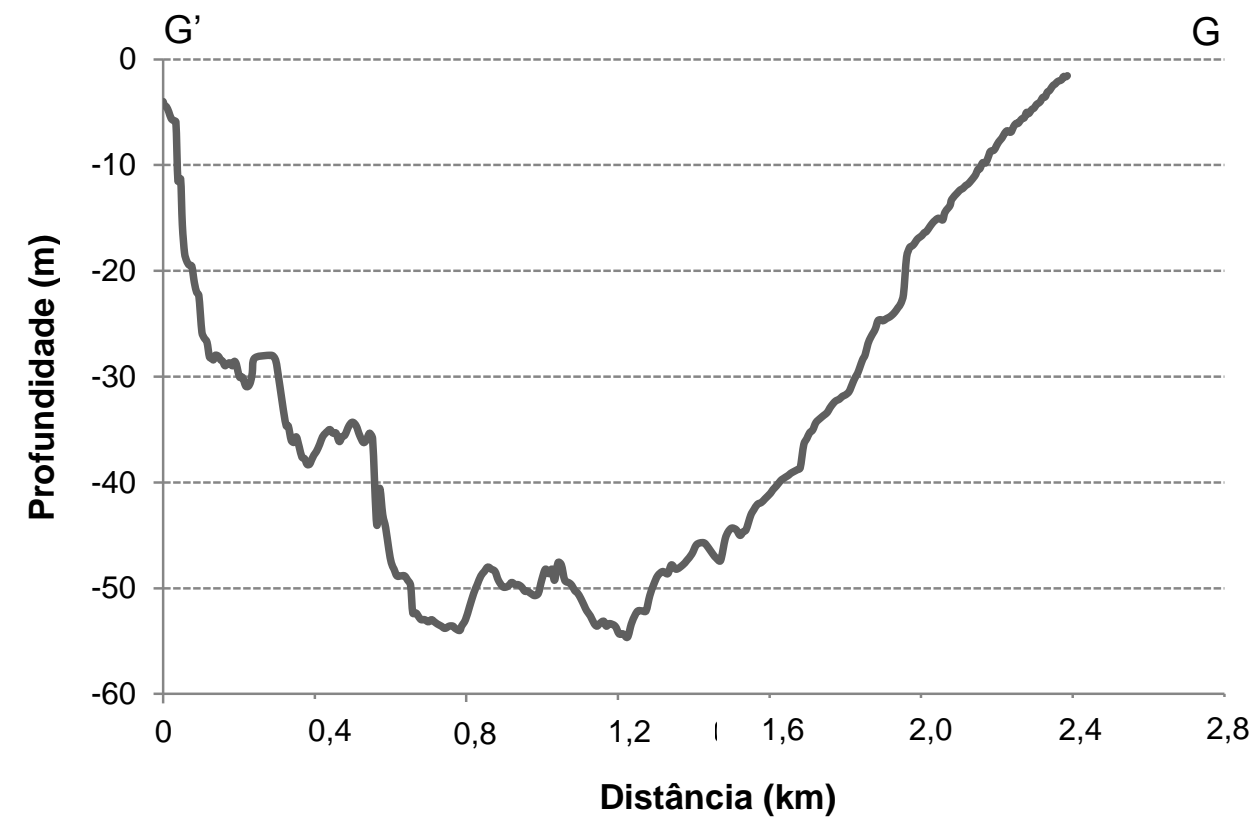

Figura 26. Perfil batimétrico G'-G do rio Amazonas (vide localização na Figura 19).

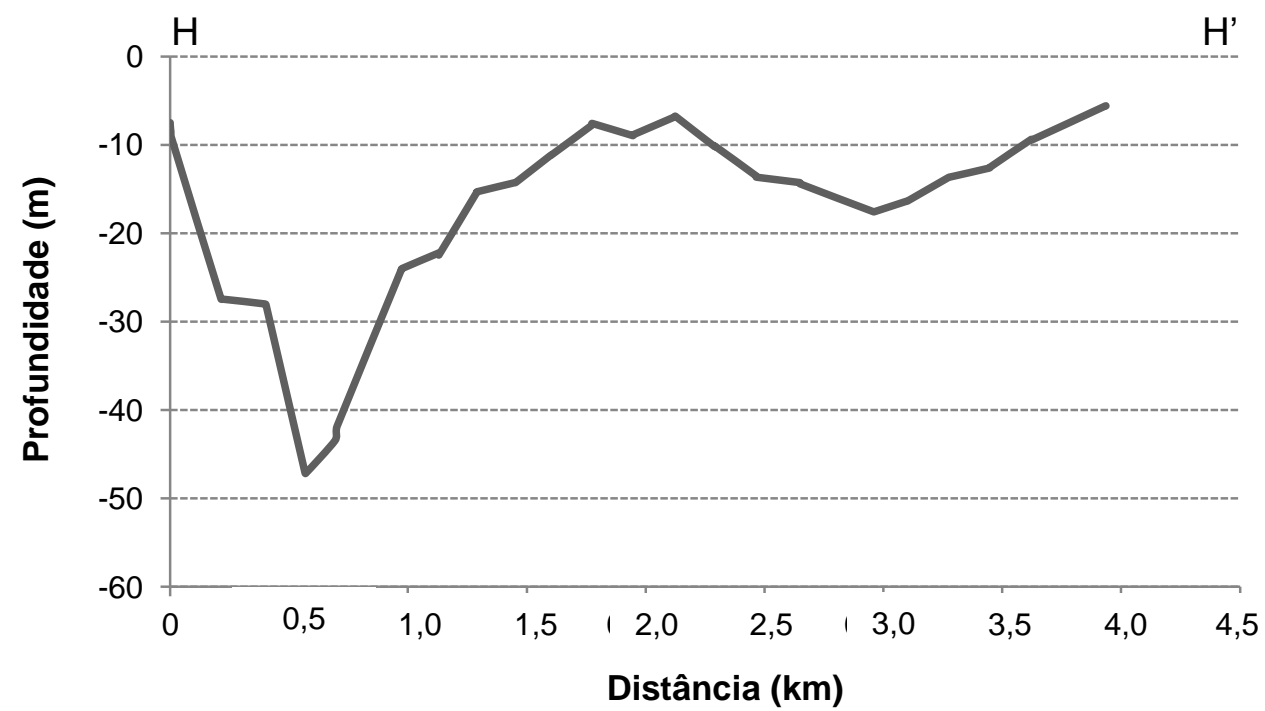

Figura 27. Perfil batimétrico H'-H do rio Amazonas (vide localização na Figura 19). 


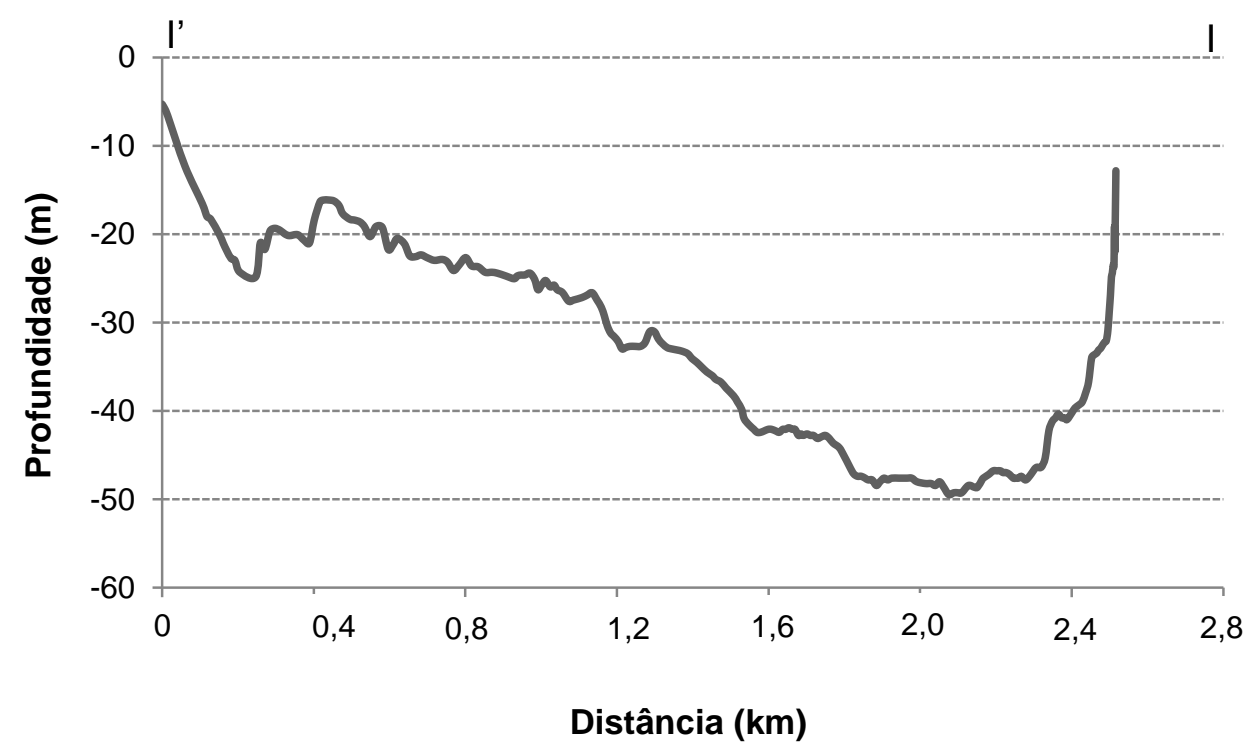

Figura 28. Perfil batimétrico l'-I do rio Amazonas (vide localização na Figura 19).

\subsection{Análise de fácies}

São apresentadas três seções colunares representativas das barras dos rios Negro (NSM-07), Solimões (NSM-16) e Amazonas (NSM-32). A Figura 29 apresenta a localização destas seções.

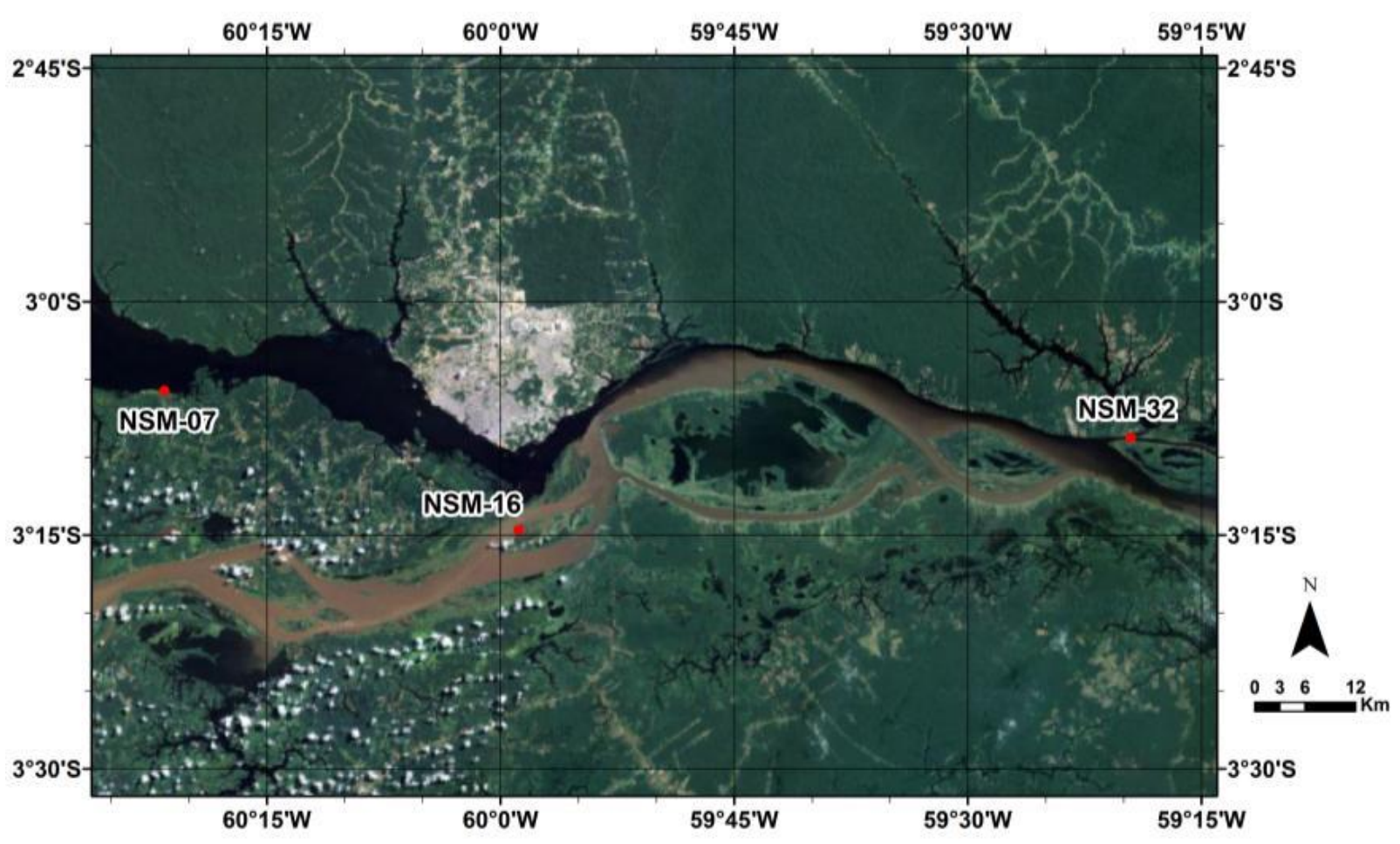

Figura 29. Mapa com a localização dos pontos onde foram descritas as seções colunares. 
O rio Negro apresenta fácies com características contrastantes em relação aos rios Solimões e Amazonas. As praias do rio Negro (Figura 30) são caracterizadas por intercalações centimétricas de areia média e grossa, ambas bem selecionadas (Quadro I e Figura 31). Níveis de seixos ocorrem de modo localizado.

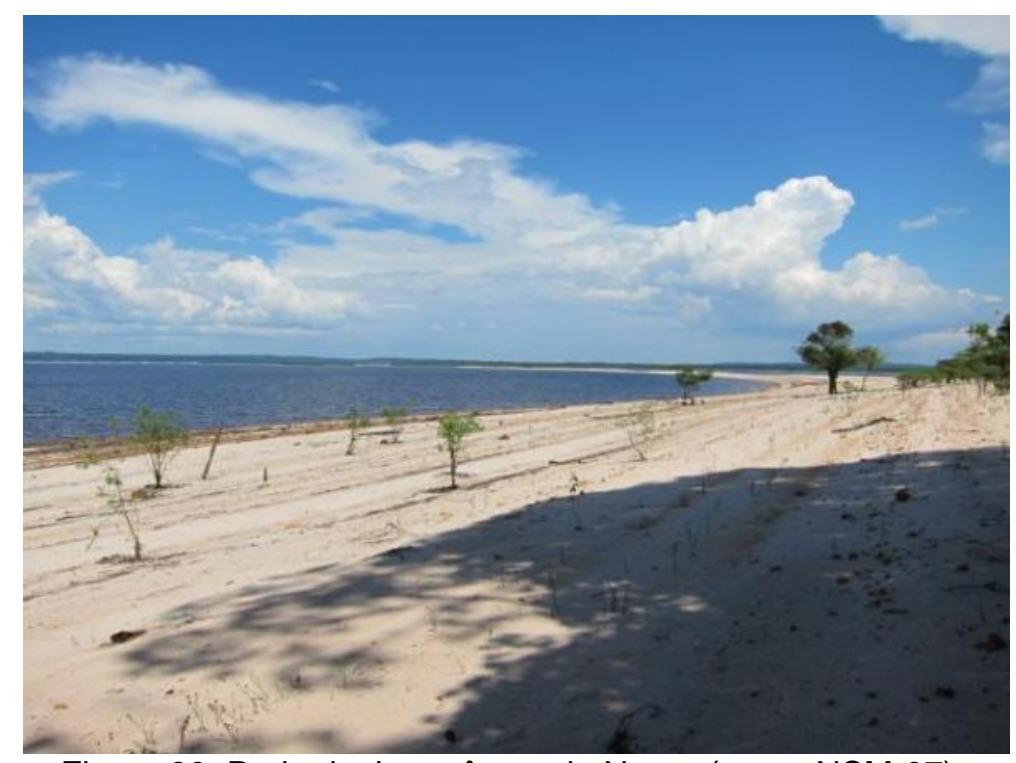

Figura 30. Praia do Japonês no rio Negro (ponto NSM-07).

\begin{tabular}{|c|c|c|}
\hline Fácies sedimentares & Descrição & Sigla \\
\hline $\begin{array}{l}\text { Areia fina a média } \\
\text { maciça }\end{array}$ & Areia fina a média mal selecionada maciça. & AFMm \\
\hline $\begin{array}{l}\text { Areia média com } \\
\text { cascalho maciça }\end{array}$ & $\begin{array}{l}\text { Areia média bem selecionada maciça com nível de } \\
\text { cascalho com coloração laranja e clastos de até } 15 \\
\mathrm{~cm} \text { de comprimento. }\end{array}$ & AMCm \\
\hline $\begin{array}{l}\text { Areia média a grossa } \\
\text { com } \\
\text { cruzada }\end{array}$ & $\begin{array}{l}\text { Areia média a grossa bem selecionada com } \\
\text { estratificação cruzada tabular em séries de } 10 \mathrm{~cm} \text { de } \\
\text { espessura. }\end{array}$ & AMGc \\
\hline $\begin{array}{lr}\text { Areia grossa } & \text { com } \\
\text { estratificação } & \text { plano- } \\
\text { paralela } & \\
\end{array}$ & $\begin{array}{l}\text { Areia grossa bem selecionada com estratificação } \\
\text { plano-paralela e seixos esparsos de até } 3 \mathrm{~cm} \text {. }\end{array}$ & AGp \\
\hline Areia grossa maciça & $\begin{array}{l}\text { Areia grossa mal selecionada com calhaus esparsos } \\
\text { de laterita de até } 20 \mathrm{~cm} \text {. }\end{array}$ & AGm \\
\hline $\begin{array}{l}\text { Areia fina a média com } \\
\text { estratificação cruzada }\end{array}$ & $\begin{array}{l}\text { Areia fina a média bem selecionada com } \\
\text { estratificação cruzada tabular em séries de } 10 \text { a } 30 \\
\mathrm{~cm} \text { de espessura. Há recobrimento de argila no } \\
\text { foreset da estratificação cruzada. A areia apresenta } \\
\text { grande quantidade de mica e minerais pesados. }\end{array}$ & AFMc \\
\hline Lama maciça & Lama maciça & $\mathrm{Lm}$ \\
\hline $\begin{array}{l}\text { Lama com laminação } \\
\text { heterolítica }\end{array}$ & $\begin{array}{l}\text { Lama com laminação heterolítica de silte e argila. Há } \\
\text { predominância de argila. }\end{array}$ & Lh \\
\hline $\begin{array}{l}\text { Areia fina com } \\
\text { estratificação cruzada }\end{array}$ & $\begin{array}{l}\text { Areia fina bem selecionada com estratificação } \\
\text { cruzada tabular em séries de } 10 \mathrm{~cm} \text { de espessura. }\end{array}$ & AFc \\
\hline
\end{tabular}

Quadro I. Fácies sedimentares descritas em afloramentos e trincheiras das margens dos rios Negro, Solimões e Amazonas. 

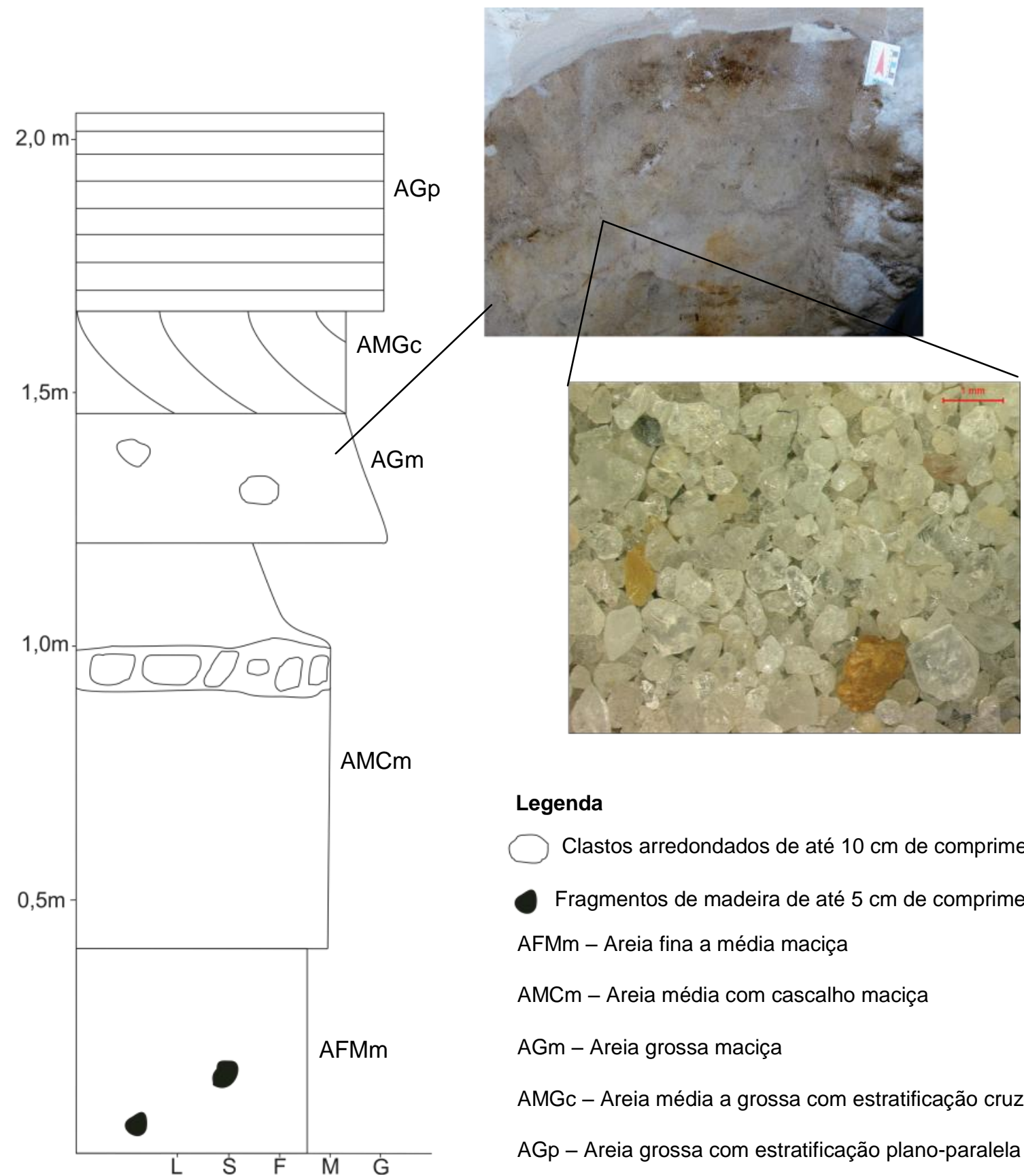

\section{Legenda}

Clastos arredondados de até $10 \mathrm{~cm}$ de comprimento

Fragmentos de madeira de até $5 \mathrm{~cm}$ de comprimento AFMm - Areia fina a média maciça

AMCm - Areia média com cascalho maciça

AGm - Areia grossa maciça

AMGc - Areia média a grossa com estratificação cruzada AGp - Areia grossa com estratificação plano-paralela

Figura 31. Seção colunar da trincheira na praia do Japonês (ponto NSM-07 do rio Negro). 
As barras dos rios Solimões e Amazonas são compostas por intercalações centimétricas de areia fina a média com estratificação cruzada e lama com laminação heterolítica (Figura 32).

Os afloramentos NSM-16 (Figura 32), localizado na Ilha da Marchetaria (rio Solimões), e NSM-32g (Figura 33), no rio Amazonas, apresentam intercalações de areia fina bem selecionada com séries de 10 a $15 \mathrm{~cm}$ de estratificações cruzadas e lama com laminação heterolítica (figuras 34 e 35). Nas séries de estratificação cruzada, há níveis de lama sobre as lâminas frontais de areia.

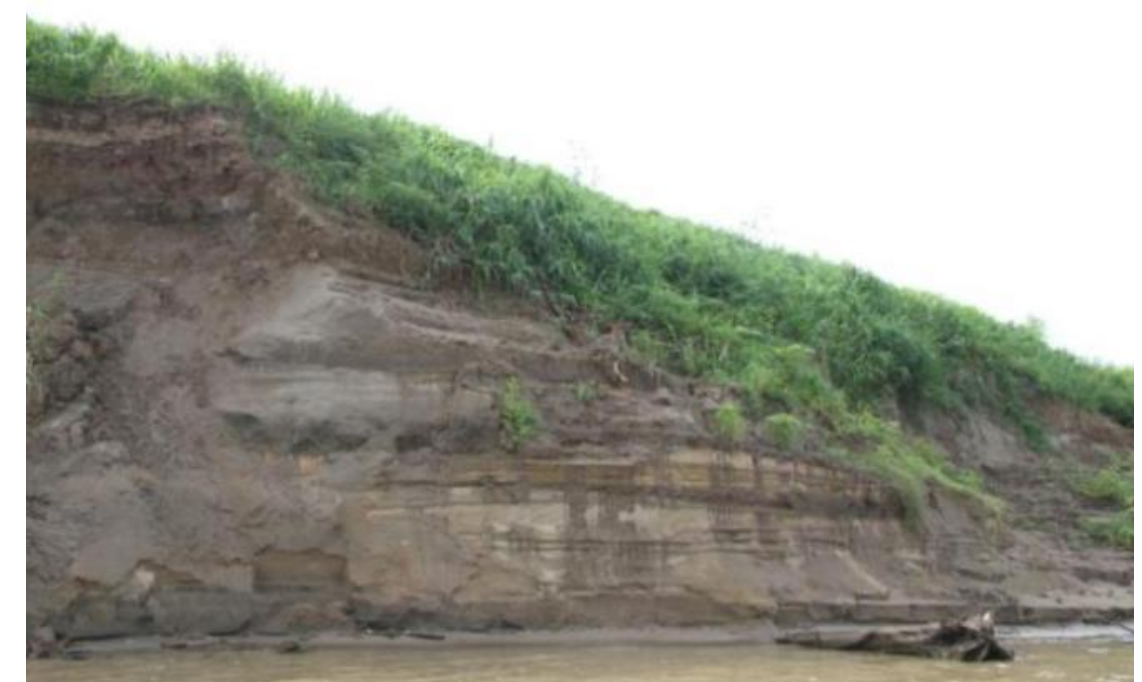

Figura 32. Afloramento NSM-16 (Ilha da Marcheteria, rio Solimões) com intercalações de fácies arenosas e lamosas. Local onde foi descrita a seção colunar da Figura 34.

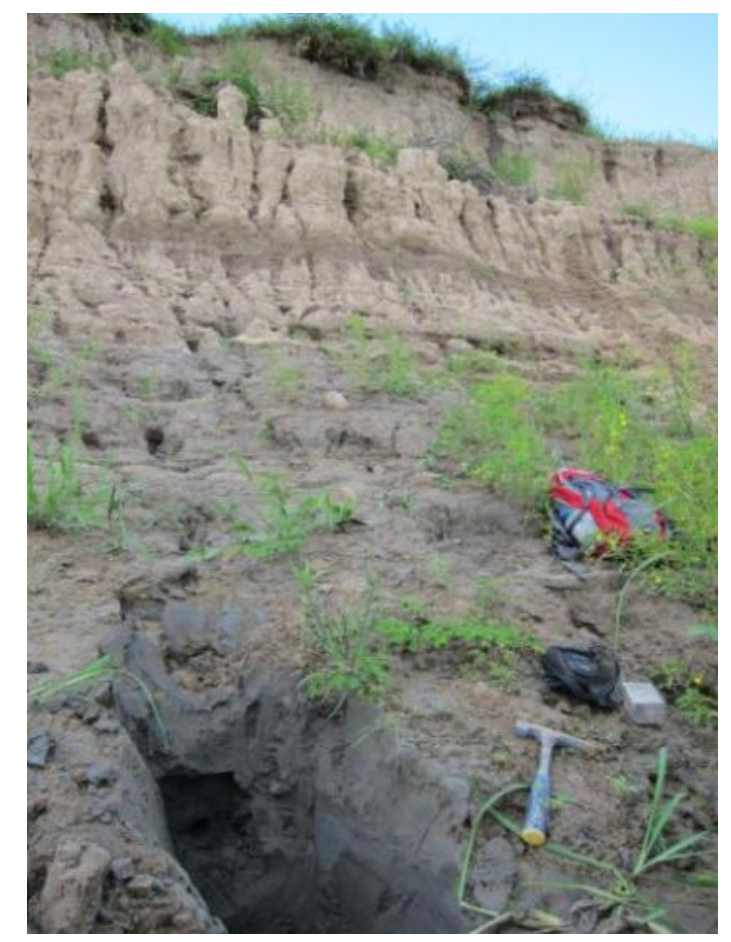

Figura 33. Afloramento NSM-32 (Paraná da Eva, rio Amazonas) onde foi descrita a seção colunar da Figura 35. Notar a ocorrência de intercalações de fácies arenosas e lamosas. 

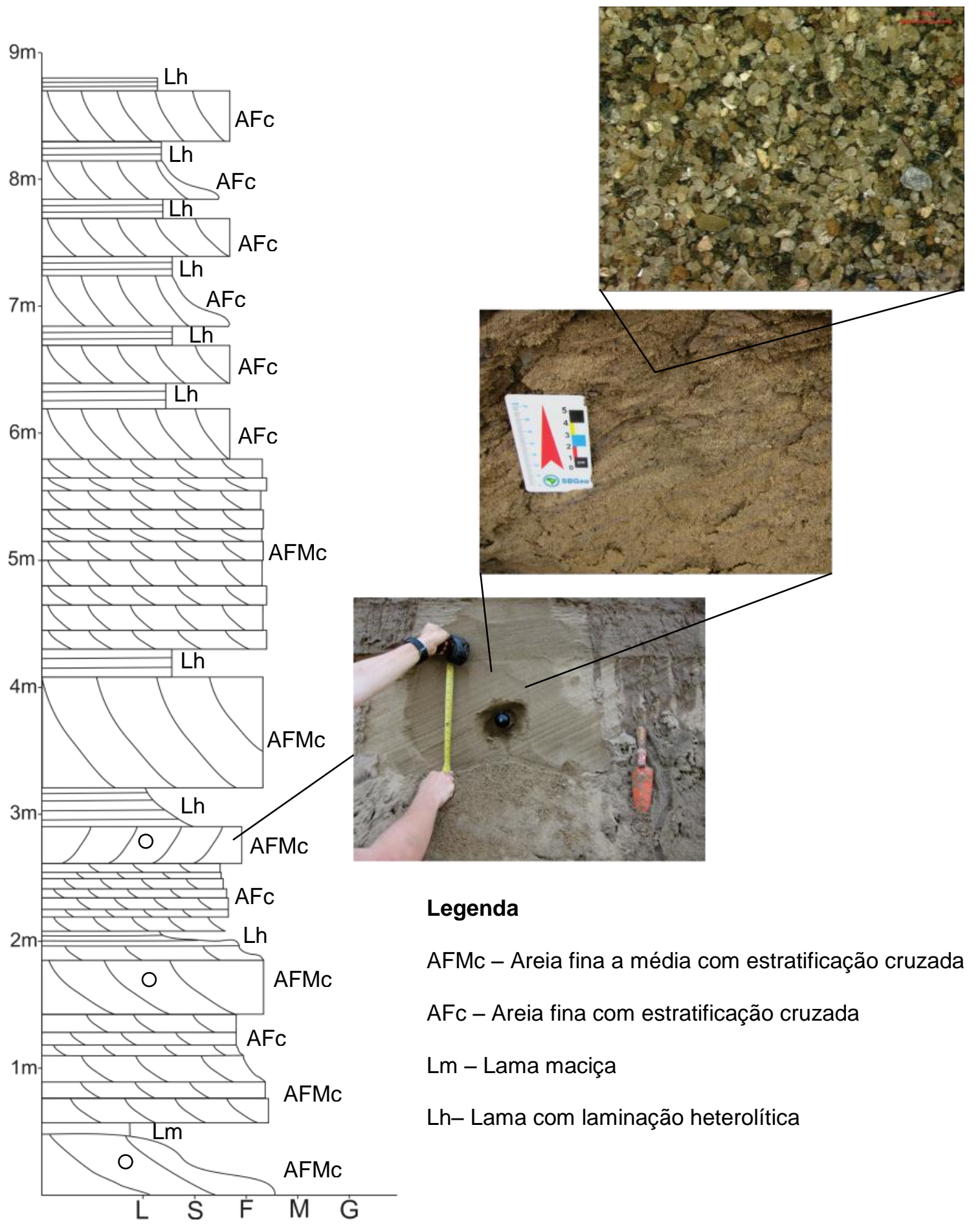

\section{Legenda}

AFMc - Areia fina a média com estratificação cruzada

AFc - Areia fina com estratificação cruzada

Lm - Lama maciça

Lh- Lama com laminação heterolítica

Figura 34. Seção colunar do afloramento NSM-16, na llha da Marchetaria no rio Solimões. A foto inferior indica local de coleta de amostra para datação LOE. 

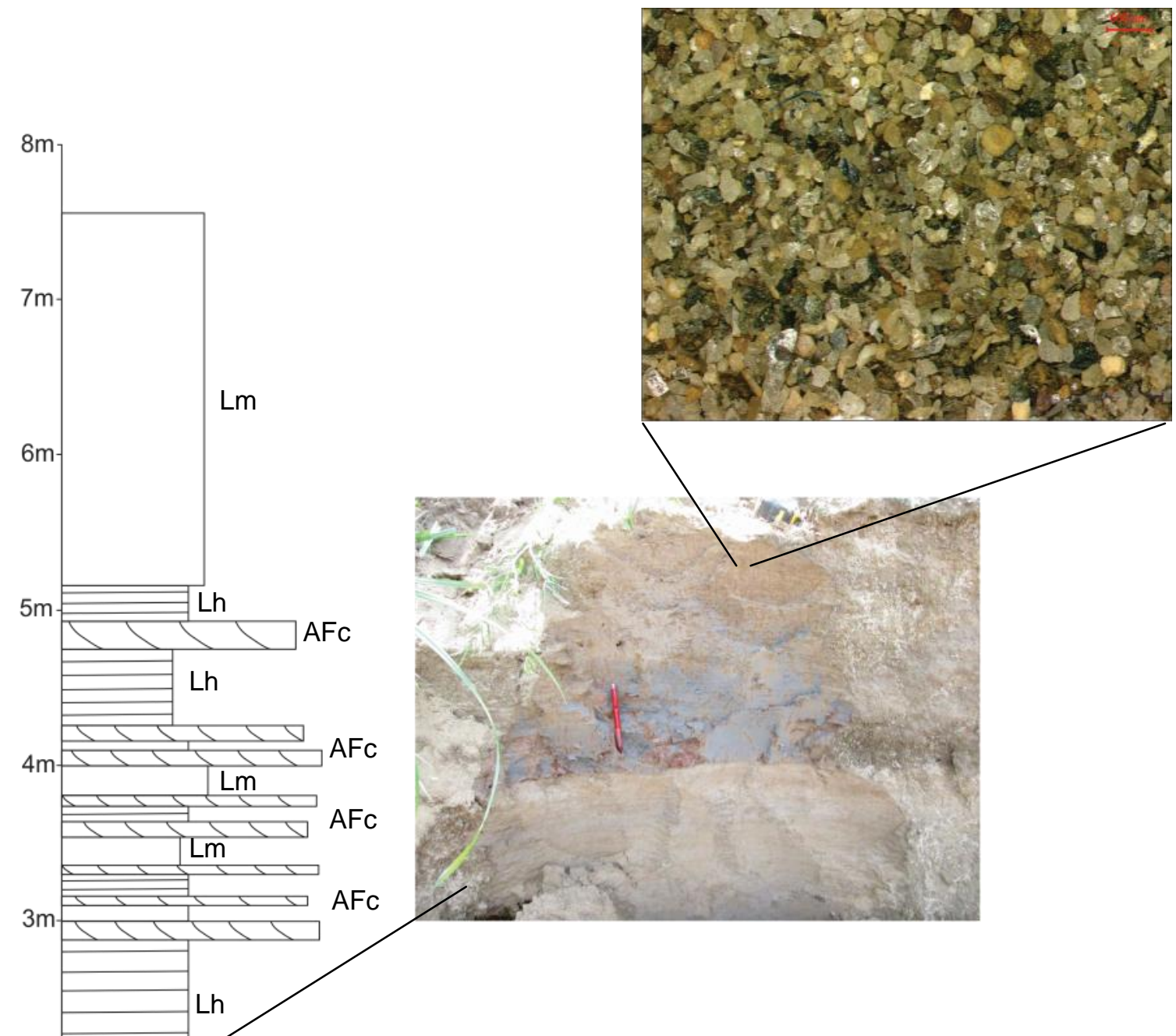

Legenda

AFc - Areia fina com estratificação cruzada

Lm - Lama maciça

Lh- Lama com laminação heterolítica

Lh

$\begin{array}{lllll}L & S & F & M & G\end{array}$

Figura 35. Seção colunar do afloramento NSM-32, no Paraná da Eva no rio Amazonas. 


\subsection{Análise granulométrica}

A caracterização granulométrica dos sedimentos superficiais da calha e de barras dos rios Negro e Solimões foi realizada com vistas para a discriminação e quantificação de suas contribuições para o aporte sedimentar do rio Amazonas. Os resultados foram representados por estatísticas (tabelas 1 e 2 ) e curvas granulométricas.

\begin{tabular}{|c|c|c|c|c|c|}
\hline Rio & $\begin{array}{c}\text { \% média } \\
\text { de areia }\end{array}$ & $\begin{array}{c}\text { Diâmetro médio da } \\
\text { fração areia }(\boldsymbol{\mu m})\end{array}$ & $\begin{array}{c}\text { \% média } \\
\text { de silte }\end{array}$ & $\begin{array}{c}\text { Diâmetro médio da } \\
\text { fração silte }(\boldsymbol{\mu m})\end{array}$ & $\begin{array}{c}\text { Número de } \\
\text { amostras }\end{array}$ \\
\hline Negro & 29,22 & 133,59 & 59,59 & 26,69 & 8 \\
\hline Solimões & 18,93 & 141,58 & 63,14 & 20,93 & 5 \\
\hline Amazonas & 31,25 & 157,06 & 57,05 & 24,64 & 5 \\
\hline
\end{tabular}

Tabela 1. Estatísticas da granulometria dos sedimentos superficiais da calha dos rios Negro, Solimões e Amazonas.

\begin{tabular}{|c|c|c|c|c|c|}
\hline Rio & $\begin{array}{c}\text { \% média } \\
\text { de areia }\end{array}$ & $\begin{array}{c}\text { Diâmetro médio da } \\
\text { fração areia }(\boldsymbol{\mu m})\end{array}$ & $\begin{array}{c}\text { \% média } \\
\text { de silte }\end{array}$ & $\begin{array}{c}\text { Diâmetro médio da } \\
\text { fração silte }(\boldsymbol{\mu m})\end{array}$ & $\begin{array}{c}\text { Número de } \\
\text { amostras }\end{array}$ \\
\hline Negro & 70,65 & 375,76 & 20,36 & 14,14 & 34 \\
\hline Solimões & 50,52 & 154,58 & 40,63 & 25,74 & 83 \\
\hline Amazonas & 46,87 & 134,36 & 44,46 & 24,87 & 23 \\
\hline
\end{tabular}

Tabela 2. Estatísticas da granulometria dos sedimentos de barras dos rios Negro, Solimões e Amazonas. As amostras foram coletadas em zonas expostas durante o período de seca.

A Figura 36 apresenta a localização das amostras de calha e das barras dos rios Negro, Solimões e Amazonas utilizadas para a realização das análises granulométricas e de sensibilidade LOE. 


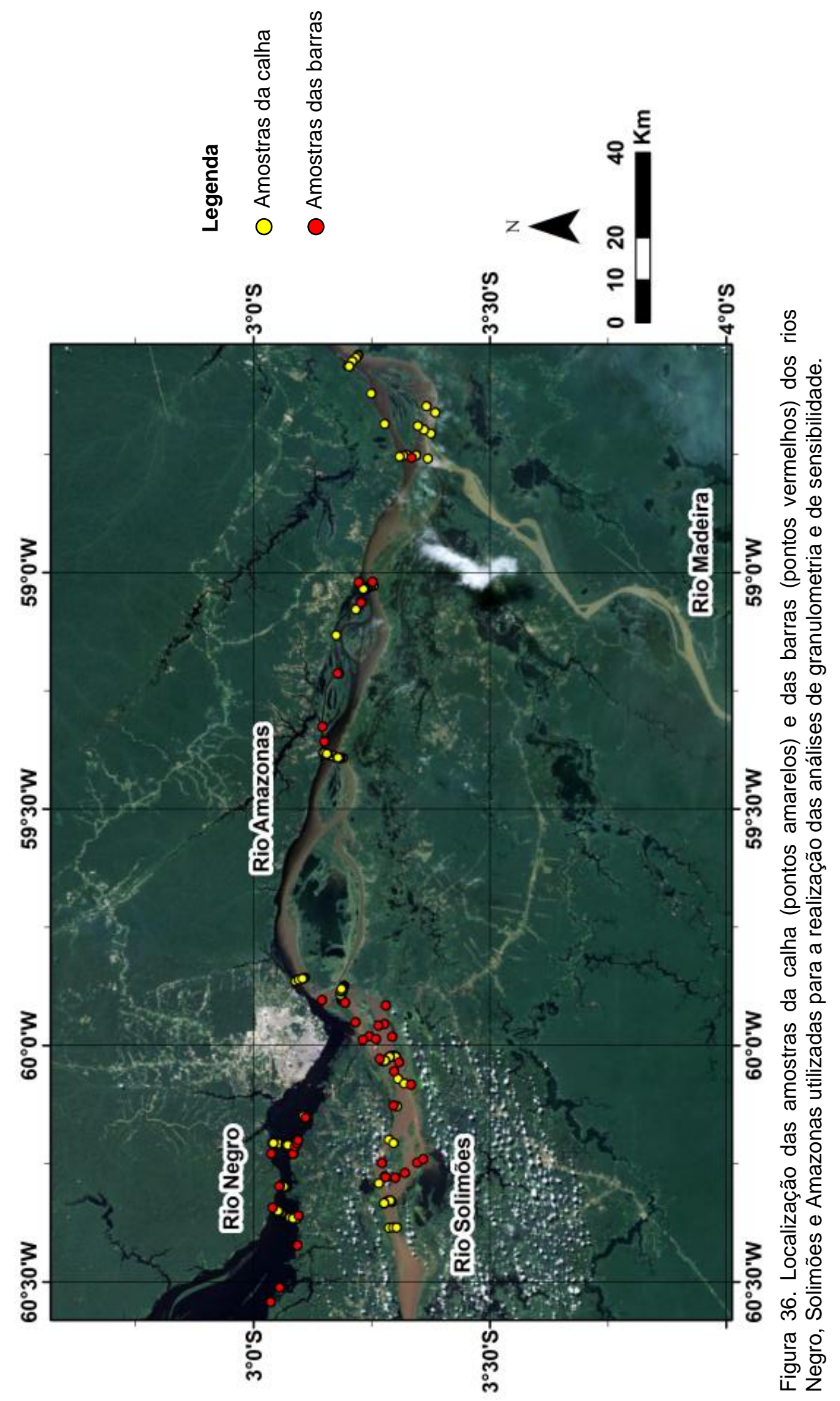


O rio Negro apresenta sedimentos lamosos no canal caracterizados por curvas granulométricas bimodais, com moda principal em $35 \mu \mathrm{m}$ e moda secundária em 15 $\mu \mathrm{m}$ (Figura 37). A fração areia (média de 29,22\%) é dominada pela classe areia fina $(133,59 \mu \mathrm{m})$.

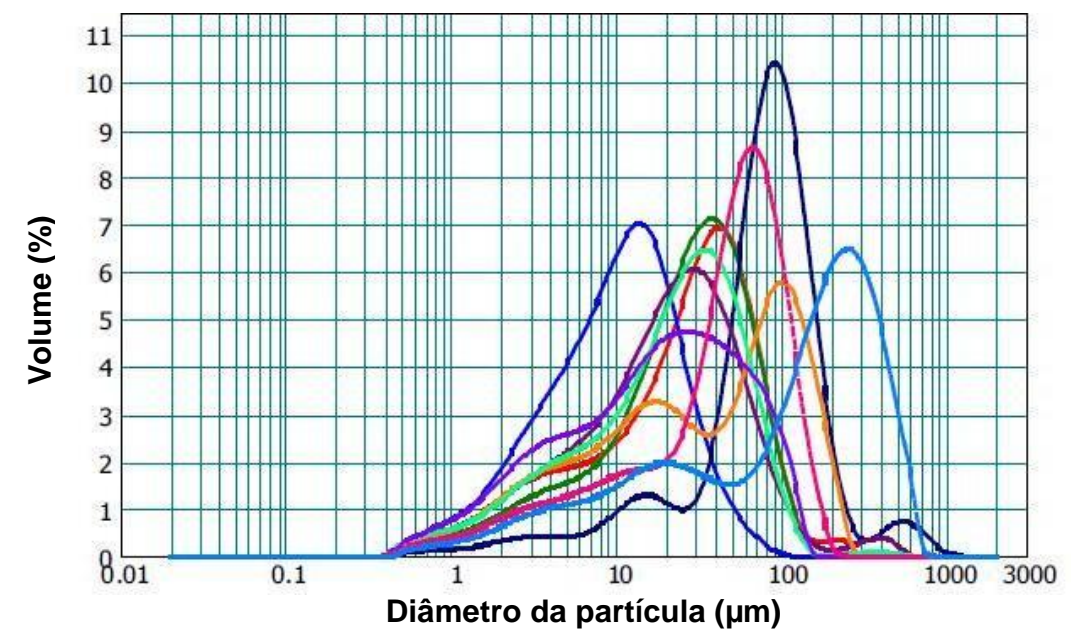

Figura 37. Curvas granulométricas dos sedimentos superficiais da calha do rio Negro.

Os sedimentos das barras anexas às margens do canal do rio Negro são dominados por areia (70,65\%), com moda em 375,76 $\mu \mathrm{m}$ (Figura 38 e Tabela 2).

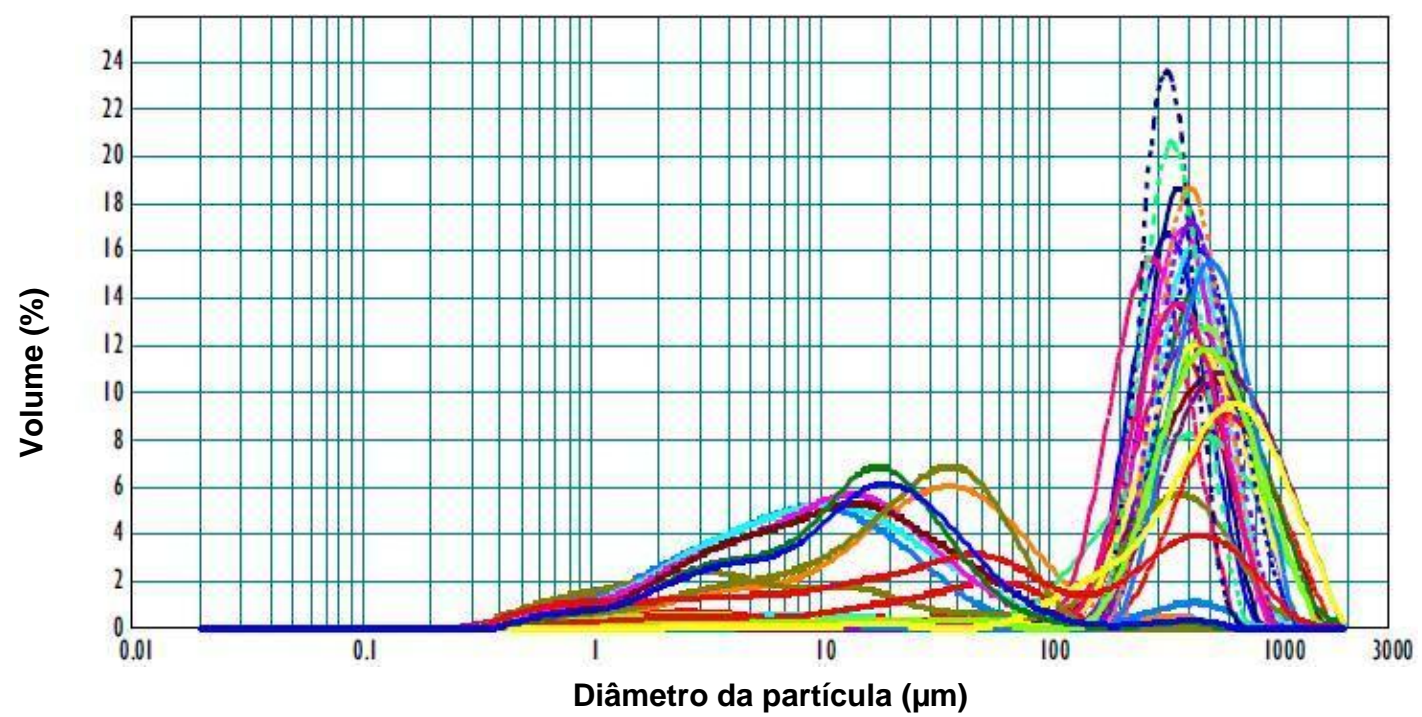

Figura 38. Curvas granulométricas dos sedimentos das barras do rio Negro.

Os sedimentos superficiais da calha do rio Solimões apresentam curvas granulométricas bimodais (Figura 39 ), sendo dominados pela fração silte $(63,14 \%)$ com moda em 20,93 $\mu \mathrm{m}$ (silte médio). A fração areia apresenta porcentagem média de $18,93 \%$ e moda $141,58 \mu \mathrm{m}$ (Tabela 1 ). 


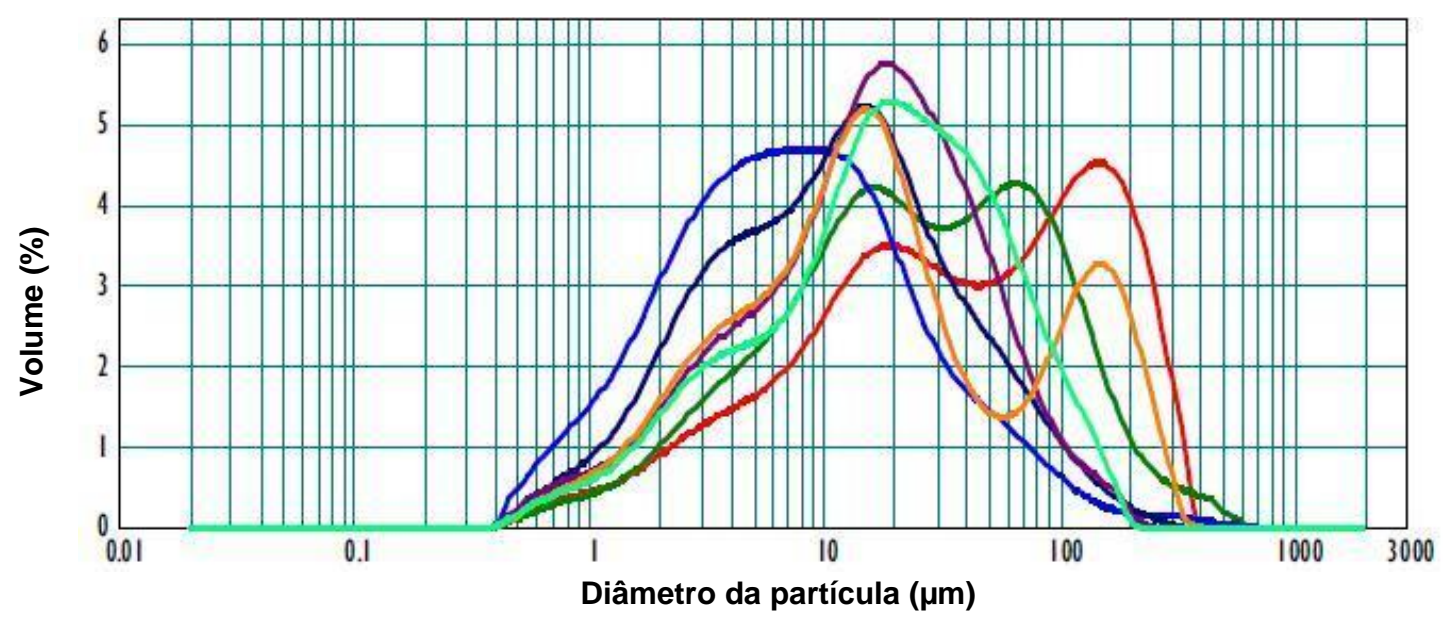

Figura 39. Curvas granulométricas dos sedimentos superficiais da calha do rio Solimões.

Os sedimentos das barras do rio Solimões também apresentam curva granulométrica bimodal (Figura 40), com 40,63\% de silte, cuja moda é 25,74 $\mu \mathrm{m}$, e areia $(50,52 \%)$ dominada pela fração fina com moda em 154,58 $\mu \mathrm{m}$ (Tabela 2).

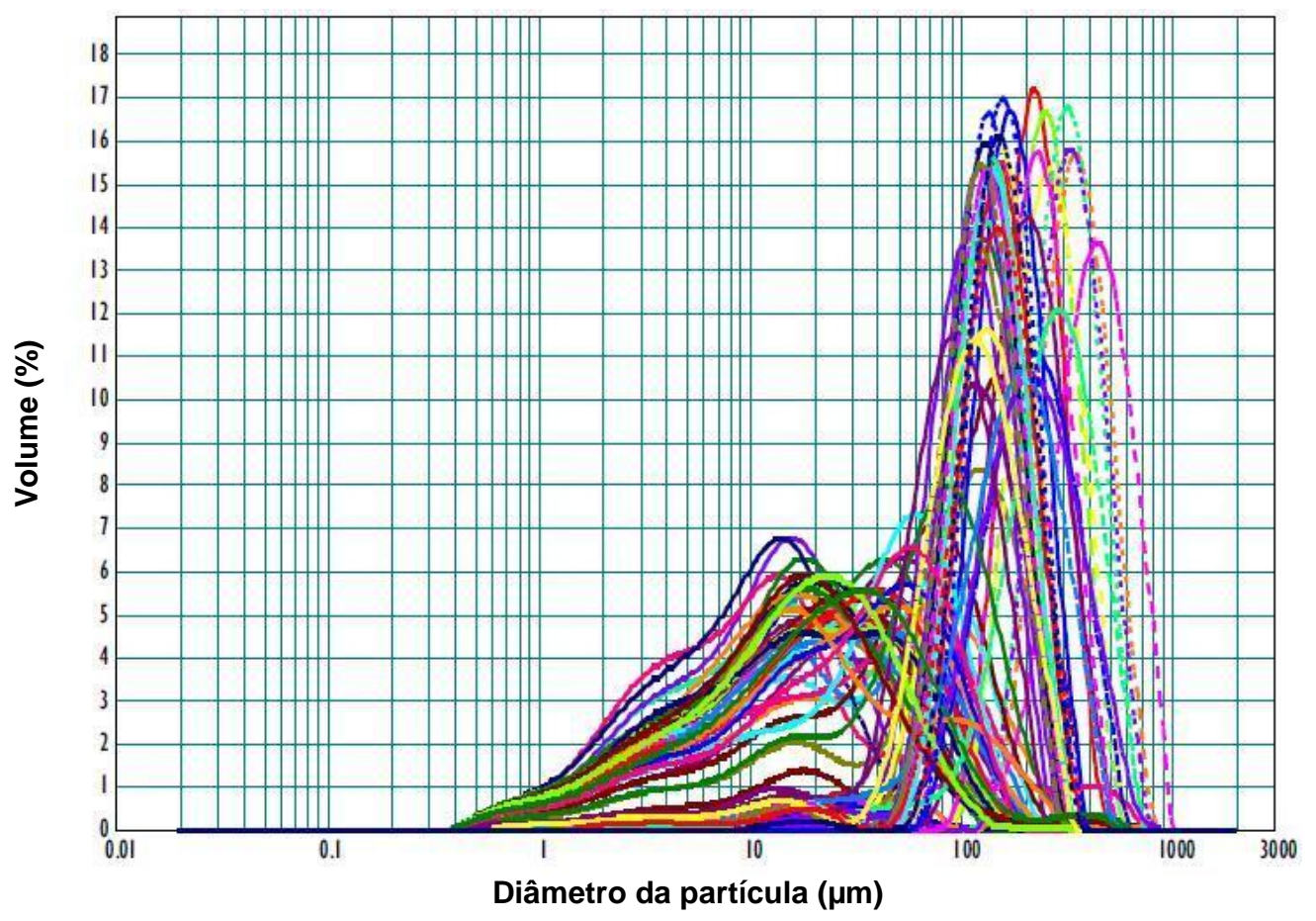

Figura 40. Curvas granulométricas dos sedimentos das barras do rio Solimões. 
A maioria das amostras dos sedimentos superficiais de calha do rio Amazonas (Figura 41) apresenta moda na fração silte $(24,64 \mu \mathrm{m})$, que representa 57,05\%.

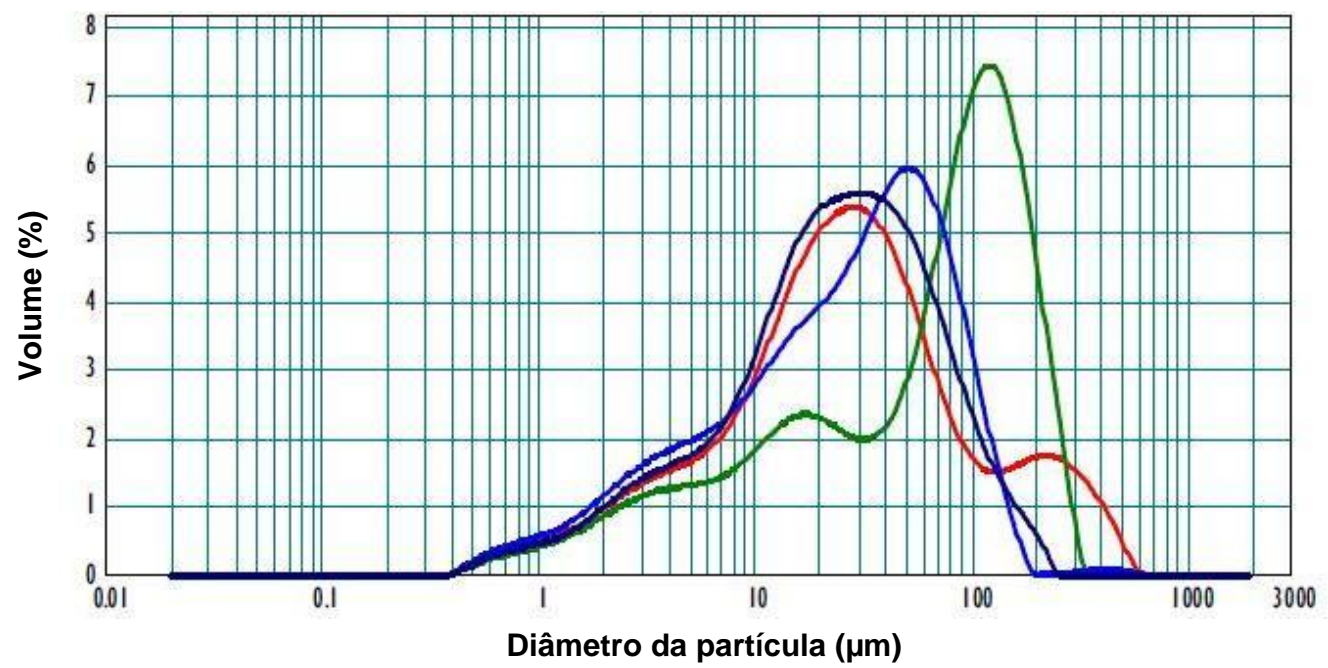

Figura 41. Curvas granulométricas dos sedimentos superficiais de calha do rio Amazonas.

As barras do rio Amazonas são compostas por silte (44,46\%) e areia muito fina a fina $(46,87 \%)$, com modas em $24,87 \mu \mathrm{m}$ e $134,36 \mu \mathrm{m}$, respectivamente (Figura 42 ).

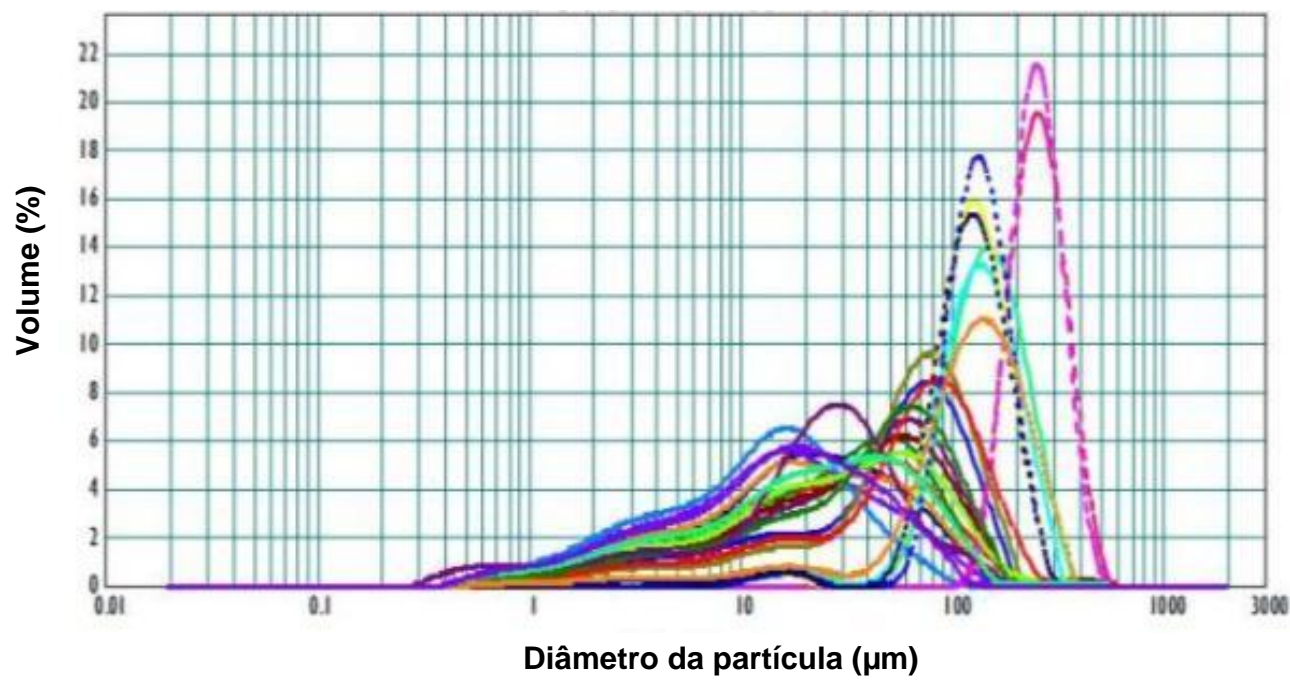

Figura 42. Curvas granulométricas dos sedimentos das barras do rio Amazonas. 


\subsection{Análise de Sensibilidade LOE}

Os dados de sensibilidade LOE foram representados pela porcentagem do sinal dominado pelo componente LOE rápido (integral de $1 \mathrm{~s}$ ) e pela razão entre sinais dominados pelos componentes rápidos relacionados a estímulo por luz infravermelho (IR) (integral de 1,2s) e azul (integral de 1s). Estas medidas foram representadas por valores individuais obtidos em alíquotas (figuras 43 e 44) e pelas médias das 12 alíquotas medidas por amostras do canal e das barras dos rios Negro, Solimões e Amazonas (figuras 45 e 46).

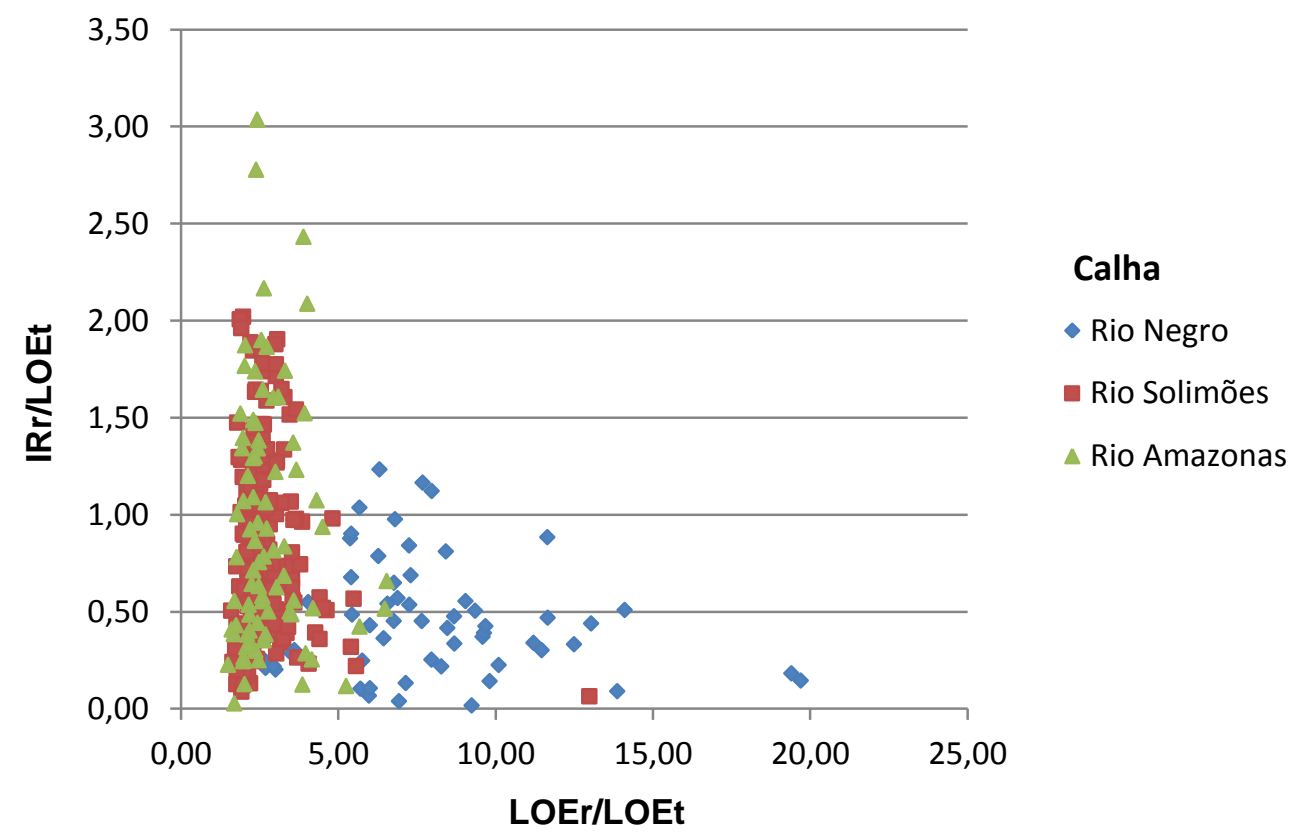

Figura 43. Sensibilidade LOE para alíquotas individuais dos sedimentos de calha dos rios Negro, Solimões e Amazonas. IRr: componente rápido com estímulo por IR; LOEr: componente rápido com estímulo por azul; e LOEt: sinal total com estímulo por azul. Alíquotas na fração $180-250 \mu \mathrm{m}$. 


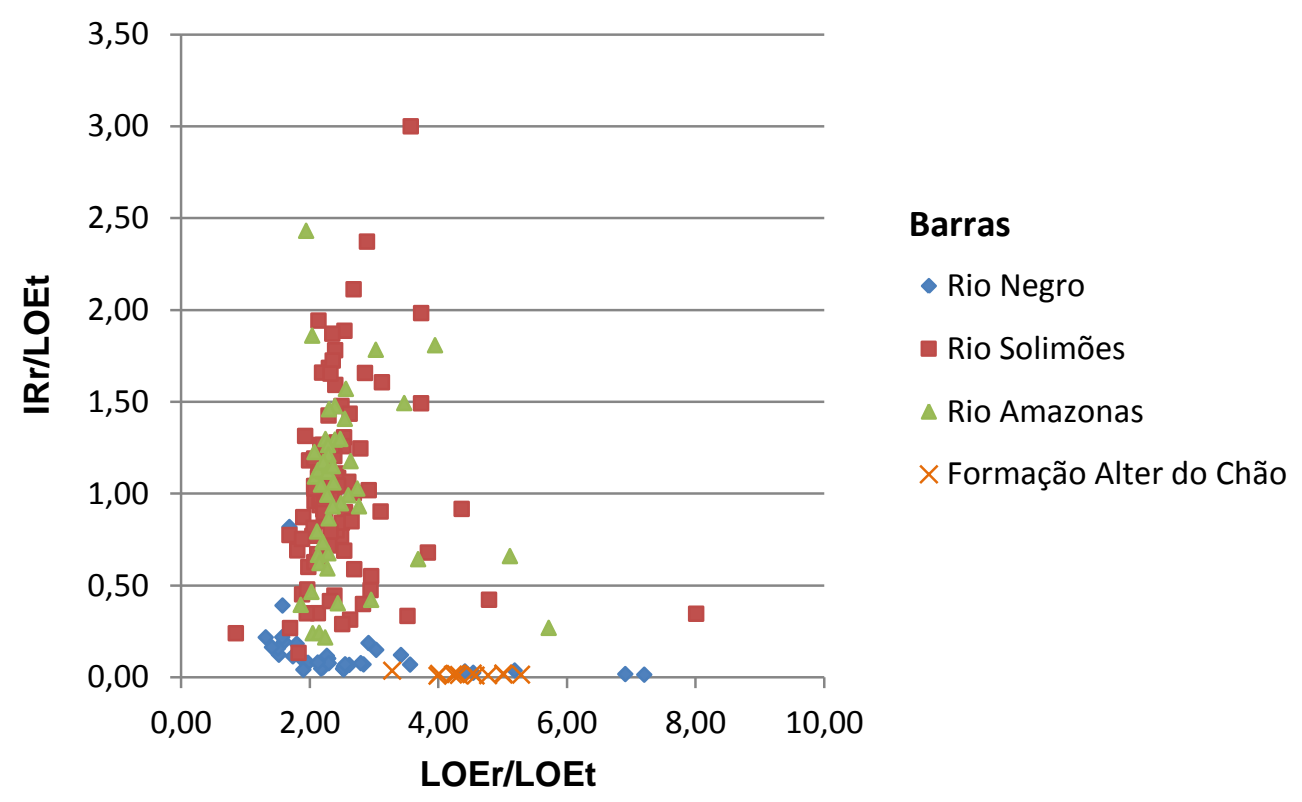

Figura 44. Sensibilidade para alíquotas individuais dos sedimentos das barras dos rios Negro, Solimões e Amazonas. IRr: componente rápido com estímulo por IR; LOEr: componente LOE rápido com estímulo por azul; e LOEt: sinal LOE total. Alíquotas na fração 180-250 $\mu \mathrm{m}$.

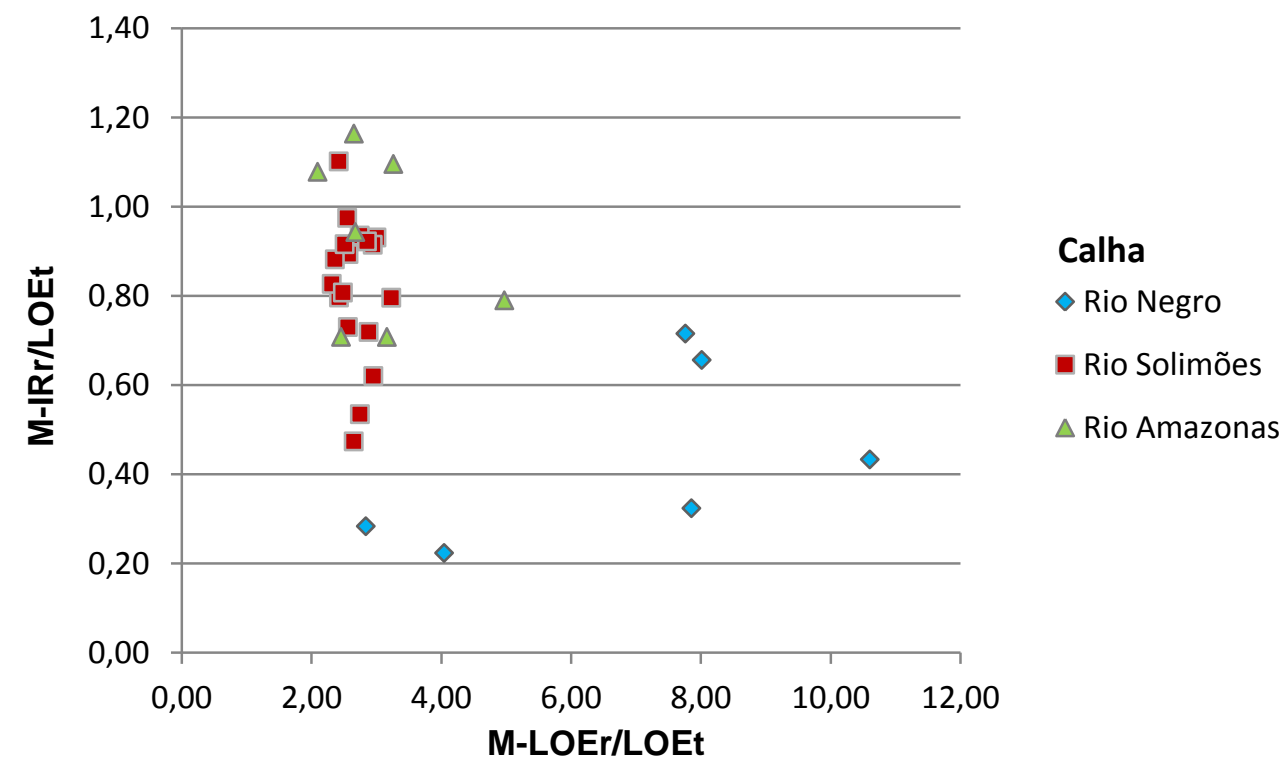

Figura 45. Sensibilidade para a média das alíquotas dos sedimentos de calha dos rios Negro, Solimões e Amazonas. M-IRr/LOEt: média da razão entre o componente rápido com estímulo por IR e componente LOE total com estímulo por azul; e MLOEr/LOEt: média da razão entre o componente LOE rápido e componente LOE total com estímulo por azul. Alíquotas na fração 180-250 $\mu \mathrm{m}$. 


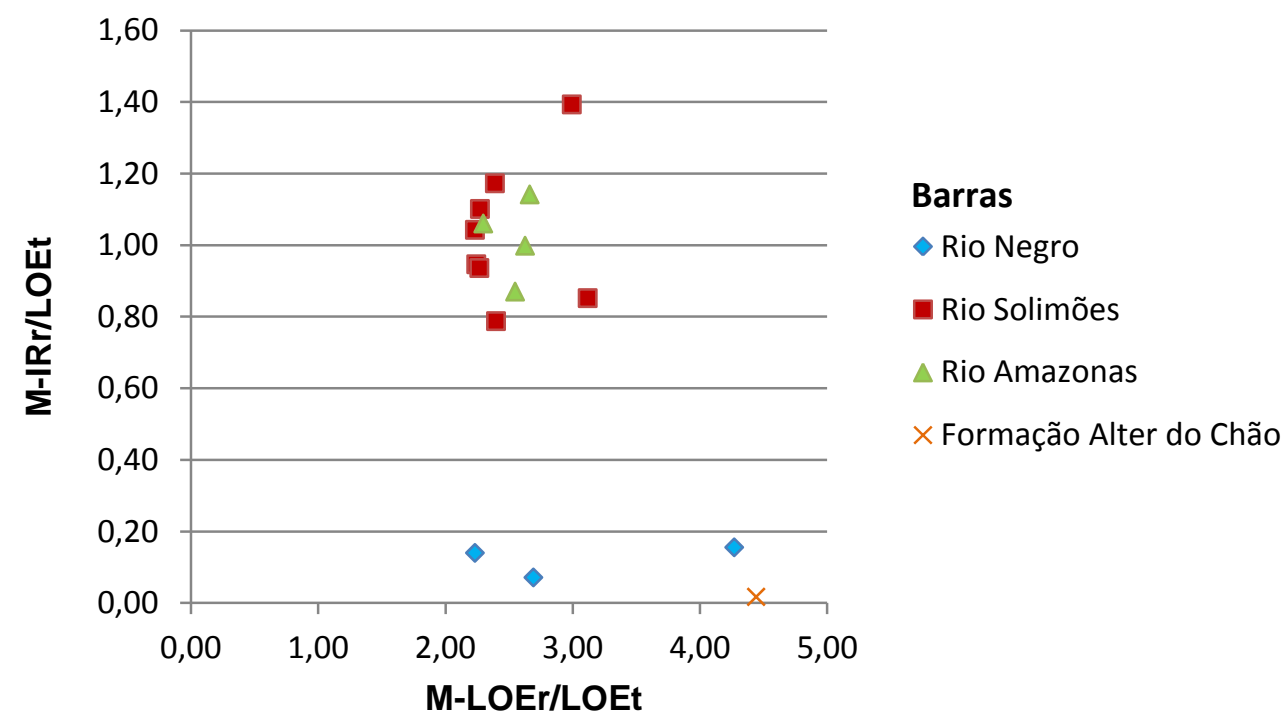

Figura 46. Sensibilidade média das alíquotas dos sedimentos das barras dos rios Negro, Solimões e Amazonas. M-IRr/LOEt: média da razão entre o componente rápido com estímulo por IR e componente LOE total com estímulo por azul; e MLOEr/LOEt: média da razão entre o componente LOE rápido e componente LOE total com estímulo por azul. Alíquotas na fração $180-250 \mu \mathrm{m}$.

Observa-se que os sedimentos do rio Negro possuem maior sensibilidade LOE e menor sensibilidade IR em relação aos sedimentos dos rios Solimões e Amazonas, tanto nos sedimentos de calha quanto nos de barras. Nota-se maior sensibilidade LOE e IR das areias da calha em relação às das barras do rio Negro, sendo que este comportamento não é marcante para os sedimentos dos rios Solimões e Amazonas. A amostra da Formação Alter do Chão apresentou sensibilidade LOE similar aos sedimentos das praias do rio Negro. As amostras de barras do rio Solimões possuem maior sensibilidade IR do que as areias da calha. Já no rio Amazonas, atenta-se para maior sensibilidade IR para os sedimentos da calha em relação aos de barra. É possível observar também maior sensibilidade IR das areias da calha do rio Amazonas comparadas à sensibilidade das areias da calha do rio Solimões.

As tabelas 3 e 4 retratam o valor em porcentagem das contribuições do aporte sedimentar dos rios Negro e Solimões no rio Amazonas. No cálculo proposto, considerou-se o valor da sensibilidade LOE ou IR do rio Amazonas como $100 \%$ e calculou-se quanto o valor de sensibilidade LOE ou IR do rio Solimões equivale em relação aos valores do rio Amazonas. A porcentagem do rio Negro seria 0 complemento da porcentagem calculada para o rio Solimões. Destaca-se que o aporte sedimentar do rio Solimões domina o rio Amazonas tanto nos sedimentos de calha quanto nos sedimentos de barra (88,08 e 98,23\%, respectivamente). O rio Negro apresenta contribuição significativa apenas para os sedimentos da calha do rio 
Amazonas, tanto em relação à sensibilidade do quartzo $(11,91 \%)$ quanto em relação à sensibilidade de feldspatos $(24,73 \%)$.

\begin{tabular}{|c|c|c|c|c|c|c|}
\hline Rio/Calha & MLOEr/LOEt & $\begin{array}{c}\text { Desvio padrão } \\
\text { MLOEr/LOEt }\end{array}$ & M-IRr/LOEt & $\begin{array}{c}\text { Desvio padrão } \\
\text { M-IRr/LOEt }\end{array}$ & $\begin{array}{c}\text { Contribuição } \\
\text { Amazonas } \\
\text { MLOEr/LOEt }\end{array}$ & $\begin{array}{c}\text { Contribuição } \\
\text { Amazonas } \\
\text { M-IRr/LOEt }\end{array}$ \\
\hline Negro & 6,50 & 2,45 & 0,38 & 0,17 & $11,91 \%$ & $24,73 \%$ \\
\hline Solimões & 2,67 & 0,76 & 0,70 & 0,42 & $88,08 \%$ & $75,26 \%$ \\
\hline Amazonas & 3,03 & 1,08 & 0,93 & 0,48 & & \\
\hline
\end{tabular}

Tabela 3. Médias dos valores de M-IRr/LOEt e MLOEr/LOEt e porcentagens dos sedimentos de calha dos rios Negro e Solimões fornecidos para o rio Amazonas.

\begin{tabular}{|c|c|c|c|c|c|}
\hline Rio/Barras & MLOEr/LOEt & $\begin{array}{c}\text { Desvio padrão } \\
\text { MLOEr/LOEt }\end{array}$ & M-IRr/LOEt & $\begin{array}{c}\text { Desvio padrão } \\
\text { M-IRr/LOEt }\end{array}$ & $\begin{array}{c}\text { Contribuição } \\
\text { Amazonas } \\
\text { MLOEr/LOEt }\end{array}$ \\
\hline Negro & 3,06 & 2,15 & 0,12 & 0,12 & $1,76 \%$ \\
\hline Solimões & 2,49 & 0,57 & 1,03 & 0,45 & $98,23 \%$ \\
\hline Amazonas & 2,53 & 0,67 & 1,02 & 0,44 & \\
\hline
\end{tabular}

Tabela 4. Médias dos valores de M-IRr/LOEt e MLOEr/LOEt e porcentagens dos sedimentos das barras dos rios Negro e Solimões fornecidos para o rio Amazonas.

\subsection{Geocronologia}

A geocronologia dos sedimentos das barras dos rios Negro, Solimões e Amazonas permitiu atribuir escala de tempo para as feições geomorfológicas observadas e teve importância para a avaliação das variações temporais da sensibilidade LOE observadas nas barras. No total, foram realizadas 15 datações LOE, sendo três em sedimentos dos rios Negro e Amazonas e oito em sedimentos do rio Solimões (Figura 47). Também foram realizadas 6 datações ${ }^{14} \mathrm{C}$ em fragmentos de madeira (Figura 47).

Como critérios de rejeição das alíquotas medidas, foram utilizados valores do teste de reciclagem (recycling ratio) de 0,9 a 1,1 e erro máximo da dose teste de $15 \%$. O recycling ratio das amostras dos rios Negro, Solimões e Amazonas apresentaram valores respectivamente entre 0,75 e 1,20; 0,80 e 1,5; 0,84 e 1,21. A aplicação de tais critérios acarretou na rejeição de número significativo de alíquotas por amostra.

Para as amostras analisadas, os testes de recuperação tiveram êxito, sendo que o sinal da dose de 0 Gy (sinal residual) foi inferior a $6 \%$ do sinal corrigido da dose natural. Para o rio Negro, que apresenta sedimentos de idades mais jovens, essa porcentagem chegou a $7 \%$. 


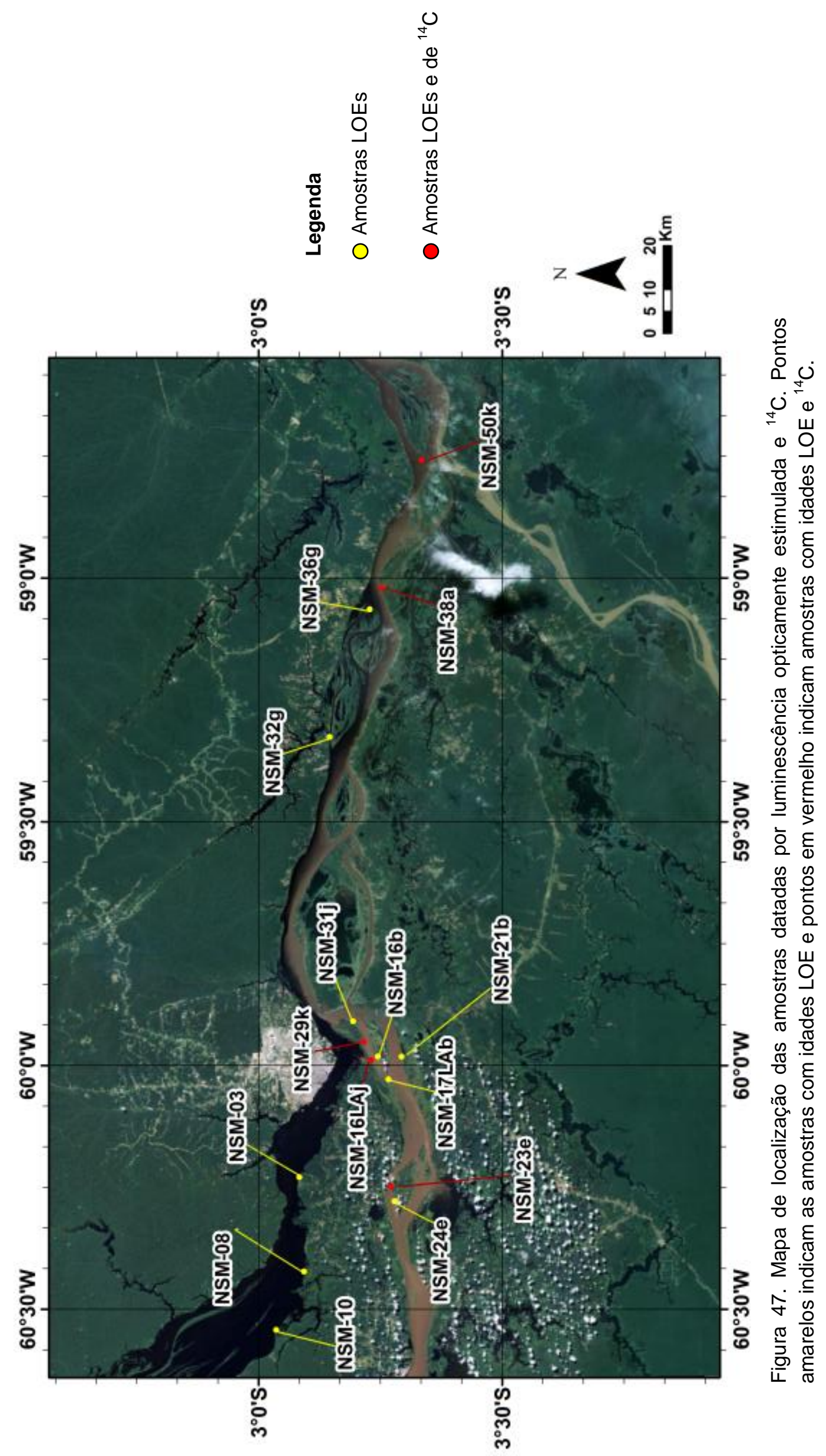


O teste do feldspato demonstrou baixo sinal IR para as areias do rio Negro (Figura 48), o que indica quantidade desprezível de feldspato e sinal LOE dominado por grãos de quartzo. Isto demonstra eficácia dos métodos de concentração de quartzo.

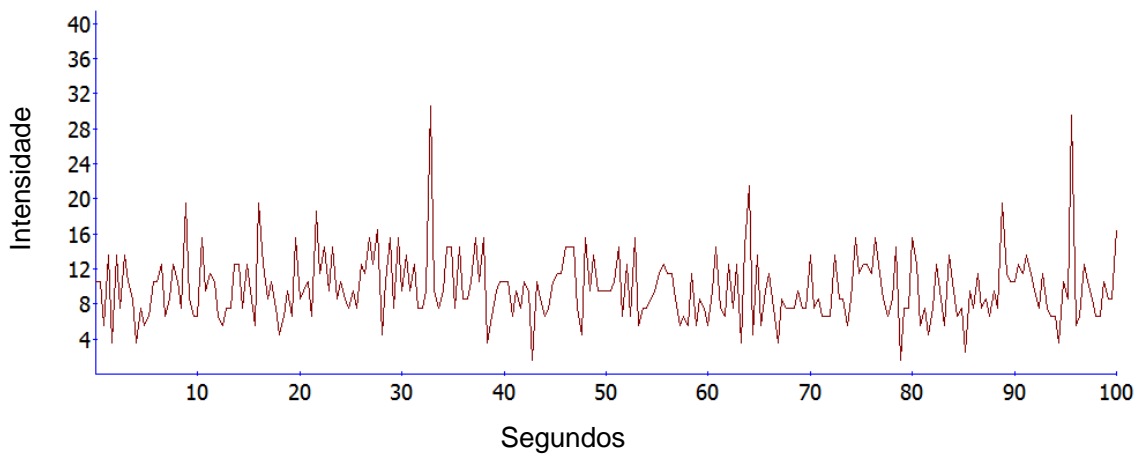

Figura 48. Sinal IR para dose de 0,18 Gy em alíquota de areia do rio Negro (NSM-08). Sinal ao nível do background indica ausência de resposta proveniente de feldspato.

Em contrapartida, as amostras dos rios Solimões e Amazonas apresentaram sinal IR significativo em termos da resposta LOE obtida mediante estímulo por luz azul. Isto ocorreu mesmo após ataque adicional por HF (figuras 49 e 50). Deste modo, foi necessária a aplicação do protocolo SAR modificado para a obtenção de sinais LOE dominados pelo quartzo.

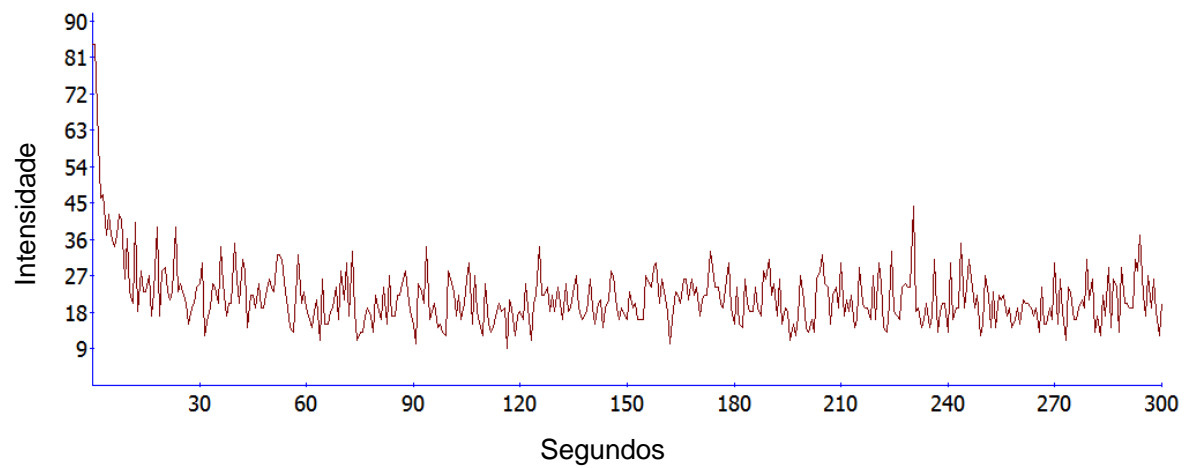

Figura 49. Sinal IR natural obtido em sedimentos arenosos do rio Solimões (NSM-24e). Sinal acima do background indica presença significativa de feldspato.

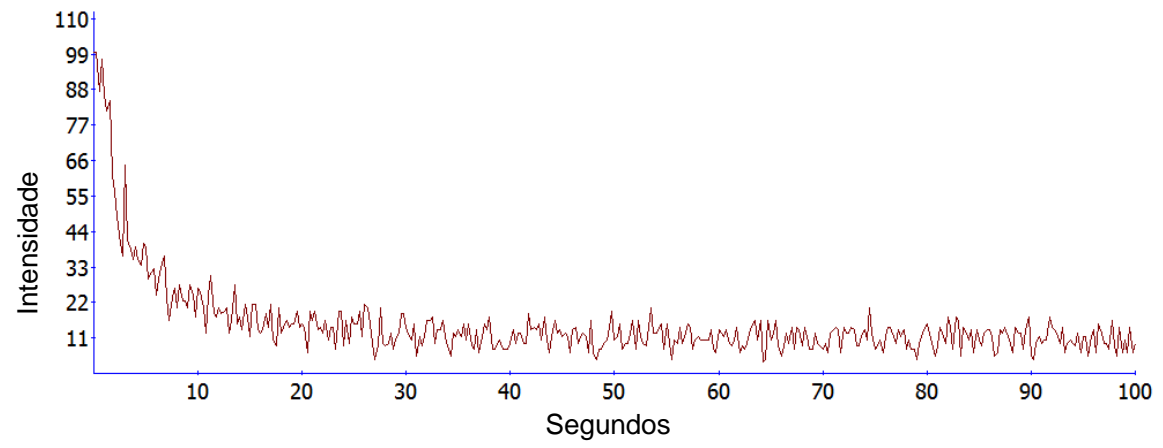

Figura 50. Sinal IR natural obtido em sedimentos do rio Amazonas (NSM-38a). Sinal acima do background indica presença significativa de feldspato. 
O teste de recuperação de dose (dose recovery) foi realizado com o protocolo SAR modificado. A dose de radiação beta administrada para a recuperação foi de 8,8 Gy. Os resultados (Figura 51) apresentaram doses com médias ponderadas de $10,0 \pm 1,5$ Gy para as areias do rio Solimões (NSM-16b) e 9,3 $\pm 1,2$ Gy para as areias do rio Amazonas (NSM-32g), considerando 12 alíquotas por amostra. Os resultados obtidos sugerem leve tendência de superestimação da dose. Porém, a dose administrada (8,8 Gy) está dentro da margem de erro da estimativa. Isso demonstrou que as amostras analisadas podem ser utilizadas como dosímetro natural e que o protocolo utilizado está adequado.

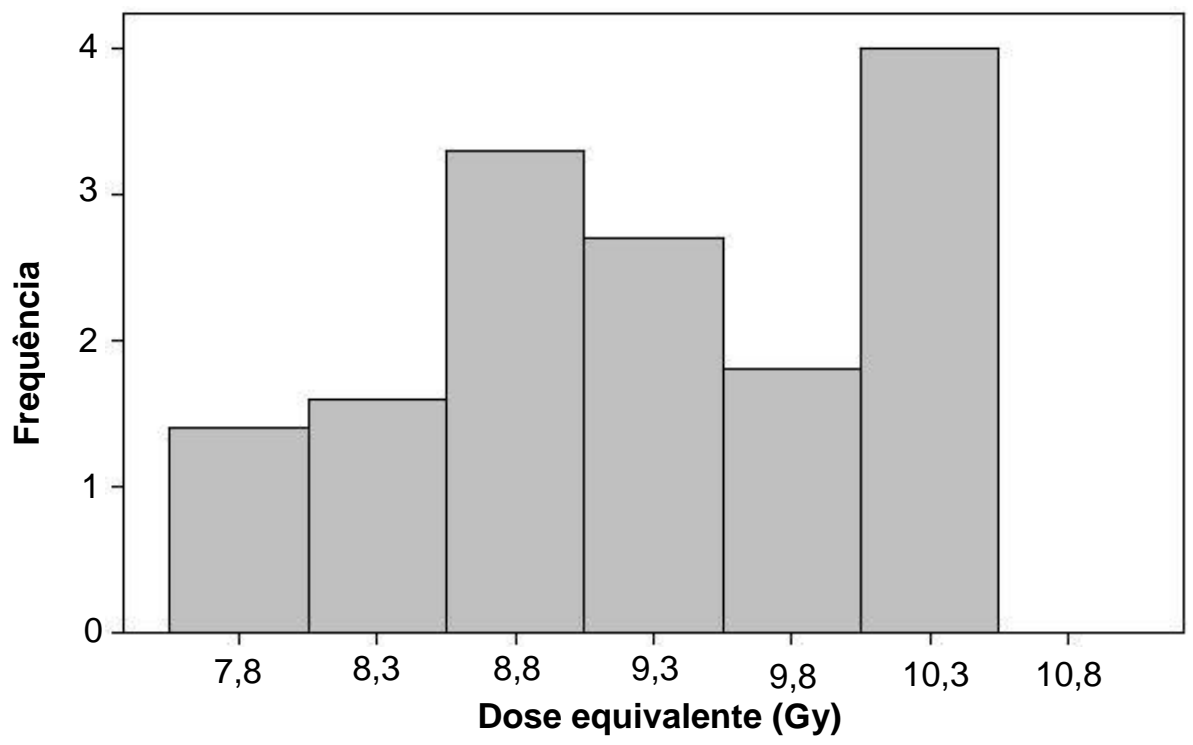

Figura 51. Teste de recuperação de dose para sedimentos dos rios Solimões (NSM-16b) e Amazonas (NSM-32g). Foram utilizadas 12 alíquotas por amostra $(n=24)$.

As curvas de dose-resposta LOE obtidas para as alíquotas de sedimentos dos rios Negro, Solimões e Amazonas apresentaram crescimento do sinal em termos da dose, com tendência linear para baixas doses (Figura 52) e tendência exponencial para doses elevadas (figuras 53 e 54).

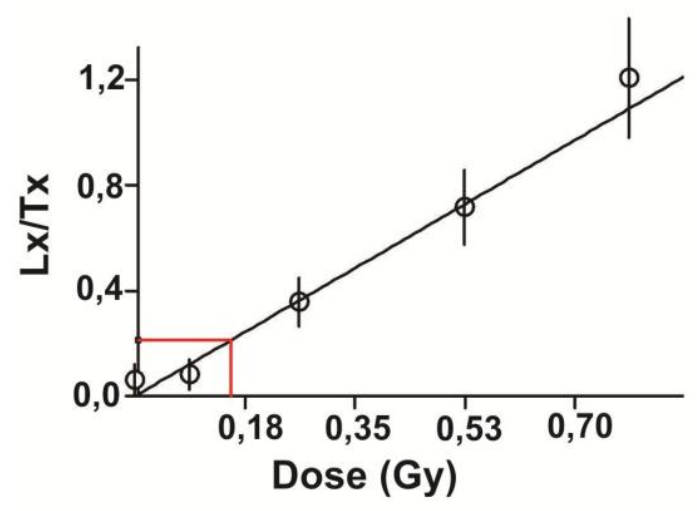

Figura 52. Curva de dose-resposta LOE de alíquota de areia do rio Negro. Lx/Tx representa o sinal LOE corrigido. 


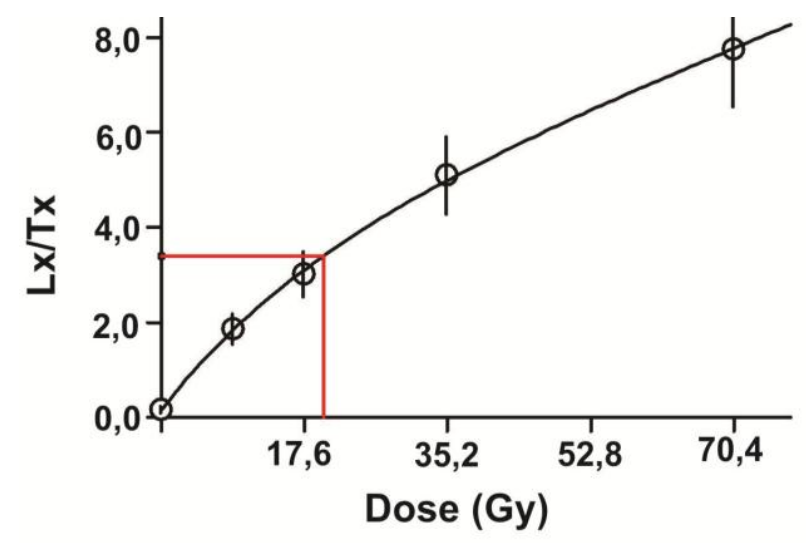

Figura 53. Curva de dose-resposta LOE de alíquota de areia do rio Solimões. Lx/Tx representa o sinal LOE corrigido.

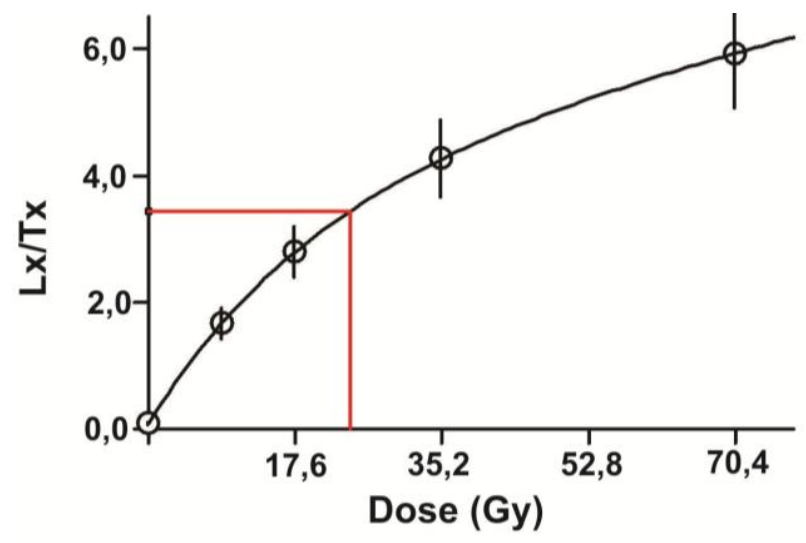

Figura 54. Curva de dose-resposta LOE de alíquota de areia do rio Amazonas. Lx/Tx representa o sinal LOE corrigido.

A distribuição de frequência das doses estimadas para a amostra NSM-08 do rio Negro apresentou baixa dispersão (figuras 55 e 56) se comparada às distribuições de doses obtidas para os sedimentos dos rios Solimões e Amazonas.

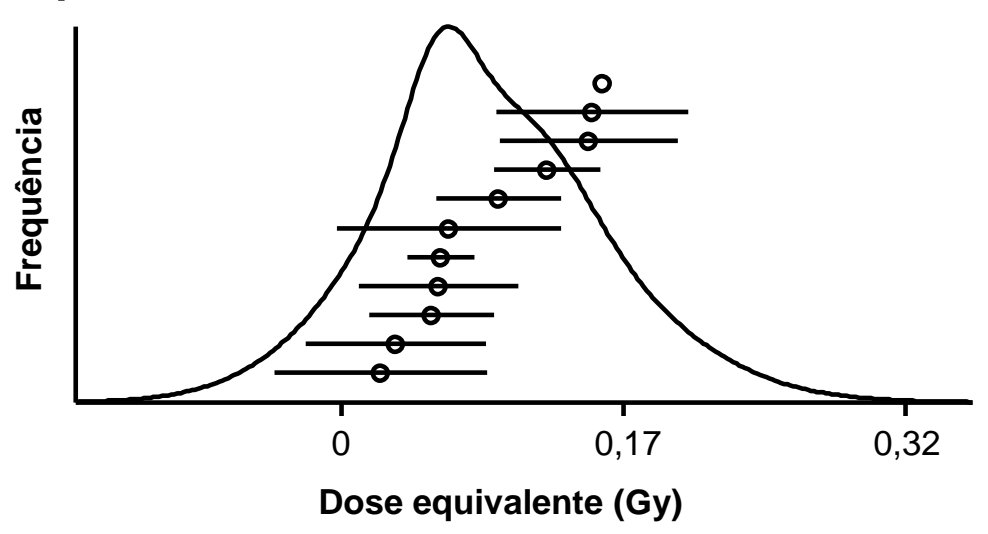

Figura 55. Histograma ponderado da amostra NSM-08 (rio Negro) com dispersão das doses relativamente baixa. 


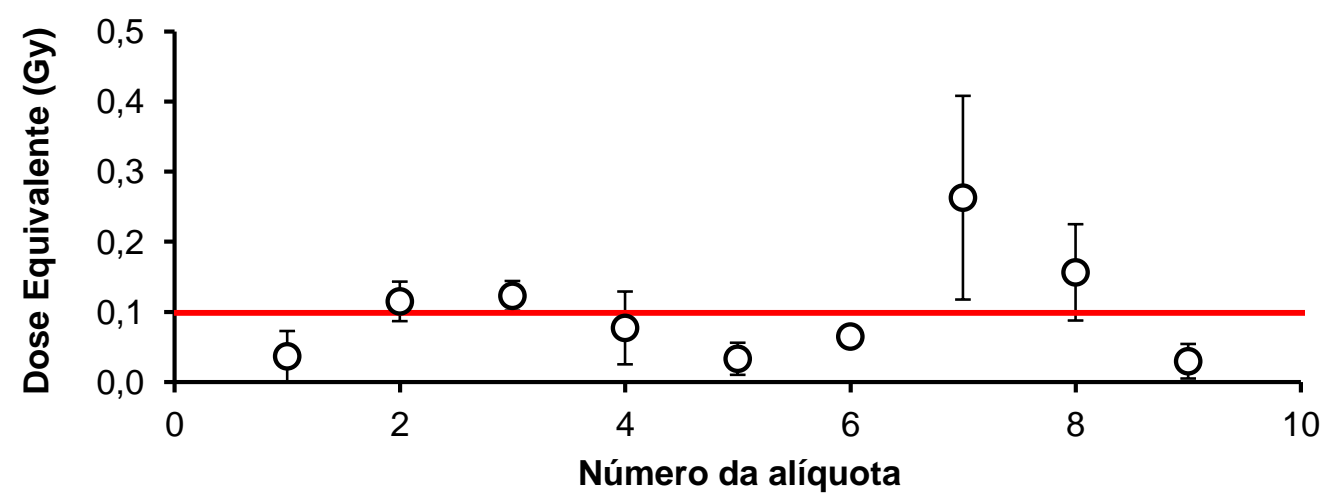

Figura 56. Valores das doses equivalentes das alíquotas da amostra NSM-08 (rio Negro). Apesar de ocorrer certa variação, a dispersão é relativamente baixa. A reta horizontal indica a dose estimada pelo Central Age Model.

Já as distribuições de doses das areias dos rios Solimões (NSM-24e) e Amazonas (NSM-32g) possuem alta dispersão (figuras 57, 58, 59 e 60). Isto demonstra, provavelmente, fotoesvaziamento incompleto destas areias. Por isso, foi utilizado o MAM (Minimum Age Model) para estimativa de dose equivalente dessas amostras. Isto visou obter estimativa de dose indicativa do último evento de fotoesvaziamento dessas areias.

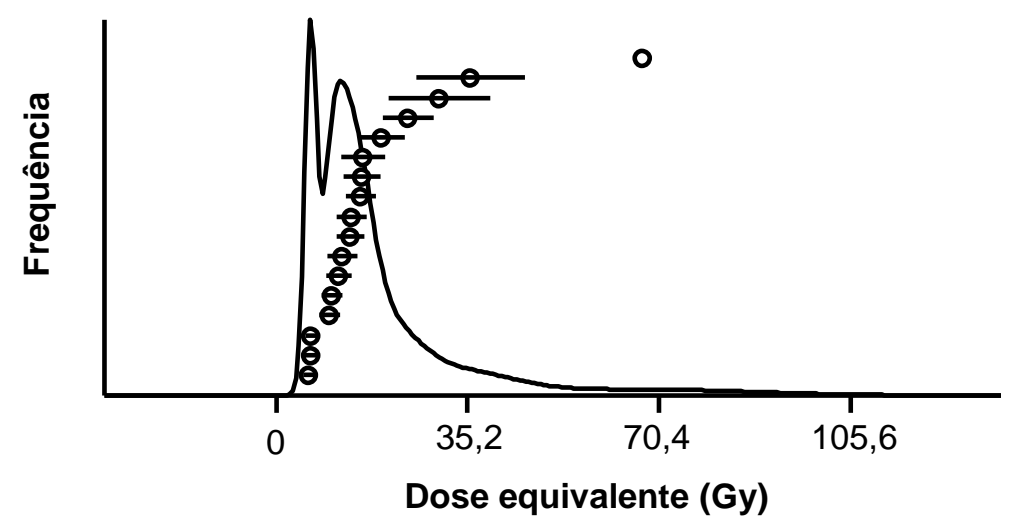

Figura 57. Distribuição de frequências das doses equivalentes da amostra NSM-24e (rio Solimões). Notar a alta dispersão.

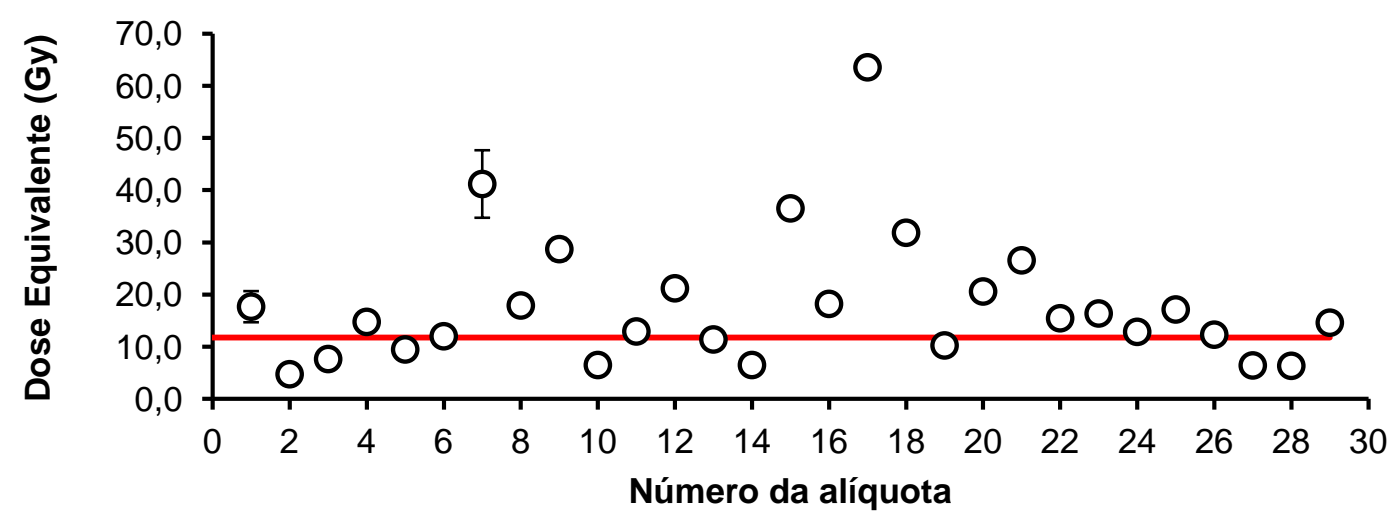

Figura 58. Valores das doses equivalentes das alíquotas da amostra NSM-24e (rio Solimões). Notar a alta dispersão. A reta horizontal indica a dose estimada pelo Central Age Model. 


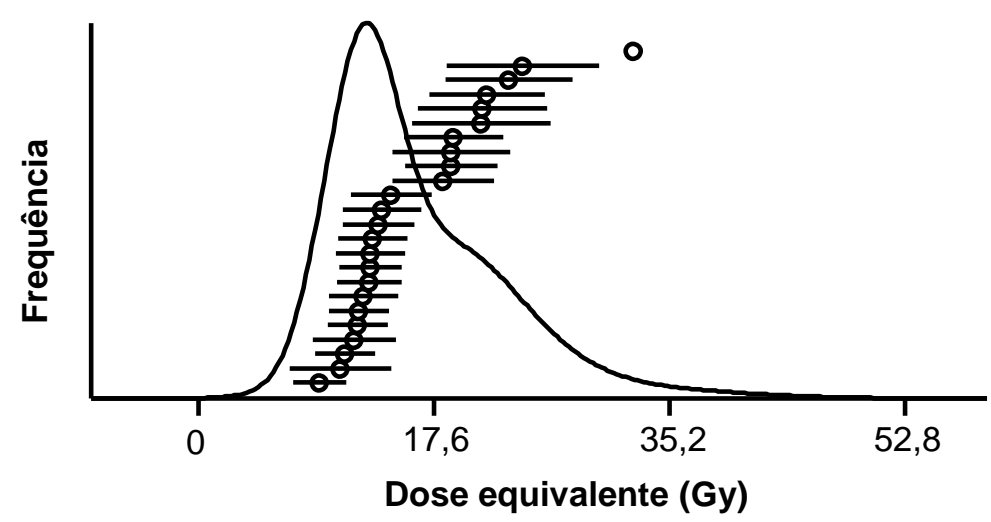

Figura 59. Distribuição de frequências das doses da amostra NSM-32g (rio Amazonas) com alta dispersão.

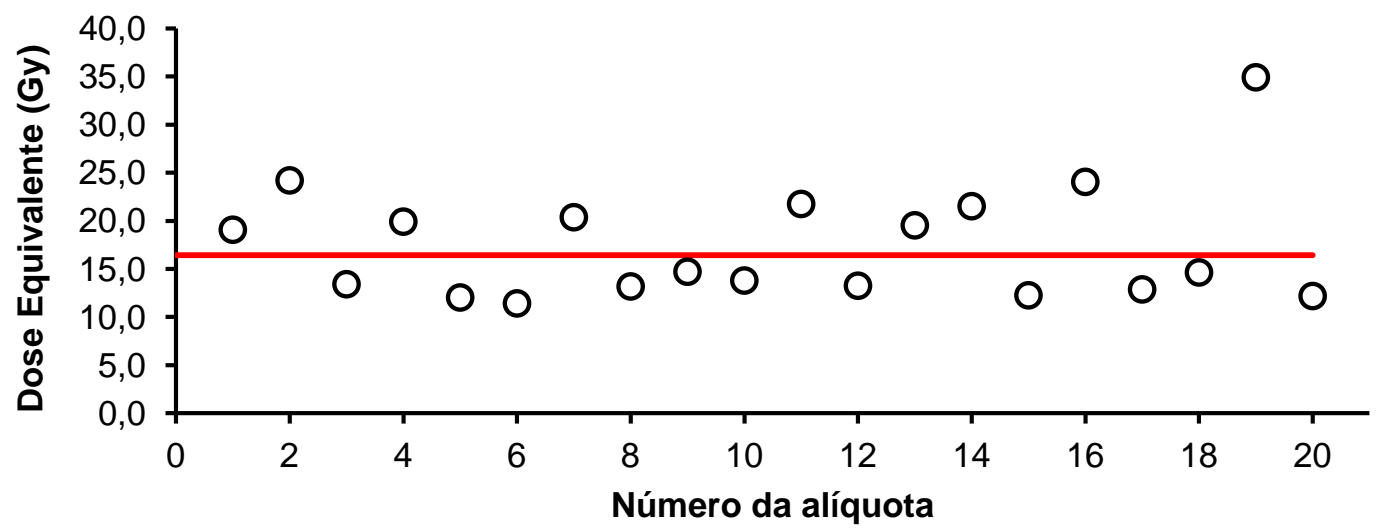

Figura 60. Valores das doses equivalentes por alíquota da amostra NSM-32g (rio Amazonas) com alta dispersão. A reta horizontal indica a dose estimada pelo Central Age Model.

A Tabela 5 apresenta os resultados das doses equivalentes, taxas de dose e idades centrais e mínimas obtidas para as amostras de sedimentos dos rios Negro, Solimões e Amazonas. 


\begin{tabular}{|c|c|c|c|c|c|c|c|c|c|c|c|c|c|c|c|}
\hline 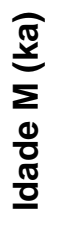 & & & & $\begin{array}{l}0 \\
0 \\
+1 \\
+ \\
0 \\
0 \\
+\end{array}$ & $\bar{N}$ & $\begin{array}{l}c \\
+ \\
+ \\
+\end{array}$ & $\begin{array}{l}10 \\
0 \\
0 \\
0 \\
+1 \\
10 \\
0 \\
0\end{array}$ & $\begin{array}{l}\bar{N} \\
0 \\
+1 \\
+1 \\
m \\
-\end{array}$ & $\begin{array}{l}\stackrel{0}{ } \\
0 \\
0 \\
+1 \\
O \\
\infty\end{array}$ & 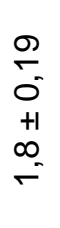 & $\begin{array}{l}\tilde{m} \\
\text { Oे } \\
\text { +1 } \\
\dot{ }^{-} \\
\text {ले }\end{array}$ & \begin{tabular}{c}
3 \\
\multirow{2}{*}{} \\
0 \\
+1 \\
$\stackrel{+}{*}$
\end{tabular} & $\begin{array}{l}\infty \\
\sigma \\
0 \\
+1 \\
\infty \\
-\end{array}$ & $\begin{array}{c}\text { O } \\
\text { o } \\
+1 \\
\stackrel{1}{0} \\
-\end{array}$ & 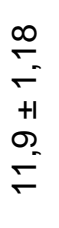 \\
\hline $\begin{array}{l}\text { बु } \\
\stackrel{0}{0} \\
0 \\
\frac{0}{0} \\
\frac{\pi}{0}\end{array}$ & $\begin{array}{l}\hat{0} \\
0 \\
+1 \\
+1 \\
0 \\
0 \\
0\end{array}$ & $\begin{array}{l}\text { J } \\
0 \\
0 \\
+1 \\
\text { J } \\
0 \\
0\end{array}$ & $\begin{array}{l}0 \\
N \\
0 \\
+1 \\
+1 \\
\end{array}$ & $\begin{array}{l}+ \\
0 \\
+1 \\
\infty \\
\infty \\
\text { D }\end{array}$ & $\begin{array}{l}\bar{\alpha} \\
c \\
+ \\
L \\
\sigma\end{array}$ & $\delta$ & $\begin{array}{l}\text { Oे } \\
0 \\
+1 \\
+ \\
= \\
=\end{array}$ & $\begin{array}{l}m \\
\tilde{0} \\
+1 \\
\stackrel{-1}{-}\end{array}$ & $\begin{array}{c}\text { o } \\
0 \\
0 \\
+1 \\
0 \\
0 \\
0\end{array}$ & $\begin{array}{l}\text { D } \\
\text { O } \\
+1 \\
+ \\
\text { ले }\end{array}$ & $\begin{array}{l}\bar{m} \\
0 \\
+1 \\
+ \\
\text { m } \\
\dot{\sigma}\end{array}$ & $\begin{array}{l}0 \\
0 \\
0 \\
+1 \\
0 \\
0 \\
0\end{array}$ & $\begin{array}{l}\infty \\
\text { N } \\
0 \\
+1 \\
\infty \\
\infty\end{array}$ & $\begin{array}{l}\text { O) } \\
\text { o } \\
+1 \\
\text { m } \\
\text { N }\end{array}$ & $\begin{array}{l}0 \\
\infty \\
0 \\
+1 \\
+ \\
\dot{0}^{-} \\
0\end{array}$ \\
\hline 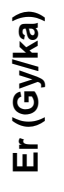 & $\begin{array}{l}\tilde{O} \\
0 \\
0\end{array}$ & $\overline{0}$ & $\overline{0}$ & : & $\stackrel{1}{C}$ & & $\frac{0}{0}$ & $\frac{\nabla}{\sigma}$ & $\frac{\nabla}{\sigma}$ & $\frac{10}{5}$ & $\frac{10}{0}$ & $\frac{N}{\sigma_{0}^{\circ}}$ & $\frac{\nabla}{0^{\circ}}$ & $\frac{N}{\sigma_{0}^{\circ}}$ & $\frac{m}{0}$ \\
\hline 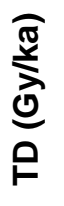 & $\begin{array}{l}\widetilde{N} \\
0 \\
0\end{array}$ & $\begin{array}{l}\text { D } \\
\text { O }\end{array}$ & $\begin{array}{l}\stackrel{\infty}{\sim} \\
\text { N }\end{array}$ & $\stackrel{\overbrace{}}{\stackrel{一}{-}}$ & g & & 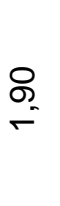 & $\stackrel{\mathscr{S}}{-}$ & $\begin{array}{l}\infty \\
\stackrel{-}{-}\end{array}$ & $\stackrel{\text { g }}{-}$ & $\frac{\infty}{\bar{c}}$ & in & $\stackrel{\mathscr{~}}{-}$ & $\frac{\infty}{\sim}$ & $\underset{\sim}{\stackrel{N}{\tau}}$ \\
\hline$\underset{\text { 山े }}{\underset{\mathrm{J}}{\mathrm{d}}}$ & & & & $\begin{array}{l}\stackrel{0}{1} \\
0\end{array}$ & is & i & $\begin{array}{c}\text { N } \\
\text { o }\end{array}$ & $\begin{array}{l}\infty \\
\text { ల } \\
\sigma^{\prime}\end{array}$ & $\begin{array}{l}\bar{N} \\
\text { Ond }\end{array}$ & $\begin{array}{c}\hat{N} \\
\text { Ò }\end{array}$ & 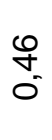 & $\begin{array}{l}\text { P } \\
\text { O) }\end{array}$ & $\begin{array}{l}\stackrel{\sim}{N} \\
\text { On }\end{array}$ & लె & $\stackrel{\stackrel{N}{N}}{\sim}$ \\
\hline 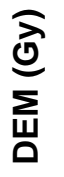 & & & & $\begin{array}{l}\stackrel{2}{0} \\
\stackrel{m}{~}\end{array}$ & خิ & & 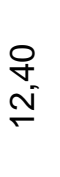 & $\begin{array}{l}\hat{\omega} \\
\stackrel{N}{N}\end{array}$ & $\begin{array}{l}\text { 岇 } \\
\text { L }\end{array}$ & $\begin{array}{l}\bigotimes \\
\stackrel{\infty}{\infty}\end{array}$ & 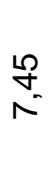 & $\begin{array}{l}\hat{\infty} \\
= \\
\bar{E}\end{array}$ & $\begin{array}{l}\widetilde{N} \\
\text { ஸे }\end{array}$ & $\begin{array}{l}\hat{\omega} \\
\text { en }\end{array}$ & 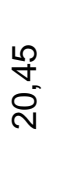 \\
\hline$\underbrace{\underset{\mathrm{J}}{\mathrm{J}}}_{\text {山े }}$ & $\begin{array}{l}\tilde{O} \\
0 \\
0\end{array}$ & $\overline{0}_{0}$ & 今. & ָָ & ล̇ & 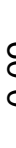 & $\frac{10}{0}$ & $\frac{0}{\circ}$ & $\frac{0}{0}$ & $\bar{\sigma}_{0}$ & $\frac{N}{0}$ & $\bar{\sigma}_{0}$ & $\frac{6}{0}$ & $\frac{L}{0}$ & $\stackrel{\infty}{+}$ \\
\hline $\begin{array}{l}\underset{\mathrm{d}}{\mathrm{J}} \\
\text { 岀 }\end{array}$ & $\begin{array}{l}\bar{N} \\
0 \\
O\end{array}$ & $\frac{0}{0}$ & $\begin{array}{l}\text { f } \\
\text { ó }\end{array}$ & $\begin{array}{l}\infty \\
\stackrel{\infty}{+} \\
\stackrel{+}{+}\end{array}$ & $\begin{array}{l}\vec{b} \\
\alpha \\
\propto\end{array}$ & & $\frac{0}{\frac{0}{N}}$ & $\begin{array}{l}\hat{N} \\
\text { m }\end{array}$ & $\begin{array}{l}\stackrel{9}{\Gamma} \\
=\end{array}$ & 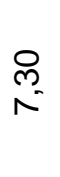 & $\begin{array}{l}\text { ల్ } \\
\text { o' }\end{array}$ & $\begin{array}{l}\stackrel{\Im}{\leftarrow} \\
\stackrel{0}{\sigma}\end{array}$ & $\begin{array}{l}0 \\
\text { L } \\
\end{array}$ & 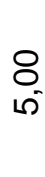 & $\begin{array}{l}\bar{\sigma} \\
\stackrel{1}{\simeq}\end{array}$ \\
\hline $\begin{array}{l}\text { तं } \\
\stackrel{2}{\complement}\end{array}$ & $\nabla$ & $\sigma$ & $\nabla$ & $\stackrel{0}{\circ}$ & $\stackrel{7}{7}$ & 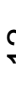 & হ & $\wedge$ & 尺 & ㅇ & $\cong$ & 尺 & $\cong$ & $\sigma$ & 0 \\
\hline$\widehat{\underline{\xi}}$ & $\begin{array}{l}\stackrel{L}{R} \\
0 \\
0\end{array}$ & $\underset{q}{q}$ & $\stackrel{\text { p }}{-}$ & $\begin{array}{l}m \\
m \\
\infty\end{array}$ & $\begin{array}{l}\text { L } \\
\text { L }\end{array}$ & & $\begin{array}{l}\stackrel{m}{\mathscr{H}} \\
\sigma\end{array}$ & $\begin{array}{l}\infty \\
m \\
\omega^{\infty}\end{array}$ & $\frac{n}{\infty}$ & $\begin{array}{l}\mathscr{\bigotimes} \\
0 \\
0\end{array}$ & $\begin{array}{l}\text { S. } \\
\text { దீ }\end{array}$ & $\begin{array}{l}\underset{+}{+} \\
\infty\end{array}$ & $\frac{g}{+}$ & $\begin{array}{l}\text { م) } \\
\text { m. } \\
0\end{array}$ & $\bar{\infty}^{\infty}$ \\
\hline$\frac{\text { o }}{\boldsymbol{\alpha}}$ & $\frac{\circ}{\stackrel{0}{2}}$ & $\begin{array}{l}\text { 음 } \\
\stackrel{0}{2}\end{array}$ & $\begin{array}{l}\text { 음 } \\
\stackrel{0}{2}\end{array}$ & 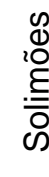 & 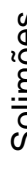 & . & 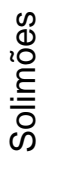 & 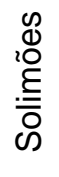 & 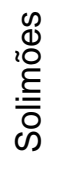 & 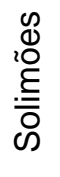 & 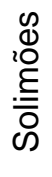 & 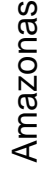 & 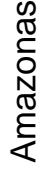 & 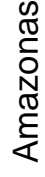 & 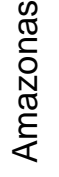 \\
\hline 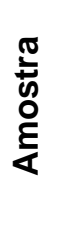 & $\sum_{\text {OD }}^{\infty}$ & $\sum_{\text {CN }}^{\infty}$ & $\begin{array}{l}\text { 응 } \\
\frac{\sum_{0}^{\prime}}{2}\end{array}$ & $\frac{0}{0}$ & $\frac{s}{c}$ & & $\frac{0}{i}$ & $\begin{array}{l}\stackrel{D}{N} \\
\sum_{\text {N }}^{1}\end{array}$ & 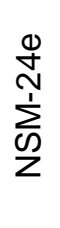 & $\begin{array}{l}\text { Dे } \\
\underset{N}{N} \\
\text { क }\end{array}$ & $\sum_{\frac{D}{2}}^{\stackrel{D}{n}}$ & 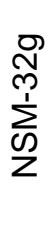 & $\begin{array}{l}8 \\
\stackrel{8}{2} \\
\stackrel{1}{>}\end{array}$ & 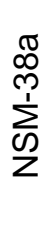 & 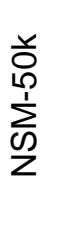 \\
\hline
\end{tabular}


Os sedimentos amostrados nas praias do rio Negro apresentam idades mais jovens $(0,65 \pm 0,07 \mathrm{ka} ; 0,34 \pm 0,04 \mathrm{ka} ; 1,7 \pm 0,26 \mathrm{ka})$, do Holoceno Tardio, se comparados aos sedimentos amostrados nas barras e terraços dos rios Solimões e Amazonas, os quais apresentaram idades entre o Holoceno Tardio $(1,3 \pm 0,21 \mathrm{ka})$ e o final do Pleistoceno $(11,9 \pm 1,18 \mathrm{ka})$.

A partir das idades obtidas para os sedimentos do rio Solimões, foi possível diferenciar duas gerações de barras. A geração mais antiga corresponde ao intervalo

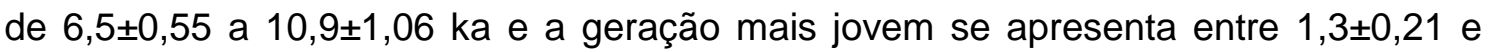
$3,4 \pm 0,32 \mathrm{ka}$. O rio Amazonas também apresenta duas gerações de barras, sendo a mais antiga de $4,7 \pm 0,43$ a $11,9 \pm 1,18 \mathrm{ka}$ e a mais jovem de $1,6 \pm 0,20$ a $1,8 \pm 0,18 \mathrm{ka}$.

A Tabela 6 apresenta os resultados das idades ${ }^{14} \mathrm{C}$ obtidas para fragmentos de madeira encontrados em afloramentos.

\begin{tabular}{|c|c|c|c|c|}
\hline Amostra & Rio & Profundidade $(\mathbf{m})$ & $\begin{array}{c}\text { Idade }{ }^{14} \mathbf{C} \text { bruta } \\
\text { convencional } \\
\text { (ka AP) }\end{array}$ & $\begin{array}{c}\text { Idade }{ }^{14} \mathbf{C} \\
\text { calibrada } \\
\text { (ka cal AP) }\end{array}$ \\
\hline NSM-16LAe & Solimões & 1,60 & $2,5 \pm 0,04$ & $2,7-2,3$ \\
\hline NSM-23b & Solimões & 1,50 & $0,14 \pm 0,03$ & $0,27-0$ \\
\hline NSM-29e & Solimões & 5,44 & $2,6 \pm 0,04$ & $2,8-2,6$ \\
\hline NSM-29i & Solimões & 6,17 & $0,36 \pm 0,03$ & $0,48-0,31$ \\
\hline NSM-38a & Amazonas & 0,35 & $1,1 \pm 0,11$ & $1,2-0,73$ \\
\hline NSM-50k & Amazonas & 8,00 & $7,5 \pm 0,05$ & $8,3-8,0$ \\
\hline
\end{tabular}

Tabela 6. Resultados das idades ${ }^{14} \mathrm{C}$ obtidas em fragmentos vegetais dos sedimentos dos rios Solimões e Amazonas.

As amostras NSM-16LAe (2,7-2,3 ka cal AP) e NSM-23b (0,27-0 ka cal AP), datadas por ${ }^{14} \mathrm{C}$, se encontram em níveis estratigráficos acima das amostras NSM16LAj $(7,1 \pm 0,67 \mathrm{ka})$ e NSM-23e $(1,3 \pm 0,21 \mathrm{ka})$, que foram datadas por LOE. Deste modo, as idades ${ }^{14} \mathrm{C}$ e LOE estão concordantes com a sequência normal de deposição.

No afloramento NSM-29 do rio Solimões, a amostra com profundidade de 6,63 $\mathrm{m}$ apresentou idade de $1,8 \pm 0,19$ ka (NSM-29k), sobreposta pela amostra NSM-29i $(6,17 \mathrm{~m})$ com $0,48-0,31 \mathrm{ka}$ cal AP e pela amostra NSM-29e com profundidade de 5,44 $\mathrm{m}$ e idade de 2,8-2,6 ka cal AP. Observa-se inversão nas idades obtidas nesse afloramento.

No ponto NSM-38, foram datadas amostras pelos métodos LOE $(1,6 \pm 0,20 \mathrm{ka})$ e ${ }^{14} \mathrm{C}(1,2-0,73 \mathrm{ka}$ cal AP) com a profundidade de 0,35 $\mathrm{m}$. No afloramento NSM-50,

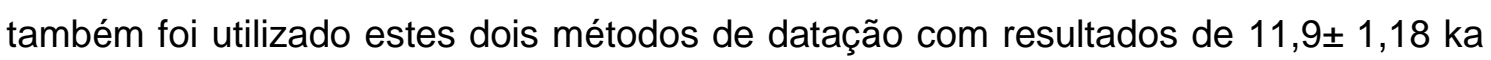


para a idade LOE e 8,3-8,0 ka cal AP para a idade ${ }^{14} \mathrm{C}$. As idades obtidas por ${ }^{14} \mathrm{C}$ se revelaram inferiores em relação às adquiridas por LOE.

\section{DISCUSSÃo}

\subsection{Dinâmica sedimentar e proveniência das areias dos rios Negro, Solimões e Amazonas}

Os resultados obtidos na geomorfologia e nas análises de fácies, granulometria e sensibilidade LOE possibilitaram caracterizar e diferenciar a dinâmica sedimentar e a proveniência dos sedimentos dos rios Negro, Solimões e Amazonas.

As margens do rio Negro são compostas por extensas praias formadas pela ação das ondas que propiciam a acumulação de sedimentos mais grossos nas partes mais rasas e sedimentos mais finos nas zonas mais profundas. Disso resultam barras com intercalações decimétricas de fácies de areia média e grossa, ambas bem selecionadas, com níveis de seixos. Já os rios Solimões e Amazonas são constituídos por barras localizadas nas margens e nas porções centrais dos canais, formadas pela alta carga sedimentar e fluxo d'água desses rios, o que favorece a deposição de intercalações decimétricas de fácies de areia fina a média com estratificação cruzada e lama com laminação heterolítica.

Os dados obtidos destacam domínio dos sedimentos do rio Solimões no rio Amazonas, uma vez que apresentam valores de sensibilidade LOE próximos, assim como porcentagens e diâmetro médio das frações areia e silte das suas barras em relação aos valores do rio Negro.

O rio Negro tem sua nascente na Colômbia e apresenta ampla bacia de captação de sedimentos. Porém, este rio apresenta redução de fluxo na confluência com o rio Branco e na região das Ilhas Anavilhanas, o que desfavorece a deposição de sedimentos vindos de montante. Como consequência, a velocidade do fluxo d'água na sua foz é baixa, assim como sua carga sedimentar anual total e sua vazão em relação ao rio Amazonas (Dunne et al., 1998). Com isso, a proveniência dos sedimentos das barras do baixo curso do rio Negro, à jusante de Anavilhanas, seria dominada por fontes proximais, representadas principalmente pelos arenitos cretáceos da Formação Alter do Chão, localizados nas áreas adjacentes às margens do rio. Esta hipótese é compatível com os dados de sensibilidade LOE, os quais apresentaram forte correlação entre os arenitos da Formação Alter do Chão e as areias das praias desse rio. Deste modo, provavelmente os arenitos da Formação Alter do Chão foram 
retrabalhados na formação das praias, representando a principal área fonte desses sedimentos.

Os sedimentos do rio Negro possuem grãos de quartzo com maior sensibilidade LOE e menor quantidade de feldspatos em relação às areias dos rios Solimões e Amazonas, tanto nos sedimentos de calha como nos das barras. Como foi constatado que os arenitos da Formação Alter do Chão correspondem à área fonte dos sedimentos arenosos do rio Negro, o grau de retrabalhamento mais elevado destas areias indicado pela sensibilidade LOE (Pietsch et al., 2008; Sawakuchi et al., 2011) estaria relacionado ao retrabalhamento pretérito desses arenitos. Isso explicaria a maior sensibilidade LOE e menor quantidade de feldspatos das areias do rio Negro, apesar da origem proximal, em relação às areias dos rios Solimões e Amazonas.

A porcentagem e diâmetro médio da fração areia das barras do rio Negro $(70,65 \%$ e $375,76 \mu \mathrm{m}$, respectivamente) são superiores aos valores observados nas barras dos rios Solimões (50,52\% e 154,58 $\mu \mathrm{m})$ e Amazonas (46,87\% e 134,36 $\mu \mathrm{m})$. Este contraste textural das areias do rio Negro pode ser explicado pela redução de fluxo á jusante de Anavilhanas. Isto aumenta a largura do rio, dando um aspecto de lago na sua foz, que favorece a ação de ondas na superfície. O efeito das ondas propicia a acumulação dos sedimentos arenosos nas porções mais rasas (média de $70 \%$ de areia nas barras do rio Negro) e dos sedimentos lamosos nas porções mais profundas do canal (média de 59\% de silte no canal do rio Negro).

A ausência de barramentos e de complexos de barras ao longo do rio Solimões favorece alta vazão $(102.340 \mathrm{~m} 3 / \mathrm{s})$ e alta concentração de sedimentos em suspensão $\left(209 \mathrm{~g} / \mathrm{m}^{3}\right.$ ) (Mangiarotti et al., 2013). Isso propicia origem distal para os sedimentos desse rio. Os sedimentos das barras dos rios Solimões e Amazonas apresentam maiores porcentagens médias de silte $(40,63 \%$ e $44,24 \%$, respectivamente) do que os do rio Negro (20,36\%). Os grãos de quartzo das areias dos rios Solimões e Amazonas apresentam sensibilidade LOE menor que os grãos do rio Negro e elevada quantidade de feldspatos. Apesar da origem distal, as areias dos rios Solimões e Amazonas possuem baixo grau de retrabalhamento. Isso pode ser explicado pela tendência bypass do rio Solimões e transporte relativamente rápido da cabeceira até a foz. $O$ que favorece para que os sedimentos desse rio continuem composicionalmente imaturos na foz, com baixa sensibilidade e elevada quantidade de feldspatos, apesar da longa distância percorrida.

Os sedimentos das barras do rio Solimões apresentam maior proporção de feldspatos do que os sedimentos da calha. Isso demonstraria maior retrabalhamento dos sedimentos da calha desse rio. Já os sedimentos do rio Amazonas possuem menor quantidade de feldspatos nas areias de barra do que nas areias da calha. Isto 
evidencia a maior contribuição dos sedimentos de calha do rio Solimões na formação das barras do rio Amazonas.

O rio Negro apresenta maior porcentagem na formação do rio Amazonas nos sedimentos de calha (11,91\% para sensibilidade LOE e $24,73 \%$ para sensibilidade IR) do que nos areias das barras (1,76\% para sensibilidade LOE). Isto ocorre devido à granulação mais grossa dos sedimentos do rio Negro. Ao adentrarem no rio Amazonas, esses sedimentos serão acumulados junto com as areias mais grossas presentes na calha, já que o topo das barras do rio Amazonas é caracterizado por granulometria mais fina.

\subsection{Idades e tempo de estocagem de sedimentos nos rios Negro, Solimões e Amazonas}

O fotoesvaziamento incompleto do sinal de luminescência durante a deposição resulta em idades superestimadas e pode ser problema para a datação de amostras fluviais (Olley et al., 2004). O fotoesvaziamento parcial do sinal de luminescência é comum em ambientes fluviais por diversas razões (Rittenour, 2008). A exposição solar do sedimento transportado pelo fluxo de água do rio é limitada pela redução da entrada de luz através da coluna de água, principalmente no caso de águas turvas com alta carga sedimentar em suspensão (Rittenour, 2008). Outros fatores importantes que controlam o fotoesvaziamento dos sedimentos fluviais estão relacionados com a profundidade da lâmina d'água, o modo de transporte dos sedimentos (suspensão ou saltação) e a distância de transporte. Em sistemas fluviais, é comum a entrada de sedimentos com fotoesvaziamento incompleto pela erosão de depósitos antigos das margens dos rios, o que também contribui para a mistura de grãos com fotoesvaziamento variável. Além disso, inundações, tempestades e outros eventos de alta descarga causam rápida erosão e transporte de sedimentos, limitando, do mesmo modo, sua exposição solar (Rittenour, 2008).

Nas amostras de sedimentos dos rios Solimões e Amazonas, foi possível observar o fotoesvaziamento incompleto devido à elevada dispersão das doses equivalentes. Nesses rios, isso estaria relacionado principalmente à sua alta carga sedimentar em suspensão que impede a entrada de luz através da coluna de água. Além disso, estes rios apresentam considerável taxa de erosão devido à alta velocidade da sua corrente, o que contribui para a mistura de sedimentos com diferentes graus de fotoesvaziamento e ciclos deposicionais, tendo como consequência a dispersão das doses equivalentes entre as alíquotas da mesma amostra. A tendência erosiva dos trechos estudados nos rios Solimões e Amazonas é 
confirmada pelo predomínio de escarpas nos terraços adjacentes ao canal. Já as amostras de sedimentos do rio Negro apresentam maior fotoesvaziamento em relação aos sedimentos dos rios Solimões e Amazonas, o que pode ser explicado pela sua menor carga sedimentar em suspensão e velocidade de corrente. Além disso, a ação das ondas no rio Negro provoca o transporte dos sedimentos por correntes em zona mais rasa, propiciando o fotoesvaziamento completo.

Métodos de luminescência têm sido propostos para diminuir a influência do fotoesvaziamento parcial sobre os valores de dose equivalentes necessários para os cálculos de idade. O primeiro grupo de métodos utiliza os múltiplos componentes do sinal LOE do quartzo para isolar e datar as armadilhas mais fotossensíveis ( $\mathrm{Li} \& \mathrm{Li}$, 2006). Um segundo grupo de métodos aproveita avanços recentes na técnica LOE que conduziram á medição de alíquotas cada vez menores, culminando no desenvolvimento da técnica de datação single-grain (Duller, 2008b).

Em amostras com fotoesvaziamento incompleto, análises de grandes alíquotas de areia podem produzir idades superestimadas a partir da contribuição de grãos nãofotoesvaziados no sinal total medido (Porat et al., 2008). Alíquotas pequenas com 100 grãos e a datação single-grain permitem que a idade de soterramento verdadeira da amostra seja isolada pela identificação da população de grãos com fotoesvaziamento completo durante a deposição. Resultados de single-grain geralmente demonstram distribuições de doses equivalentes com assimetria positiva, sendo que a população mais jovem representa os grãos totalmente fotoesvaziados na deposição (Rittenour, 2008).

Devido à grande dispersão de resultados de doses equivalentes na análise de grãos individuais, foram desenvolvidos métodos estatísticos para isolar grãos ou alíquotas representativos da idade de soterramento relacionada ao último evento de deposição (Rittenour, 2008). Esses métodos incluem o Central Age Model (CAM), Minimum Age Model (MAM) e Finite Mixture Model (FMM) (Galbraith et al., 1999; Galbraith, 2005). A escolha dos métodos estatísticos é diferente para cada amostra e depende dos mecanismos dominantes que afetam a dispersão das doses equivalentes: fotoesvaziamento incompleto, mistura pós-deposicional ou taxa de dose heterogênea (Bailey \& Arnold, 2006). Para as amostras do rio Negro, foi utilizado o Central Age Model (CAM) devido à baixa dispersão dos seus dados, evidenciando um fotoesvaziamento completo dos seus grãos. Já para as amostras dos rios Solimões e Amazonas, foi utilizado o modelo de idade MAM, que é adequado para amostras com fotoesvaziamento incompleto, que apresentam distribuições de dose equivalente com alta dispersão. 
$\mathrm{Na}$ Amazônia foram realizadas poucas datações em sedimentos quaternários. Datações por ${ }^{14} \mathrm{C}$ são escassas devido à falta de material orgânico (Latrubesse \& Franzinelli, 2002; Rossetti et al., 2005). Datações LOE foram realizadas em paleodunas eólicas no médio rio Negro (Carneiro-Filho et al., 2002) e na região da confluência dos rios Negro e Solimões (Soares et al., 2010), seguindo protocolos de alíquotas múltiplas (MAR) e únicas (SAR). O protocolo MAR é considerado inadequado para estimativa de doses em amostras naturais, sendo muito pouco utilizado em relação ao SAR. As idades obtidas por Soares et al. (2010) por meio do método SAR variam de $1,6 \pm 0,1 \mathrm{ka}$ a $65,0 \pm 2,4 \mathrm{ka}$.

Com as idades obtidas pelo método LOE neste estudo foi constatado tempo de estocagem mínimo para as areias de barras expostas durante a seca do rio Negro no Holoceno tardio $(0,65 \pm 0,07 ; 0,34 \pm 0,04 ; 1,7 \pm 0,26 \mathrm{ka})$ e para as areias dos rios Solimões e Amazonas entre o Holoceno tardio $(1,3 \pm 0,21 \mathrm{ka})$ e o final do Pleistoceno $(11,9 \pm 1,18 \mathrm{ka})$.

A geometria interna das barras dos rios Solimões e Amazonas permitiu comparar a direção da migração dos cordões de crescimento das barras com as idades de deposição obtidas (Figura 61). 


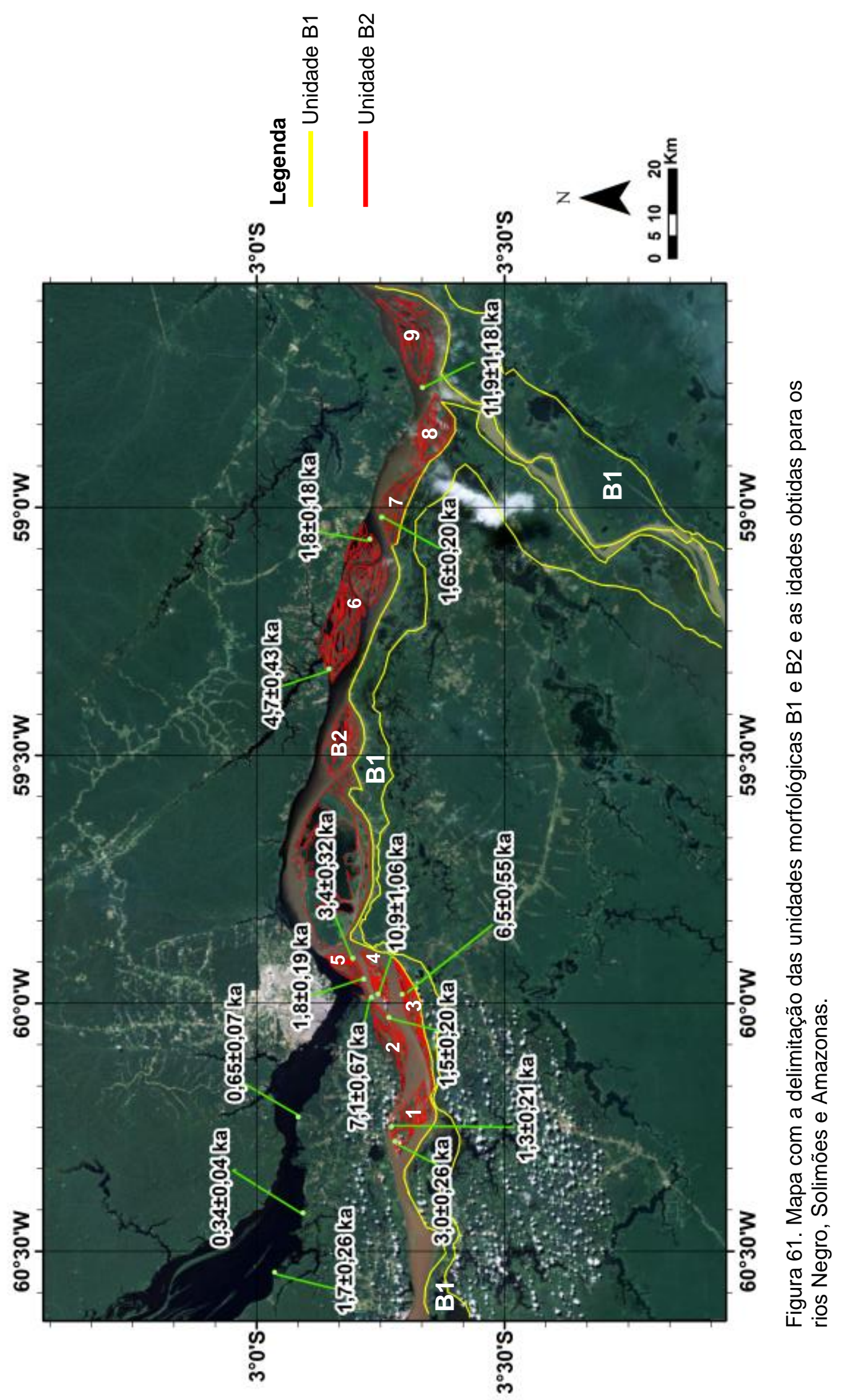


As idades obtidas na barra 1 estão coerentes com a direção (W para E) de crescimento da primeira geração de cordões dessa barra, localizada na sua parte oeste (Figura 62). A linha de crescimento mais a leste apresenta idade mais jovem $(1,3 \pm 0,21 \mathrm{ka})$ em relação à situada mais à oeste $(3,0 \pm 0,26 \mathrm{ka})$. A amostra mais jovem foi coletada a 5,38 $\mathrm{m}$ de profundidade. Neste mesmo afloramento (NSM-23), foi datado fragmento de material vegetal por ${ }^{14} \mathrm{C}$ coletado a uma menor profundidade $(1,5 \mathrm{~m}), \mathrm{o}$ qual resultou em idade de 0,27-0 ka cal AP. Isso demonstra boa correlação entre as idades LOE e ${ }^{14} \mathrm{C}$ e valida o protocolo de estimativa de dose usado neste estudo.

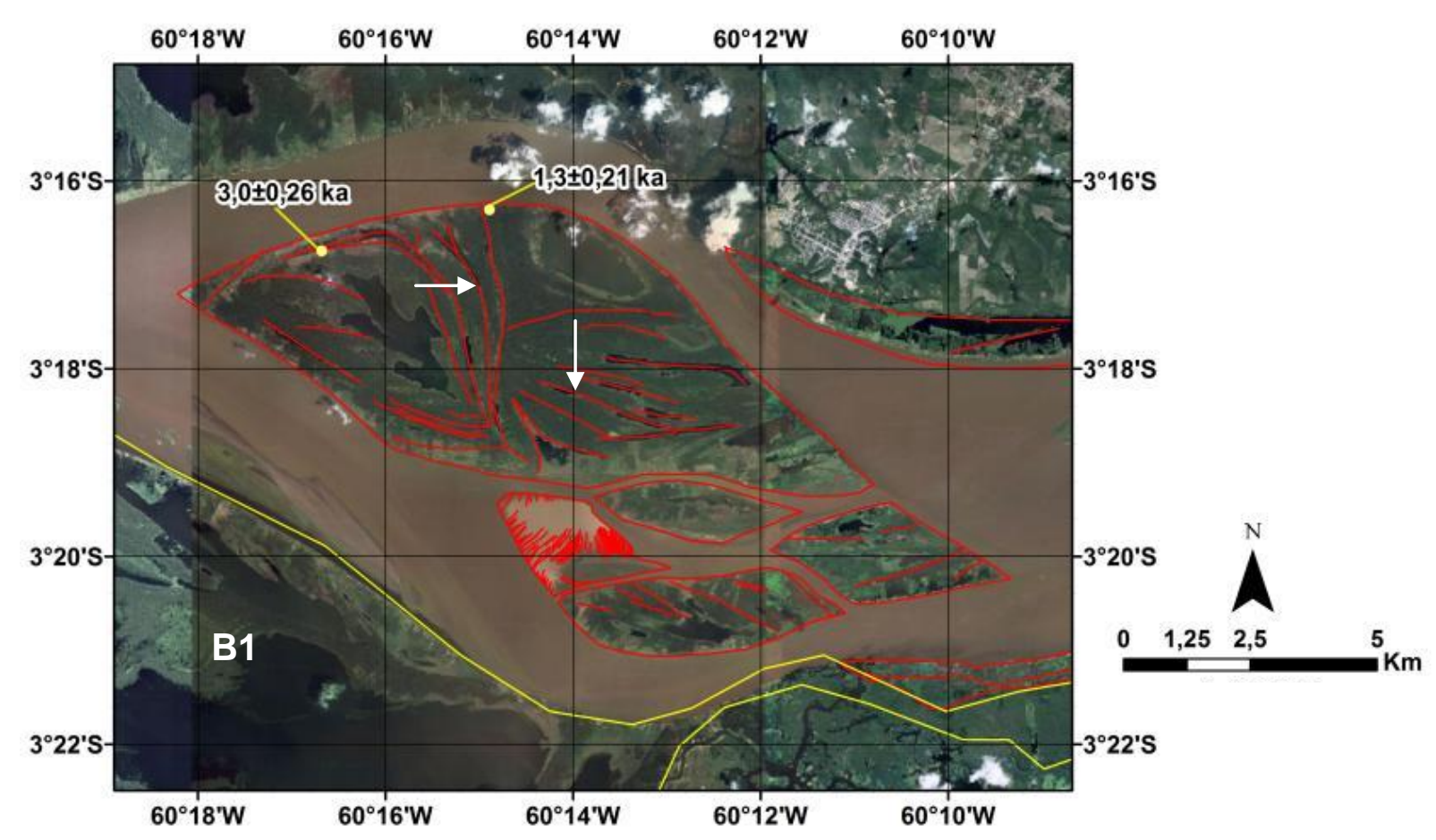

Figura 62. Cordões de crescimento (em vermelho) da barra $1 \mathrm{com}$ as idades LOE obtidas dos pontos NSM-23e $(1,3 \pm 0,21 \mathrm{ka})$ e NSM-24e $(3,0 \pm 0,26 \mathrm{ka})$.

A amostra datada da barra 2 apresenta idade de 1,5 $\pm 0,20$ ka por estar localizada na geração mais jovem de cordões que acompanha a margem do rio Solimões e cresce para SSE. Já nas barras 3, 4 e 5, as amostras datadas estão localizadas nas gerações mais interiores de cordões, sendo que na barra 3 a direção de migração é para SSE (Figura 63). Com isso, as idades obtidas das barras 3, 4 e 5 se revelaram mais antigas $(6,5 \pm 0,55 ; 10,9 \pm 1,06$ e 7,1 $1 \pm 0,67 \mathrm{ka}$; respectivamente) em

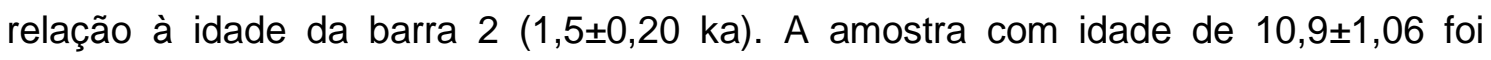
coletada a 8,33 $\mathrm{m}$ de profundidade. Neste mesmo afloramento (NSM-16), foi datado material orgânico por ${ }^{14} \mathrm{C}(2,7-2,3 \mathrm{ka}$ cal AP) a 1,60 $\mathrm{m}$ de profundidade ressaltando a coerência estratigráfica dos resultados obtidos pelos métodos LOE e ${ }^{14} \mathrm{C}$. 


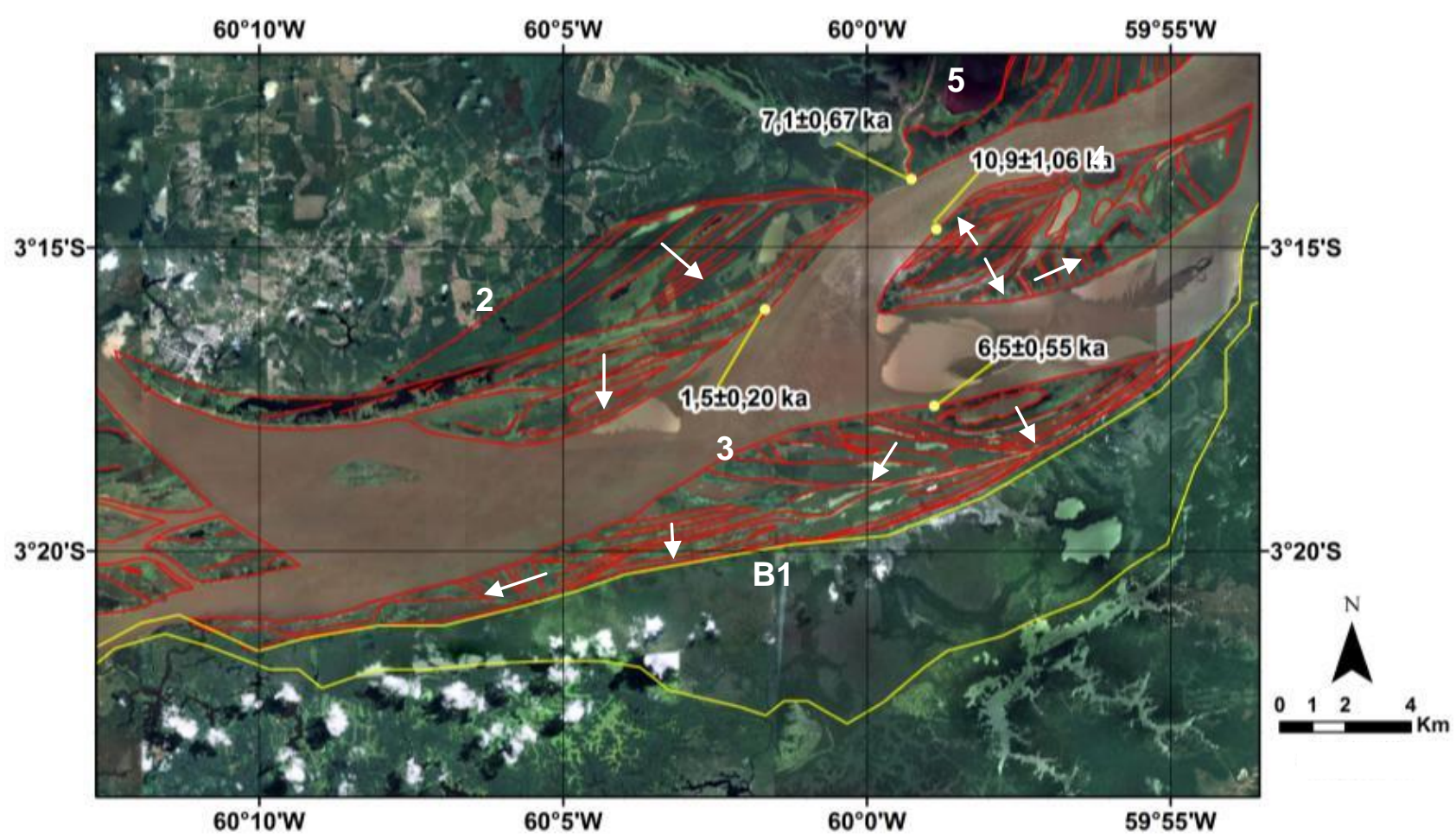

Figura 63. Cordões de crescimento das barras 2, 3 e 4 (em vermelho) e as idades LOE obtidas

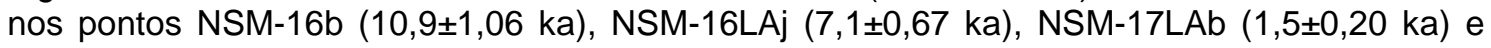
NSM-21b $(6,5 \pm 0,55 \mathrm{ka})$.

A idade obtida na parte nordeste da barra $5(3,4 \pm 0,32 \mathrm{ka})$ equivale provavelmente ao núcleo da barra (Figura 64) enquanto que a idade adquirida na área central dessa barra $(1,8 \pm 0,19 \mathrm{ka})$ corresponderia aos cordões mais externos.

Datações por ${ }^{14} \mathrm{C}$ foram realizadas no afloramento $\mathrm{NSM}-29$ e revelaram inversão estratigráfica de idades (NSM-29i a 6,17m com 0,48-0,31 ka cal AP e NSM29 e a 5,44 $\mathrm{m}$ e idade de 2,8-2,6 ka cal AP). Isto pode ser explicado pela possibilidade das amostras datadas por ${ }^{14} \mathrm{C}$ corresponder a restos de raízes ou material infiltrado, já que as idades LOE são aparentemente robustas.

Com os resultados de datação obtidos, é possível afirmar que o rio Negro foi barrado há pelo menos $7,1 \pm 0,67$ ka e que o encontro dos rios Negro e Solimões estava localizado mais a sudoeste em relação à confluência atual. 


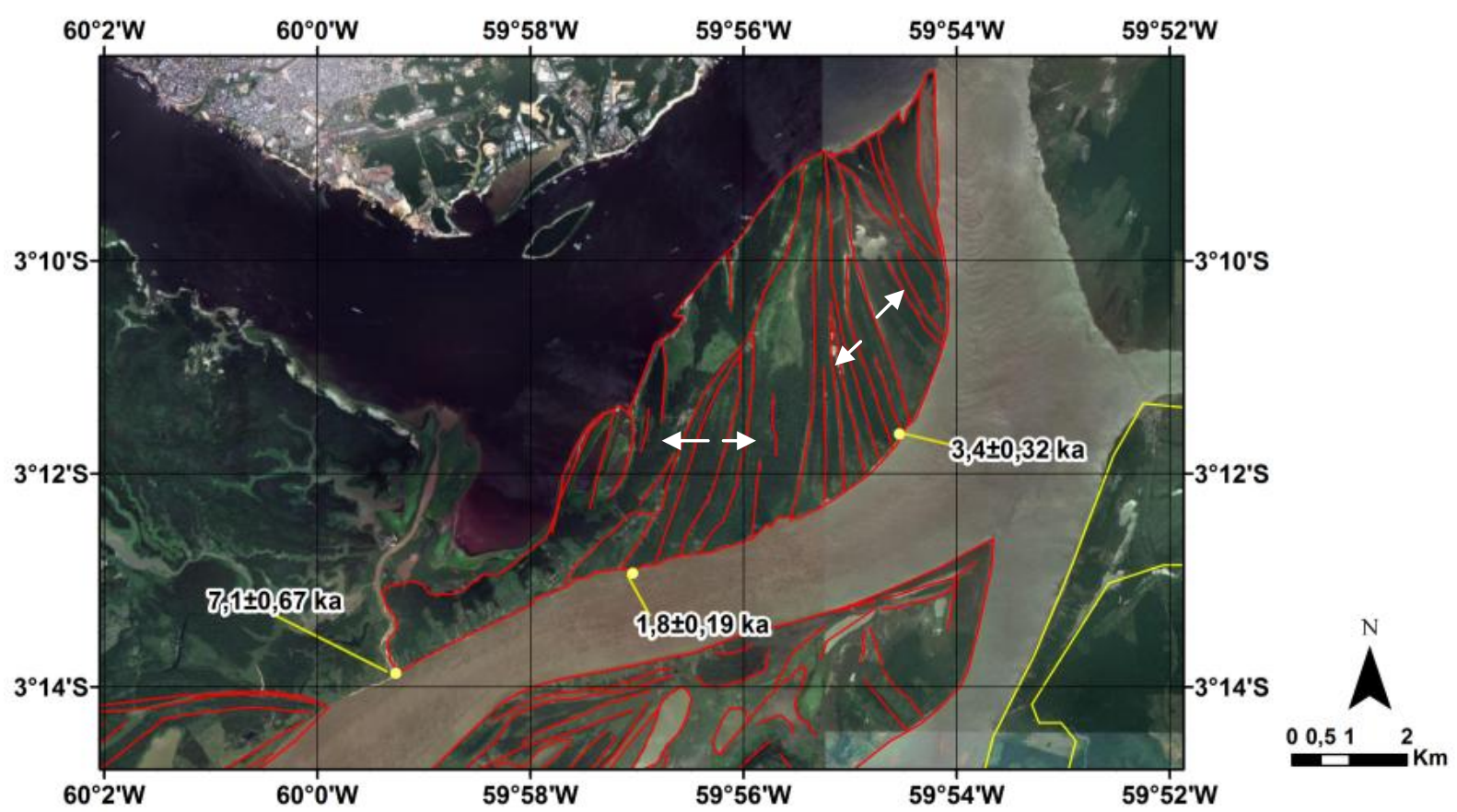

Figura 64. Cordões de crescimento da barra 5 (em vermelho) e as idades obtidas dos pontos

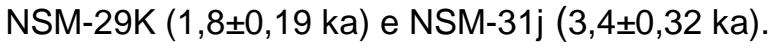

Dentro do complexo de barras do Paraná da Eva no rio Amazonas (unidade 6 na Figura 65) foram datadas duas amostras. A idade mais antiga $(4,7 \pm 0,43 \mathrm{ka})$ corresponde à barra próxima à desembocadura do rio Preto da Eva, com migração para NE, localizada adjacente ao substrato. A amostra mais jovem $(1,8 \pm 0,18 \mathrm{ka})$, localizada no outro extremo do Paraná da Eva, apresenta migração para SE.

A barra 7, com migração para NE, apresenta idade LOE de 1,6 $\pm 0,20$ ka e idade ${ }^{14} \mathrm{C}$ de $1,2-0,73 \mathrm{ka}$ cal AP na mesma camada (NSM-38a a 0,35 m de profundidade). Essas amostras evidenciam correlação relativamente boa entre os dois métodos de datação. As amostras da barra 9 do rio Amazonas (NSM-50) apresentaram idade de $11,9 \pm 1,18 \mathrm{ka}$ a $7,81 \mathrm{~m}$ de profundidade pelo método LOE e idade de 8,3-8,0 ka cal AP a $8 \mathrm{~m}$ pelo método de ${ }^{14} \mathrm{C}$. Apesar da diferença, as idades são similares se considerado o erro, sendo que os valores da idade LOE são levemente superestimados em relação às idades ${ }^{14} \mathrm{C}$.

$\mathrm{O}$ fato de idades LOE se apresentarem relativamente mais antigas que as idades ${ }^{14} \mathrm{C}$ em uma mesma camada deposicional pode ser explicado por fotoesvaziamento incompleto do sedimento. A idade LOE superestimada em relação à idade ${ }^{14} \mathrm{C}$ provavelmente corresponde à mistura de sedimentos com fotoesvaziamento variável. Durante o transporte dos rios Solimões e Amazonas, os grãos sofreram fotoesvaziamento incompleto devido à elevada carga sedimentar desses rios que impede a passagem da luz solar. Com isso, os grãos conservariam a dose equivalente 
adquirida em soterramento prévio a montante. Deste modo, a idade obtida desses sedimentos estaria parcialmente relacionada à barra antecessora e não somente à barra atual. Assim, no caso das amostras NSM-38a e NSM-50k, a estimativa máxima da idade de posição dessas barras corresponde aos resultados de ${ }^{14} \mathrm{C}(1,2-0,73 \mathrm{ka}$ cal AP e 8,3-8,0 ka cal AP, respectivamente). Teoricamente, a idade calculada pelo MAM corresponderia à idade mínima da barra antecessora. Porém, o número reduzido de alíquotas torna o MAM com baixa confiabilidade estatística. A diferença entre as idades LOE e ${ }^{14} \mathrm{C}$ seria estimativa do tempo de residência dos sedimentos em zona submersa, sendo aproximadamente 0,4 ka para a amostra NSM-38a e 3 ka para a amostra NSM-50k.

Outra possível explicação para a idade LOE obtida estar superestimada em relação à idade ${ }^{14} \mathrm{C}$ seria que o fragmento de material orgânico coletado poderia corresponder a pedaços de raízes de árvores formadas posteriormente à deposição da camada correspondente. 


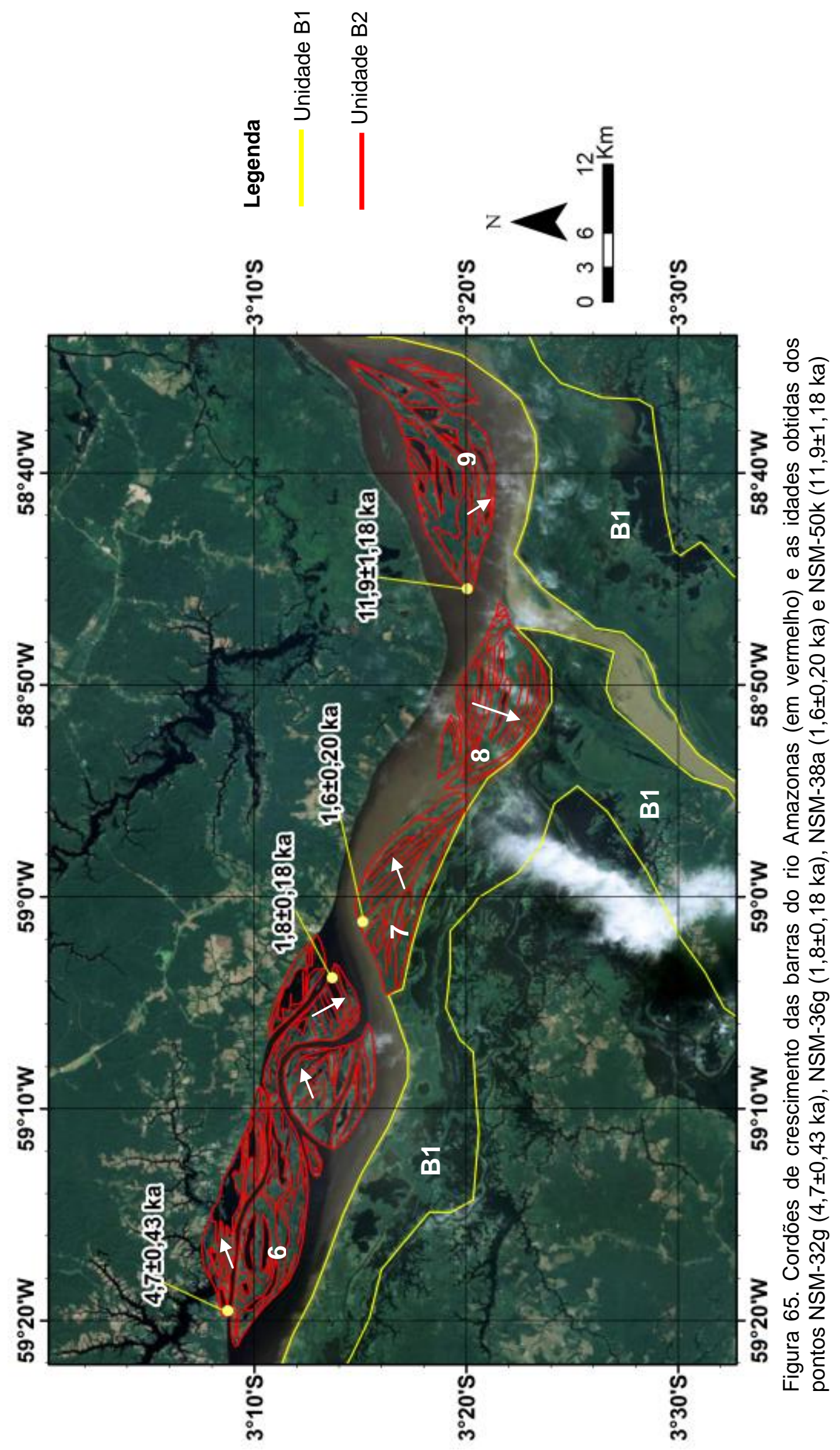




\subsection{Fatores que controlam a acumulação e erosão de sedimentos fluviais e sua relação com as idades de deposição obtidas}

A acumulação e erosão dos sedimentos fluviais são controladas pela variação do nível de base, velocidade do fluxo de água do rio e pelo volume da carga sedimentar em suspensão e de fundo.

O aumento significativo do nível de base ocorre quando há aumento do nível do mar, proporcionando a retenção de sedimentos do rio, o que favorece a deposição e formação de barras. Estudos realizados para o Suriname, região próxima à foz do rio Amazonas, propõem fim da subida abrupta do nível do mar há aproximadamente $7 \mathrm{ka}$, com estabilização e queda gradual a partir dos 6 ka (Milne et al., 2005).

A velocidade do fluxo de água e o volume da carga sedimentar em suspensão são controlados principalmente pela variação na precipitação e pela susceptibilidade á erosão, influenciada pelo relevo e pela cobertura vegetal. Eventos extremos de precipitação provocam o aumento da velocidade do fluxo do rio, que favorece a denudação das rochas localizadas em suas cabeceiras elevando assim o volume da carga sedimentar em suspensão. Estudos com registros de $\delta^{18} \mathrm{O}$ em espelotemas nos Andes peruanos (Van Breukelen et al., 2008; Kanner et al., 2012) relatam variações de precipitação durante o Quaternário tardio. Os Andes peruanos localizam-se próximos às cabeceiras do rio Solimões, onde estes trabalhos apontam importante ocorrência de precipitação extrema em 16 ka relacionado ao evento Heinrich 1, com diminuição gradual das chuvas a partir dessa idade, demonstrando uma tendência média milenar (Kanner et al., 2012). Este evento pode ter contribuído para o aumento da velocidade do fluxo de água e do volume da carga sedimentar em suspensão dos rios Solimões e Amazonas, propiciando a intensificação do crescimento das barras a jusante.

Outros estudos em espeleotemas dos Andes peruanos destacam eventos extremos de precipitação de curta duração. Estas pesquisas apontam aumento abrupto na precipitação a partir de $9 \mathrm{ka}$, até chegar ao valor atual de $1500 \mathrm{~mm} / \mathrm{ano}$ (Van Breukelen et al., 2008).

A correlação entre eventos de precipitação e as idades obtidas (Figura 66) revelou maior acúmulo de sedimentos em períodos com alta frequência de eventos extremos de chuvas depois de $5 k$ a atrás. 


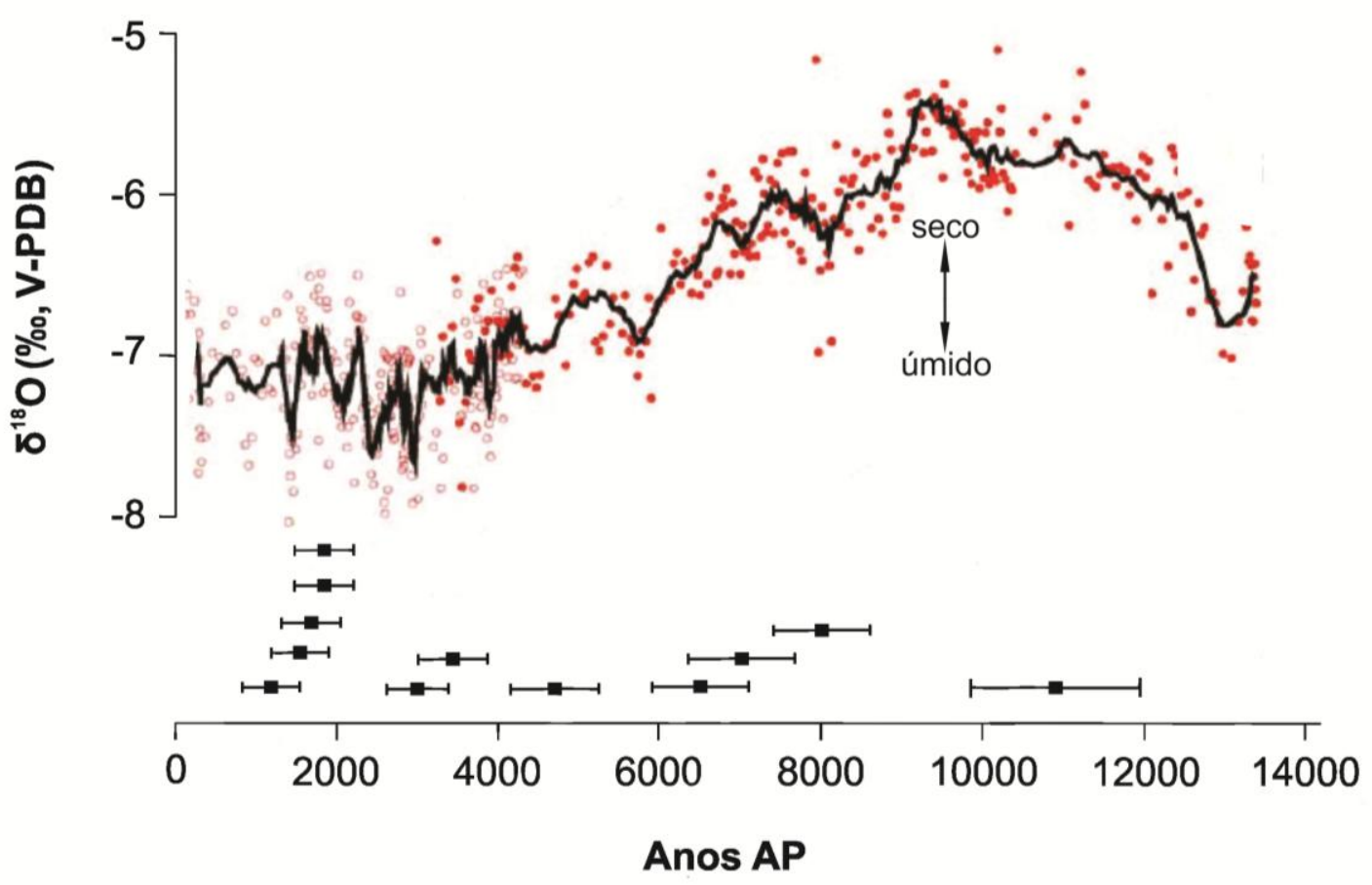

Figura 66. Comparação das idades de crescimento das barras dos rios Solimões e Amazonas (quadrados pretos) com os registros de $\delta^{18} \mathrm{O}$ em espelotemas dos Andes peruanos (curva preta que representa a média de 11 pontos dos dados de $\delta^{18} \mathrm{O}$ ). Modificado de Van Breukelen et al. (2008). 


\section{CONCLUSÕES}

O rio Negro apresenta extensas praias em suas margens, caracterizadas por intercalações decimétricas de fácies de areia média e grossa. Os rios Solimões e Amazonas exibem barras ao longo das margens e do canal, compostas por intercalações decimétricas de fácies de areia fina a média com estratificação cruzada e lama com laminação heterolítica.

As barras do rio Negro possuem maiores porcentagem e diâmetro médio da fração areia em relação aos sedimentos dos rios Solimões e Amazonas devido à ação das ondas na superfície do rio Negro.

Os arenitos da Formação Alter do Chão são a principal área fonte das areias das praias do rio Negro. A maior sensibilidade LOE registrada nos sedimentos do rio Negro, em relação aos dos rios Solimões e Amazonas, está relacionada com o retrabalhamento pretérito desses arenitos.

As areias dos rios Solimões e Amazonas apresentam elevada quantidade de feldspatos se comparadas com as areias do rio Negro, o que indica retrabalhamento sedimentar reduzido sofrido pelos primeiros. Os sedimentos do rio Solimões prevalecem no rio Amazonas em relação às areias oriundas do rio Negro. Os sedimentos do rio Negro se acumulam principalmente na calha do rio Amazonas.

O tempo de estocagem mínimo dos sedimentos de barras do rio Negro corresponde ao Holoceno tardio $(0,65 \pm 0,07 ; 0,34 \pm 0,04 ; 1,7 \pm 0,26 \mathrm{ka})$ e para as areias dos rios Solimões e Amazonas está entre o Holoceno tardio $(1,3 \pm 0,21 \mathrm{ka})$ e o final do Pleistoceno $(11,9 \pm 1,18 \mathrm{ka})$.

A comparação das idades adquiridas pelos métodos LOE e ${ }^{14} \mathrm{C}$ se revelaram satisfatórias, validando o protocolo de estimativa de dose usado neste estudo. Porém, em determinadas amostras, a idade LOE apresentou-se levemente superestimada.

As idades de formação das barras dos rios Solimões e Amazonas estariam relacionadas com eventos de precipitação extrema a partir do Holoceno médio identificados em estudos com registros de $\delta^{18} \mathrm{O}$ em espelotemas nos Andes peruanos. 


\section{REFERÊNCIAS BIBLIOGRÁFICAS}

Archer, A.W. 2005. Review of Amazonian depositional systems. In: Blum, M., Marriott, S., Leclair, S. (eds) Fluvial Sedimentology VII. Special Publication of the International Association of Sedimentologists, vol. 35, pp. 17-39.

Bailey, R. M. \& Arnold, L. J. 2006. Statistical modeling of single grain quartz De distributions and an assessment of procedures for estimating burial dose. Quaternary Science Reviews 25, 2475-2502.

Baker, P.A.; Seltzer, G.O.; Fritz, S.C.; Dunbar, R.B.; Grove, M.J.; Tapia, P.M.; Cross, S.L.; Rowe, H.D.; Broda, J.P.; 2001. The history of South America tropical precipitation for the past 25,000 years. Science 291, 640-643.

Behling, H.; Keim G.; Irion, G.; Junk, W.; Mello, J.N. 2001. Holocene environmental changes in the Central Amazon Basin inferred from Lago Calado (Brazil). Palaeogeography, Palaeoclimatology, Palaeoecology, v. 173, p. 87-101.

Bookhagen, B. \& Strecker, M.R. 2010. Modern Andean rainfall variation during ENSO cycles and its impact on the Amazon drainage basin. In: Hoorn,C.; Wesselingh,F.P. (eds.). Amazonia: landscape and species evolution. A look into the past. Wiley-Blackwell, Oxford, pp. 223-242.

Buylaert, J.P.; Murray, A.S.; Thomsen; K.J.; Jain, M. 2009. Testing the potential of an elevated temperature IRSL signal from K-feldspar. Radiation Measurements 44, 560-565.

Caputo, M.V. 2011. Discussão sobre a Formação Alter do Chão e o Alto de Monte Alegre. Contribuições à Geologia da Amazônia, vol.7, p.7-23.

Carneiro-filho, A.; Schwartz D.; Tatumi, S.H.; Rosique, T. 2002. Amazonian paleodunes provide evidence for drier climate phases during the Late Pleistocene-Holocene. Quat Res 58: 205-209.

Cheng, H.; Sinha, A.; Cruz, F.W.; Wang, X.; Edwards, R.L.; d’Horta, F.M.; Ribas, C.C.; Vuille, M.; Stott, L.D.; Auler, A. S. 2013. Climate change patterns in Amazonia and biodiversity. Nature Communications, 4, 1411. 
Cordeiro, R.C.; Turcq, B.; Sifeddine, A.; Lacerda, L.D.; Silva Filho, E.V.; Gueiros, B.; Potty, Y.P. 2011. Biogeochemical indicators of environmental changes from 50 $\mathrm{Ka}$ to $10 \mathrm{Ka}$ in a humid region of the Brazilian Amazon. Palaeogeography, Palaeoclimatology, Palaeoecology 299, 426-436.

Duller, G.A.T. 2004. Luminescence dating of Quaternary sediments: recent advances. Chichester: Journal of Quaternary Science, 19:183-192.

Duller, G.A.T. 2008a. Luminescence dating: Guidelines on using luminescence dating in archaeology. Swindon: English Heritage. 43p.

Duller, G. A. T. 2008b. Single-grain optical dating of Quaternary sediments why aliquot size matters in luminescence dating. Boreas 37, 589-612.

Dunne, T.; Mertes, L.A.K.; Meade, R.H.; Richey, J.E.; Forsberg, B.R. 1998. Exchange of sediments between the floodplain and channel of the Amazon River in Brazil. Geol. Soc. Am. Bull. 110, 450- 467.

Faria, M.S.G.; Bahia, R.; Almeida, M.E.; Oliveira, M.A. 2004. Folha SA-20-Manaus e Folha SA-21-Santarém. In: Schoblenhaus, C.; Gonçalves, J.H.; Santos, J.O.S.; Abram, M.B.; Leão Neto, R.; Matos, G.M.M.; Vidotti, R.M.; Ramos, M.A.B.; Jesus, J.D.A. (eds.). Carta Geológica do Brasil ao Milionésio, Sistema de Informações Geográficas. Programa Geologia do Brasil. CPRM, Brasília. CDROM.

Franzinelli, E. \& Igreja, H.L.S. 2002. Modern sedimentation in the Lower Negro river, Amazonas State, Brazil. Geomorphology, 44 (3): 259-271.

Freitas, H.A.; Pessenda, L.C.R.; Avarena, R.; Gouveia, S.E.M.; Ribeiro, A.S.; Boulet, R. 2001. Late Quaternary Vegetation Dynamics in the Southern Amazon Basin Inferred from Carbon Isotopes in Soil Organic Matter. Quaternary research, v.55, n.1, p.39-46.

Galbraith, R.F.; \& Laslett, G.M. 1993. Statistical models for mixed fission track ages. International Journal of Radiation Applications and Instrumentation. Part D. Nuclear Tracks and Radiation Measurements 21: 459-470. 
Galbraith, R.F.; Roberts, R.G.; Laslett, G.M.; Yoshida, H.; Olley, J.M. 1999. Optical dating of single and multiple grains of quartz from Jinmium rock shelter, northern Australia: Part I, experimental design and statistical models. Archaeometry 41: 339-364.

Galbraith, R.F.; Roberts, R.G.; and Yoshida, H; 2005. Error Variation in OSL Palaeodose Estimates From Single Aliquots of Quartz: a Factorial Experiment. Radiation Measurements 39: 289-307.

Gosse, J. C. \& Phillips, F. M. 2001. Terrestrial in situ cosmogenic nuclides; theory and application. Quaternary Science Reviews, 29, 1475-1560.

Haug, G.H., Haughen, K.A., Sigman, D.M., Peterson, L.C., Roehl, U., 2001. Southward migration of the Intertropical Convergence Zone through the Holocene. Science 293, 1304-1308.

Hoorn,C.; Wesselingh,F.P. (Eds.) 2010. Amazonia: landscape and species evolution. A look into the past. Wiley-Blackwell, Oxford. 464p.

Kanner, L.C.; Burns, S.J.; Cheng, H.; Edwards, L. 2012. High-Latitude Forcing of the South American Summer Monsoon During the Last Glacial. Science, 335, 570.

Latrubesse, E.M. \& Franzinelli, E. 2002. The Holocene alluvial plain of the middle Amazon River, Brazil. Geomorphology, 44 (3): 241-257.

Latrubesse, E.M. \& Franzinelli, E. 2005. The late quaternary evolution of the Negro river, Amazon, Brazil: implications for island and floodplain in large anabranching tropical systems. Geomorghology, 70: 372-397.

Leon, J. G.; Calmant, S.; Seyler, F.; Bonnet, M.P.; Cauhope, M.; Frappart, F.; Filizola, N.; Fraizy, P. 2006. Rating curves and estimation of average water depth at the upper Negro River based on satellite altimeter data and modeled discharges. Journal of Hidrology. 328: 481-496.

Li, S.H. \& Li, B. 2006. Dose measurement using fast component of LM-OSL signals from quartz. Radiation Measurements 41, 534-541. 
Mangiarotti, S.; Martinez, J.M.; Bonnet, M.P.; Buarque, D.C.; Filizola, N.; Mazzega, P. 2013. Discharge and suspended sediment flux estimated along the mainstream of the Amazon and the Madeira Rivers (from in situ and MODIS Satellite Data). International Journal of Applied Earth Observation and Geoinformation, 21, 341355.

McComarc, F.G.; Hogg, A.G.; Blackwell, P.G.; Buck, C.E.; Higham, T.F.G.; Reimer, P.J. 2004. SHCa104 Southern Hemisphere Calibration 0-11.0 cal Kyr BP. Radiocarbon, v.46, n.3, p.1087-1092, 2004.

Mertes, L.A.K.; Dunne, T.; Martinelli, L.A. 1996. Channel-floodplain geomorphology along the Solimões-Amazon River, Brazil. Geological Society of america Bulletin, v. 108, n.9, p.1089-1107.

Milne, G.A.; Long, A.J.; Basset, S.E. 2005. Modelling Holocene relative sea-level observations from the Caribbean and South America. Quaternary Science Reviews, 24, 1183-1202.

Moska, P. \& Murray, A.S., 2006. Stability of the quartz fast-component in insensitive samples. Radiation Measurements 41, 878-885.

Murray, A.S. \& Roberts , R.G. 1998. Measurement of the equivalent dose in quartz using a regenerative-dose single-aliquot protocol. Radiation Measurements. 29, 503-515p.

Murray, A.S. \& Wintle, A.G. 2000. Luminescence dating of quartz using an improved single-aliquot regenerative-dose protocol. Radiation Measurements. 32. 57-73p.

Nogués-Paegle, J.; Mechoso, C.R.; Fu, R. 2002. Progress in Pan American CLIVAR Research: understanding the South American Monsoon. Meteorological, 27:330.

Olley, J. M., Pietsch, T. \& Roberts, R. G. 2004. Optical dating of Holocene sediments from a variety of geomorphic settings using single grains of quartz. Geomorphology, 60, 337-358.

Pietsch, T.J., Olley, J.M., Nanson, G.C., 2008. Fluvial transport as a natural luminescence sensitiser of quartz. Quaternary Geochronology, 3, 365-376. 
Porat, N., Duller, G. A. T., Amit, R., Zilberman, E. \& Enzel, Y. 2008. Recent faulting in the southern Arava, Dead Sea Transform: Evidence from single grain luminescence dating. Quaternary International, 199, Issues 1-2, p.34-44.

Prescott, J.R. \& Stephan, L.G. 1982. The contribuition of cosmic radiation to the environmental dose for thermoluminescent dating, latitude, altitude and depth dependences. PACT, 6:17-25p.

Rittenour, T. M. 2008. Luminescence dating of fluvial deposits: applications to geomorphic, palaeoseismicand archaeological research. Boreas, Vol. 37, pp. 613-635.

Rossetti, D.F.; Toledo, P.M.; Góes A.M. 2005. New geological framework for Western Amazonia (Brazil) and implications for biogeography and evolution. Quat Res 63: 78-89.

Sarges, R.R.; Silva, T.M.; Riccomini, C. 2011. Caracterização do relevo da região de Manaus, Amazônia Central. Revista Brasileira de Geomorfologia ,v. 12, no 1.

Sawakuchi, A.O., Blair, M., DeWitt, R., Faleiros, F.M., Hyppolito, T.N., Guedes, C.C.F. 2011. Thermal history versus sedimentary history: OSL sensitivity of single quartz grains extracted from igneous and metamorphic rocks and sediments. Quaternary Geochronology, 6, 261-272.

Silva, C.R.; Peixinho, F.C.; Monteiro, A.; Pinto, E.J.A.; Azambuja, A.M.S.; Farias, J.A.M.; Pickbrenner, K.; Weschendelder, A.B.; Santos, A.L.M.R.; Marcuzzo, F.F.N.; Costa, M.R.; Nascimento, J.R.S.; Furtunato, O.M.; Medeiros, V.S.; Almeida, I.S. 2011. Levantamento da geodiversidade. Projeto atlas pluviométrico do Brasil Isoietas anuais médias. Período 1977 a 2006. CPRM, escala 1: 1.000 .000 .

Soares, E.A.A.; Silva, C.L; Nogueira, A.C.R.; Sugiuo, K.; Barros, D.S; Santos, W.H.D. 2001. Os depósitos quaternários na confluência dos rios Negro e Solimões, municípios de Iranduba e Manacapuru, Amazonas. In: Simpósio de Geologia da Amazônia, 7. Belém. Resumos Expandidos, p.19-22.

Soares, E. A. A. 2007. Depósitos Pleistocenos da região de confluência dos rios Negro e Solimões, Amazonas. Tese de Doutoramento. Instituto de Geociências, Universidade de São Paulo, São Paulo. 205 p. 
Soares, E.A.A.; Tatumi, S.H.; Riccomini, C. 2010. OSL age determinations of Pleistocene fluvial deposits in Central Amazonia. Anais da Academia Brasileira de Ciências 82(3), 691-699.

Stanley, D. J. \& Hait, A. K. 2000. Deltas, radiocarbon dating, and measurement of sediment storage and subsidence. Geology 28, 295-298.

Stuiver, M \& Reimer, P.J. 1993. Extended ${ }^{14} \mathrm{C}$ data base and revised calib $3.0{ }^{14} \mathrm{C}$ age calibration program. Radiocarbon, v.35, n. 1, 1993, p. 215-230.

Thomsen, K.J., Jain, M., Bøtter-Jensen, L., Murray, A.S., and Jungner, H. 2003. Variation With Depth of Dose Distributions in Single Grains of Quartz Extracted From an Irradiated Concrete Block. Radiation Measurements 37: 315-321.

Van Breukelen, M.R.; Vonhof, H.B.; Hellstrom, J.C.; Wester, W.C.G.; Kroon, D. 2008. Fossil dripwater in stalagmites reveals Holocene temperature and rainfall variation in Amazonia. Earth Planet. Sci. Lett. 7p.

Vera, C.; Higgins, W.; Amador, J. 2006. Towards a Unified View of the American Monsoon Systems. J Clim 19:4977-5000.

Walker, R.G. \& James, N.P. 1992. Facies, facies models and modern stratigraphic concepts. In: Walker, R.G. \& James, N.P. Facies Models: response to sea level change. Geological Association of Canada, St John's, Newfoundland, p. 1-14.

Wallinga, J.,Murray, A. S., Duller, G. A. T. \& Tornqvist, T. E. 2002. Testing optically stimulated luminescence dating of sand-sized quartz and feldspar from fluvial deposits. Earth and Planetary Science Letters, 193, 617-630.

Wintle A.G. \& Murray, A.S. 2006. A Review of quartz optically stimulated luminescence characteristics and their relevance in single-aliquot regeneration dating protocols. Radiation Measurements, 41, 369-391p. 